\author{
Flaviana Lima Guião-Leite
}

\title{
Avaliação da eficiência da eletroforese capilar como técnica analítica na prospecção de metabólitos de esteróides em extratos fecais de onça-pintada (Panthera onca)
}

Tese apresentada ao Programa de Pós-graduação em Reprodução Animal da Faculdade de Medicina Veterinária e Zootecnia da Universidade de São Paulo para obtenção de título de Doutor em Medicina Veterinária

Departamento:

Reprodução Animal

Área de concentração:

Reprodução Animal

Orientador:

Prof. Dr. Cláudio Alvarenga de Oliveira 
Autorizo a reprodução parcial ou total desta obra, para fins acadêmicos, desde que citada a fonte.

DADOS INTERNACIONAIS DE CATALOGAÇÃO-NA-PUBLICAÇÃO

(BIblloteca Virginle Butr D'Apice da Faculdade de Medicina Veterinaria e Zootecnla da Uniwersidade de săo Paulo)

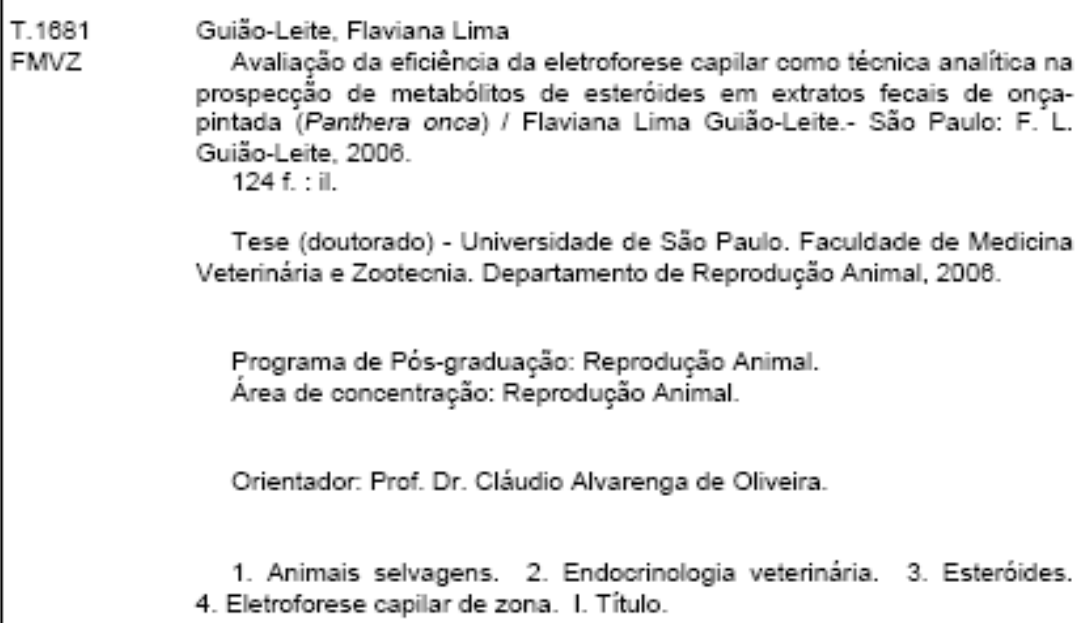

Tese (doutorado) - Universidade de São Paulo. Faculdade de Medicina Veterinária e Zootecnia. Departamento de Reproduçäo Animal, 2008.

Programa de Pós-graduação: Reprodução Animal.

Área de concentração: Reprodução Animal.

Orientador: Prof. Dr. Cláudio Alvarenga de Oliveira.

1. Animais selvagens. 2. Endocrinologia veterinária. 3. Esteróides. 4. Eletroforese capilar de zona. I. Título. 


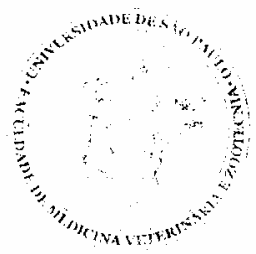

\author{
UNIVERSIDADE DE SÃO PAULO \\ Faculdade de Medicina Veterinária e Zootecnia \\ Comissão de Bioética
}

\title{
PARECER
}

Interessado: Flaviana Lima Guião Leite

Assunto: Protocolo de experimentação adotado em experimento animal.

A Comissão de Bioética da Faculdade de Medicina Veterinária e Zootecnia da Universidade de São Paulo, após analisar o projeto sob o número 830/2006, intitulado: “Estudo prospectivo de metabólitos de esteróides sexuais em extratos fecais de onça-pintada (Panthera onca, Linnaeus, 1758) e puma (Puma concolor, Wozencraft, 1993) por eletroforese capilar", no qual foram utilizadas 02 (duas) onças-pintadas, sob responsabilidade do Prof. Dr. Cláudio Alvarenga de Oliveira constatou que o mesmo foi realizado de acordo com os princípios de bioética, adotados por esta Comissão.

São Paulo, 20 de fevereiro de 2006

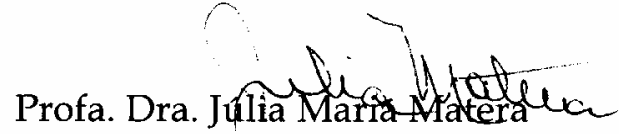

Presidente da Comissão de Bioética

FMVZ/USP 


\section{FOLHA DE AVALIAÇÃO}

Nome: GUIÃO-LEITE, Flaviana Lima

Título: Avaliação da efíciência da eletroforese capilar como técnica analítica na prospecção de metabólitos de esteróides em extratos fecais de onça-pintada (Panthera onca)

Tese apresentada ao Programa de Pósgraduação em Reprodução Animal da Faculdade de Medicina Veterinária e Zootecnia da Universidade de São Paulo para obtenção do título de Doutor

Data: em Medicina Veterinária

\section{Banca Examinadora}

Prof. Dr.

Instituição:

Assinatura:

Julgamento:

Prof. Dr.

Instituição:

Assinatura:

Julgamento:

Prof. Dr.

Instituição:

Assinatura:

Julgamento:

Prof. Dr.

Instituição:

Assinatura:

Julgamento:

Prof. Dr.

Instituição:

Assinatura:

Julgamento: 
Como não, mais uma vez dedicar este trabalho aos animais, minha vida continua sendo dedicada a eles e não vou me deixar esmorecer. 


\section{Agradecimentos}

Este é um momento um tanto quanto complicado... Porque sou uma pessoa grata por natureza e se for agradecer de verdade teria que mencionar o nome de todas as minhas professoras e funcionários das escolas pelas quais passei. Desde o Jardim Escola Colméia, em Pinheiros, minha primeira escola, aonde minha mãe percebeu que sua filha mais velha, na época com três aninhos seria muito independente... E os amigos que fiz em todas as cidades aonde morei... Teria que colocar os nomes de cada membro da minha família, que é grande... O que quero dizer é que cada pessoa que passou ou que ficou na minha vida deixou ou está deixando sua contribuição pra tudo o que sou e nas etapas cumpridas da minha vida. Até mesmo aquelas que interagiram comigo de uma forma negativa, a estas devo agradecer com mais carinho, porque no embate com pessoas difíceis ou que simplesmente não nos querem bem que a gente cresce, se fortifica e aprende a lidar com o mundo, seria muito fácil e monótono se todos fossem nossos amigos e se não tivéssemos sempre um ou mais problemas a resolver...

Mas como minha memória não é das melhores e fatalmente me esqueceria de alguns nomes, vou me perdoar e aqui me ater àqueles que estiveram comigo nesta empreitada, que me acompanharam nos bons e nos maus momentos.

Vou começar agradecendo ao Prof. Renato Campanarut Barnabe, ao Prof. Marcelo Guimarães, que me abriram as portas do Departamento de Reprodução Animal.

Ao Prof. Cláudio Alvarenga, meu orientador, pela valiosa oportunidade e por ter confiado a mim este projeto.

Aos amigos que fiz no Laboratório de Dosagens Hormonais (LDH), sempre ali, agüentando os odores das extrações: Adriana, Alexandre, Cláudia Calamari, Cláudia Nascimento, Débora, Eduardo, Fabiana, Érika, Lilian, Mariana, Marie, Patrícia, Priscila, Rodrigo, Rogério, Thaís, Tatiana e Thiesa. 
Preciso agradecer de forma especial à cinco pessoas do LDH: à Érika, que me recebeu no laboratório e me iniciou na "arte" das extrações; à Priscila, que gentilmente me cedeu as amostras remanescentes de seu projeto de mestrado e sempre, sempre estava à disposição a me ajudar; à Lilian e à Débora, companheiras em todos os momentos, no PAE e acima de tudo no "rejuvenescimento"; e ao Alexandre, por estar sempre disposto a me socorrer frente aos mistérios dos computadores!!!!

Aos colegas, professores e funcionários do Departamento de Reprodução Animal, especialmente a Thaís, Harumi e Miguel.

À Prof. Marina, por ter abraçado a nossa causa, aberto as portas de seu laboratório e pelo empenho para a realização deste projeto.

Agradeço também ao Claudinei, parceiro nas primeiras análises realizadas.

Muito tenho a agradecer a Profa. Elisabete, que, sem seu apoio este trabalho não teria sido possível.

Ao Prof. Arnaldo Alves Cardoso, por permitir a utilização de seu laboratório na UNESP-Araraquara.

À Maria Amélia, Ibrahin e Prof. Valquíria, pelo apoio nas análises por cromatografia líquida.

Aos amigos do Laboratório de Odontologia Comparada e seu líder, Prof. Marco Antônio Gioso.

Às amigas Dulce e Karlinha, excelentes companheiras.

À Amélia, sempre disposta a cuidar dos meus felídeos, à propósito, tenho que agradecer a eles também: John-John, Fiel, Lud, Ágata, Ludinho e Pelud, não sei o que seria de mim sem vocês!!!!!

Ah! Os canídeos também merecem ser lembrados: Kadesh, Sophia, Ferrugem e Luca. 
Aos queridos Carlinha, Giovanno, Fernando, Gianine, Rodrigo, Tatiana, Jorge e ao Café Creme da Paulista, aonde pudemos reviver os bons tempos de Viçosa.

Aos amigos, na verdade, minha família adotiva: Tarcízio, Regina, Rebeca e Tarcizinho.

Ao Sr. João Rossi e D. Bernadete, com muito carinho.

Ao meu amado companheiro, João Luiz, um pouco responsável por esta empreitada e sem quem eu não a teria cumprido, agradeço o apoio, o carinho e a compreensão.

À minha família, tão amada, tão importante: meus pais, Lêda e João Flávio; meus “segundos" pais: Antônio e Berenice; meus irmãos: João Flávio, Fernando, Luciana e Juliana; meus avós Edith, Edson (in memorian), Izabel (in memorian) e Cardoso (in memorian); meus tios: Yayá (in memorian) Cecília, Rodolpho, Bernadete (in memorian), José Ricardo, Eliana, Salomé, Dilger, Cláudia e Alessandro e a todos os meus primos: Ma, Bia, Gu, Marília, Teco, Dudu, Matheus e Gabriela, sei que todos vocês torcem por mim e saibam que eu não seria nada sem vocês.

Por fim, à Deus, pelo dom da vida, por ter colocado no meu caminho estas pessoas, e os animais, agradeço. 


\section{Resumo}

GUIÃO-LEITE, F. L. Avaliação da eficiência da eletroforese capilar como técnica analítica na prospecção de metabólitos de esteróides em extratos fecais de onça-pintada (Panthera onca). [Evaluation of the efficiency of the capillary electrophoresis as analytical technique in the research of steroids metabolites in jaguar fecal extracts (Panthera onca)]. 2006. 124 f. Tese (Doutorado em Medicina Veterinária) - Faculdade de Medicina Veterinária e Zootecnia, Universidade de São Paulo, 2006.

O objetivo deste trabalho foi desenvolver um protocolo de extração hormonal à partir de fezes de onça-pintada (Panthera onca) e validar uma metodologia de análise destes extratos por eletroforese capilar, verificando a eficiência analítica desta técnica no estudo dos metabólitos de esteróides sexuais em fezes, com o intuito de utilização futura desta metodologia na rotina dos laboratórios de endocrinologia. Foram testados sete tratamentos para as amostras de fezes liofilizadas: quatro protocolos de extração em diferentes solventes, um de hidrólise ácida e dois protocolos de extração em fase sólida (SPE). O protocolo de extração em acetonitrila foi satisfatório como pré-tratamento da amostra e aliado à SPE C-18 apresentou bons resultados no que diz respeito à sensibilidade, precisão, recuperação e tempo de análise. Com base nos resultados obtidos, a eletroforese capilar pode ser considerada uma ótima alternativa para a prospecção de metabólitos de hormônios, podendo ser utilizada em análises de rotina nos laboratórios de endocrinologia animal, sobretudo naqueles que se dedicam às metodologias não-invasivas de avaliação da função reprodutiva em animais selvagens.

Palavras-chave: Animais selvagens, Eletroforese capilar de zona, Endocrinologia veterinária, Esteróides. 


\begin{abstract}
GUIÃO-LEITE, F. L. Evaluation of the efficiency of the capillary electrophoresis as analytical technique in the research of steroids metabolites in jaguar fecal extracts (Panthera onca). [Avaliação da eficiência da eletroforese capilar como técnica analítica na prospecção de metabólitos de esteróides em extratos fecais de onça-pintada (Panthera onca)]. 2006. $124 \mathrm{f}$. Tese (Doutorado em Medicina Veterinária) - Faculdade de Medicina Veterinária e Zootecnia, Universidade de São Paulo, 2006.
\end{abstract}

The objective of this work was to develop a protocol of hormonal extraction from jaguar feces (Panthera onca) and validate a methodology of analysis of these extracts with capillary electrophoresis, verifying the analytical efficiency of this technique in the study of the steroids metabolites in feces, with the objective of future use of this methodology in the routine of the endocrinology laboratories. Seven treatments were tested for the samples: four extraction protocols in different solvents, one of acid hydrolysis and two extraction protocols in solid phase (SPE). The extraction protocol in acetonitrila was satisfactory as pre-treatment of the samples and ally to SPE C-18, it presented good results with respect to the sensibility, precision, recovery and time of analysis. Based on the obtained results, the capillary electrophoresis can be considered a great alternative for the research of metabolites of hormones, it could also be used in routine analyses in the endocrinology laboratories, mainly in those that are devoted to the non-invasive evaluation methodologies of the reproductive function in wild animals.

Key words: Steroids, Veterinary endocrinology, Wild animals, Zone capillary electrophoresis. 


\section{SUMÁRIO}

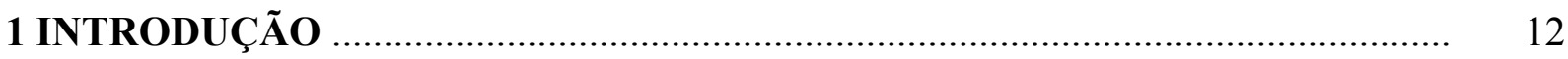

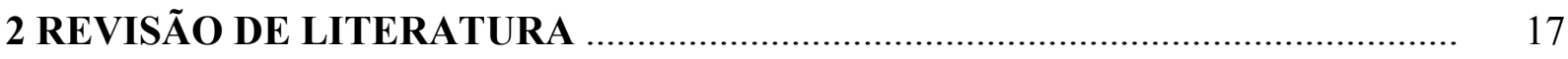

2.1 OS HORMÔNIOS ESTERÓIDES............................................................................ 18

2.2 MÉTODOS NÃO-INVASIVOS DE ESTUDO DA FUNÇÃO ENDÓCRINA ........... 27

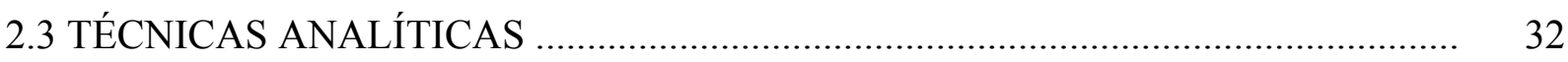

2.3.1 ELETROFORESE CAPILAR (CE) ………………..................................... 32

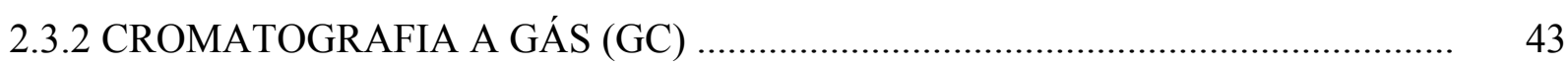

2.3.3 CROMATOGRAFIA LÍQUIDA DE ALTA PERFORMANCE (HPLC) ................ 46

2.4 PANTHERA ONCA: DADOS BIOLÓGICOS............................................................. 49

3 MATERIAL E MÉTODOS …………………………………………………...... 53

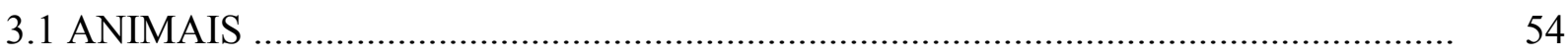

3.2 COLHEITA, ARMAZENAMENTO, QUANTIFICAÇÃO POR RADIOIMUNOENSAIO E SELEÇÃO DAS AMOSTRAS FECAIS A SEREM INVESTIGADAS ........ 54

3.3 PADRÕES E REAGENTES ………………………………………………...... 55

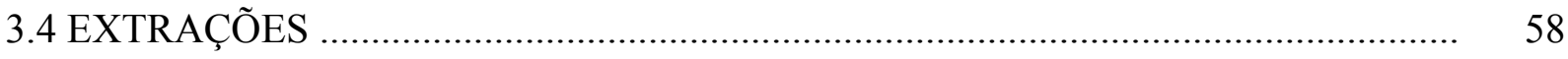

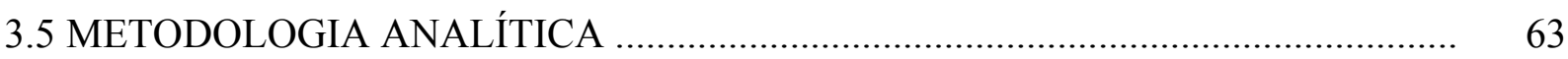

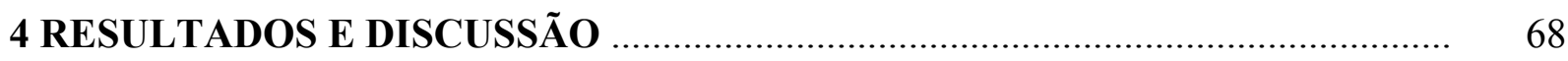

4.1 COMPOSIÇÃO DO ELETRÓLITO ........................................................................... 69

4.2 PROCEDIMENTOS DE EXTRAÇÃO …………………………………………... 83

4.3 VALIDAÇÃO DO MÉTODO ……………………………………………….... 105

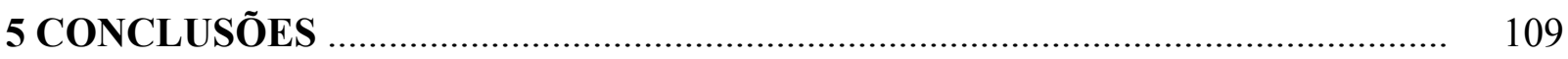

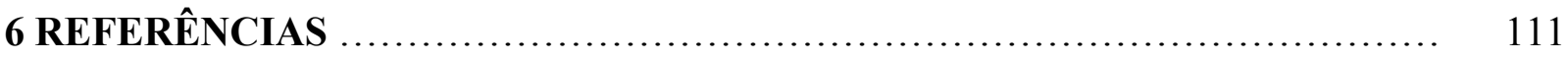


INTRODUCÃO 


\section{INTRODUÇÃO}

O processo de extinção de uma espécie pode ser um evento natural, decorrente da própria evolução. Porém, sabe-se que este processo é predominantemente causado por atividades humanas. Segundo Corson (1996), até o início deste século, poderemos ter perdido um milhão ou mais de espécies de vegetais, animais e outros organismos - mais do que a extinção maciça na história geológica, incluindo o desaparecimento dos dinossauros.

O número total de espécies de vertebrados ameaçados de extinção chega a mais de 10.000, destas, aproximadamente um quarto são espécies de mamíferos, um oitavo são espécies de aves e um terço são espécies de anfíbios. A velocidade da perda de biodiversidade está aumentando e pode tornar-se maior à medida que os ecossistemas tornam-se afetados pelas mudanças climáticas devido ao aquecimento global. (COCKREM, 2005)

Como enumerado por Soulé (1986), as seis principais classes de interferência humana que contribuem para a degradação da diversidade biológica são 1) a perda de habitat, 2) a fragmentação dos habitats, 3) a super exploração dos recursos naturais, 4) a introdução de espécies exóticas e doenças, 5) a poluição do ar, do solo e da água e 6) as mudanças climáticas.

Atualmente, existe difundida por todo o mundo a compreensão de que algo precisa ser feito para se evitar o desaparecimento de qualquer espécie. Naturalmente, que o primeiro passo seria a desaceleração da degradação do ambiente. Sabemos que este aspecto é de difícil execução devido aos interesses políticos, estratégicos e econômicos envolvidos. Simultaneamente às gestões neste sentido, torna-se necessário que o desempenho reprodutivo de algumas espécies em cativeiro seja otimizado. Para tanto, estudos devem ser implementados em áreas como: nutrição, comportamento, fisiologia reprodutiva e reprodução artificial (GUIMARÃES, 2001).

Entre as mais de 4000 espécies de mamíferos, em menos de 100 se têm estudos sobre qualquer detalhe de sua reprodução, quanto ao comportamento ou fisiologia reprodutiva. Isto significa que não se sabe quais os requerimentos para que haja reprodução bem sucedida para a maioria das espécies que precisam ser manejadas (LASLEY et al., 1994).

Os predadores da ordem Carnivora podem ser utilizados como alicerce para a identificação dos problemas relativos à diminuição da biodiversidade, pois ocupam o topo da cadeia alimentar sendo co-responsáveis pelo equilíbrio dos ecossistemas onde ocorrem. Alimentando-se de animais mais fracos, evitam que a superpopulação cause danos ao 
ambiente ou leve à disseminação de doenças. Assim, quando se trabalha para a preservação destes animais, outras espécies indiretamente são preservadas (GUIÃO-LEITE, 2002).

Os felídeos são importantes representantes da Ordem Carnívora, constituem 37 espécies, todas, em graus variados, ameaçadas de extinção (CITES, 1997) no Brasil temos oito espécies: Herpailurus yagouaroundi (Gato mourisco), Leopardus wiedii (Gato maracajá), Leopardus pardalis (Jaguatirica), Leopardus tigrinus (Gato-do-mato-pequeno), Oncifelis colocolo (Gato palheiro), Oncifelis geoffroyi (Gato-do-mato-grande), Panthera onca (Onça pintada) e Puma concolor (Onça parda) (OLIVEIRA, 1994).

A onça pintada é o maior felino das Américas, e único representante atual do gênero Panthera no Novo Mundo (GONYEA, 1976). A distribuição histórica desta espécie se estendia do Arizona, Novo México e Texas no sul dos Estados Unidos da América ao Rio Negro $\left(40^{\circ} \mathrm{S}\right)$ ou Rio Santa Cruz $\left(50^{\circ} \mathrm{S}\right)$ na Argentina (ARRA, 1974; CARMAN, 1984). Atualmente ela está oficialmente extinta nos Estados Unidos, é muito rara no México, mas ainda pode ser encontrada na América do Sul (HILTON-TAYLOR, 2000). A destruição de habitats aliada à perseguição, devido principalmente ao alegado prejuízo econômico causado às criações de animais domésticos, faz com que as populações venham sendo severamente reduzidas, estando então classificada pela IUCN (União Internacional para Conservação da Natureza) como espécie vulnerável à extinção e inclusa na Lista Oficial da Fauna Ameaçada de Extinção do IBAMA.

Visto a importância dos felinos neotropicais no ecossistema e a carência de informações em sua morfofisiologia reprodutiva, o estudo das características hormonais destas espécies, torna-se extremamente relevante, principalmente como base para $o$ desenvolvimento e sedimentação das técnicas em reprodução assistida.

Segundo Brown (1994), a caracterização da normalidade endócrina é essencial para que se tenha sucesso reprodutivo, identificando-se quais indivíduos apresentam problemas relativos à fertilidade, e determinando-se o tipo de técnica em reprodução assistida necessária (inseminação artificial, fecundação in vitro, transferência de embriões).

Os métodos convencionais para obtenção de dados sobre a normalidade endócrina em animais domésticos baseiam-se na análise de amostras de sangue coletadas seqüencialmente. Esta abordagem é impossível para a maioria das espécies selvagens, muito susceptíveis ao estresse. Métodos não-invasivos como as dosagens hormonais de metabólitos excretados em urina e fezes são alternativas potencialmente atrativas (BROWN, 1994).

Durante a última década, a monitoração dos metabólitos de esteróides sexuais excretado nas fezes proveu caracterização efetiva do ciclo estral, prenhez e padrões sazonais 
da reprodução de várias espécies de primatas, ungulados e equídeos (BAMBERG et al., 1991; HEISTERMANN et al., 1993; HINDLE, 1990; HOPPEN et al., 1992; KIRKPATRIC et al.,1992; LASLEY; KIRKPATRICK, 1991; RISLER et al., 1987; SCHWARZENBERGER et al., 1993; SHIDELER et al., 1993; WASSER et al., 1991, 1988).

As técnicas não-invasivas para extração e dosagem de esteróides sexuais apresentam várias vantagens, principalmente por se eliminar a necessidade de contenção física ou química. Procedimentos anestésicos esporádicos para coleta de amostras de sangue podem não afetar o potencial reprodutivo, mas causam distúrbios temporários na dinâmica de secreção hormonal (amplitude do pulso e freqüência) dependendo da droga utilizada (JOHNSON; GAY, 1981; CLARKE; DOUGHTON, 1983; FULLER et al., 1984), além disso, a anestesia pode interferir ou bloquear a ovulação em gatos domésticos, por exemplo (HOWARD, 1992), contra-indicando a utilização de anestésicos no período peri-ovulatório em felinos não-domésticos.

Os métodos analíticos freqüentemente utilizados para a análise de esteróides incluem as técnicas colorimétricas, fluorimétricas, cromatográficas (cromatografia em camada delgada, TLC; cromatografia líquida de alta performance, HPLC; cromatografia gasosa e gasosa acoplada a espectrometria de massas GC e GC-MS) e os imunoensaios (SAWAYA et al., 1998, DRAISCI et al., 1998, VALBUENA et al., 1997). De todos os métodos mencionados, os imunoensaios são o mais sensíveis e usados rotineiramente nos laboratórios, mas apesar da sensibilidade, permite a determinação de somente um esteróide a cada análise, aumentando o custo e o tempo de análise (DRAISCI et al., 1998). O radioimunoensaio (RIA) permite uma análise sensível e rápida de um grande número de amostras, entretanto, a maior desvantagem desta técnica é a necessidade de radioisótopos e a produção de lixo radioativo (SU et al., 2003).

A cromatografia líquida de alta performance (HPLC) vem sendo utilizada como técnica de apoio às técnicas imunométricas, permitindo a separação dos principais compostos para direcionar a escolha dos anticorpos para posterior quantificação por radioimunoensaio (RIA), enzimaimunoensaio (EIA) ou imunoadsorção enzimática (ELISA) (ZIEGLER; WITTWER, 2005; BUSSO et al., 2005; DLONIAK et al., 2004; DEHNHARD et al., 2003; HUBER et al., 2003; GOYMANN et al., 2002; WASSER et al., 2000; SCHWARZENBERGER et al., 1998; SPANNER et al., 1997; GRAHAM; BROWN, 1997; GRAHAM; BROWN, 1996; GRAHAN et al., 1995; BROWN et al., 1994; SHIDELER et al., 1993; BROWN et al., 1993; LASLEY et al., 1994; SHILLE et al., 1990; ZIEGLER et al., 
1989). No entanto, principalmente por motivos econômicos, esta técnica não se estabeleceu como técnica de rotina na área de investigações por métodos não-invasivos.

Durante a década passada, a eletroforese capilar (CE) emergiu como uma técnica promissora, efetiva e econômica para a separação de uma grande variedade de substâncias, incluindo os esteróides. A atração para o uso da $\mathrm{CE}$ em análises farmacêuticas recai na velocidade e baixo custo das análises, redução no consumo e descarte de solventes tendo ainda a possibilidade de oferecer um rápido desenvolvimento do método (ALTRIA, 1999).

O objetivo deste trabalho foi desenvolver um protocolo de extração hormonal a partir de fezes de onça-pintada e validar uma metodologia de análise destes extratos por eletroforese capilar, verificando a eficiência analítica desta técnica no estudo dos metabólitos de esteróides sexuais em fezes, com o intuito de utilização futura desta metodologia na rotina dos laboratórios de endocrinologia animal, sobretudo naqueles que se dedicam às metodologias não-invasivas de avaliação da função reprodutiva em animais selvagens.

Este estudo foi executado em cooperação entre os Departamentos de Reprodução Animal da Faculdade de Medicina Veterinária e Zootecnia, e Química Fundamental do Instituto de Química, pertencentes à Universidade de São Paulo e recebemos ainda importante apoio do Instituto de Química da Universidade Estadual de São Paulo, Campus Araraquara. 
$\underline{\text { Revisão de Literatura }}$ 


\section{REVISÃO DE LITERATURA}

A revisão de literatura foi redigida em quatro tópicos, (1) compreendendo aspectos fisiológicos e estruturais dos hormônios esteróides, (2) métodos não-invasivos de estudo da função endócrina, (3) metodologias analíticas e (4)dados biológicos sobre a onça-pintada.

\subsection{OS HORMÔNIOS ESTÉRÓIDES}

No decorrer de sua evolução, o metazoário desenvolveu sistemas neurais e hormonais capazes de enfrentar as complexidades de seu ambiente. O sistema neural contém elementos receptores que detectam mudanças no meio externo e interno, e transmitem informação sobre essas mudanças a efetores que se encarregam das reações orgânicas necessárias. O sistema hormonal é constituído por células que descarregam seu conteúdo no meio fluido interno do organismo, dessa forma afetando o comportamento celular. Em organismos em estado de desenvolvimento, a atividade hormonal se manifesta na regulação da metamorfose e, em estágios posteriores, na regulação do crescimento. Em animais adultos, os hormônios são responsáveis pela integração da atividade de sistemas e subsistemas orgânicos. Alteram a função celular em resposta à variação no meio externo, induzem a manutenção do trabalho celular, e alteram o nível de atividade de tecidos e órgãos, mantendo a constância de composição do meio interno. Porém, sendo as atividades celulares estereotipadas, nem estímulos neurais nem estímulos hormonais podem induzir atividades novas; apenas são capazes de estimular ou modular as funções celulares (FRIEDEN; LIPNER, 1975).

A disciplina conhecida como endocrinologia evoluiu inicialmente do estabelecimento de ligações entre a patologia de certos órgãos e determinadas doenças. Em 1855, Addison reconheceu uma relação entre redução de pressão sangüínea, fraqueza muscular, perda de peso, escurecimento da pele e patologia da glândula adrenal. Em 1879, Gull relacionou os sintomas de pele seca, cabelo ralo, intumescência da face e das mãos e língua inchada ao mixedema, deficiência patológica da tireóide em adultos; em 1871, Hilton e Fagge estabeleceram a relação entre o estado cretinóide e um mau funcionamento da tireóide na primeira infância (FRIEDEN; LIPNER, 1975). 
Um conjunto de técnicas gerais de experimentação foi sendo desenvolvido simultaneamente com esses estudos clínicos. A análise da ação de hormônios nos laboratórios levou à identificação de estados patológicos antes desconhecidos, e a uma melhor compreensão do sistema endócrino e de sua patologia. A endocrinologia também contribuiu para o tratamento racional das desordens das glândulas endócrinas e para um entendimento mais amplo da bioquímica e fisiologia geral dos seres vivos (FRIEDEN; LIPNER, 1975).

$\mathrm{O}$ estudo experimental da endocrinologia exigiu que muitas condições patológicas encontradas no homem fossem reproduzidas em animais. Algumas dessas condições foram induzidas no laboratório através da remoção cirúrgica de órgãos específicos, indicando-se a relação do órgão extirpado com o estado patológico. O primeiro experimento desse tipo foi realizado por Berthold, que demonstrou o papel dos testículos no comportamento masculino (FRIEDEN; LIPNER, 1975).

Historicamente, a aquisição de conhecimentos sobre cada um dos hormônios dos vertebrados se desenvolveu de forma paralela, indo da identificação e descrição do estado patológico à descoberta do hormônio. A essas observações, seguiram-se o desenvolvimento de técnicas de dosagem, o isolamento dos princípios ativos e sua subseqüente purificação, identificação e síntese (FRIEDEN; LIPNER, 1975).

Os hormônios podem ser classificados em três grupos químicos principais: (1) proteínas e peptídeos; (2) esteróides; e (3) um grupo misto, menos homogêneo, em geral estreitamente ligado ou derivado de aminoácidos (FRIEDEN; LIPNER, 1975).

O primeiro hormônio esteróide, estrona, foi isolado em 1929 pouco antes da estrutura característica em anel do núcleo do esteróide ter sido elucidada. Atualmente mais de 225 esteróides de ocorrência natural foram isolados e quimicamente caracterizados. Adicionalmente um incontável número de esteróides e análogos vêm sendo sintetizados quimicamente (NORMAN; LITWACK, 1997).

Os esteróides derivam de um núcleo fenantrênico ao qual se liga o grupo ciclopentano, isto é, a estrutura da 1,2-ciclopentanoperidrofenantreno, um esterano. O esteróide (ou esterol) animal mais comum é o colesterol, derivado do complexo esterano com um grupo hidroxílico no C-3, uma dupla ligação entre C-5 e C-6, um grupo metílico no C-10 e no C-13, e uma cadeia lateral iso-heptânica metilada no C-17; seu nome advém do fato de ser um constituinte das pedras biliares humanas e de depositar-se no canal biliar. Na verdade, o colesterol é um componente fundamental de todos os tecidos normais e principal constituinte de lipídeos esterificados, da bainha de mielina, e da maior parte das membranas celulares, além de ser o precursor metabólico de quase todos os hormônios esteróides (Figura 1). Comparativamente, 
os hormônios esteróides comuns têm menos átomos de carbono na cadeia lateral, mas com freqüência têm mais substituições que o colesterol (FRIEDEN; LIPNER, 1975).

As estruturas e a nomenclatura dos esteróides foi bem descrita por Kirk e Marples (1995) e esteróides com 21 átomos de carbono são conhecidos como pregnanos, enquanto aqueles que possuem 18 e 19 átomos de carbono são conhecidos como estranos e androstanos respectivamente.

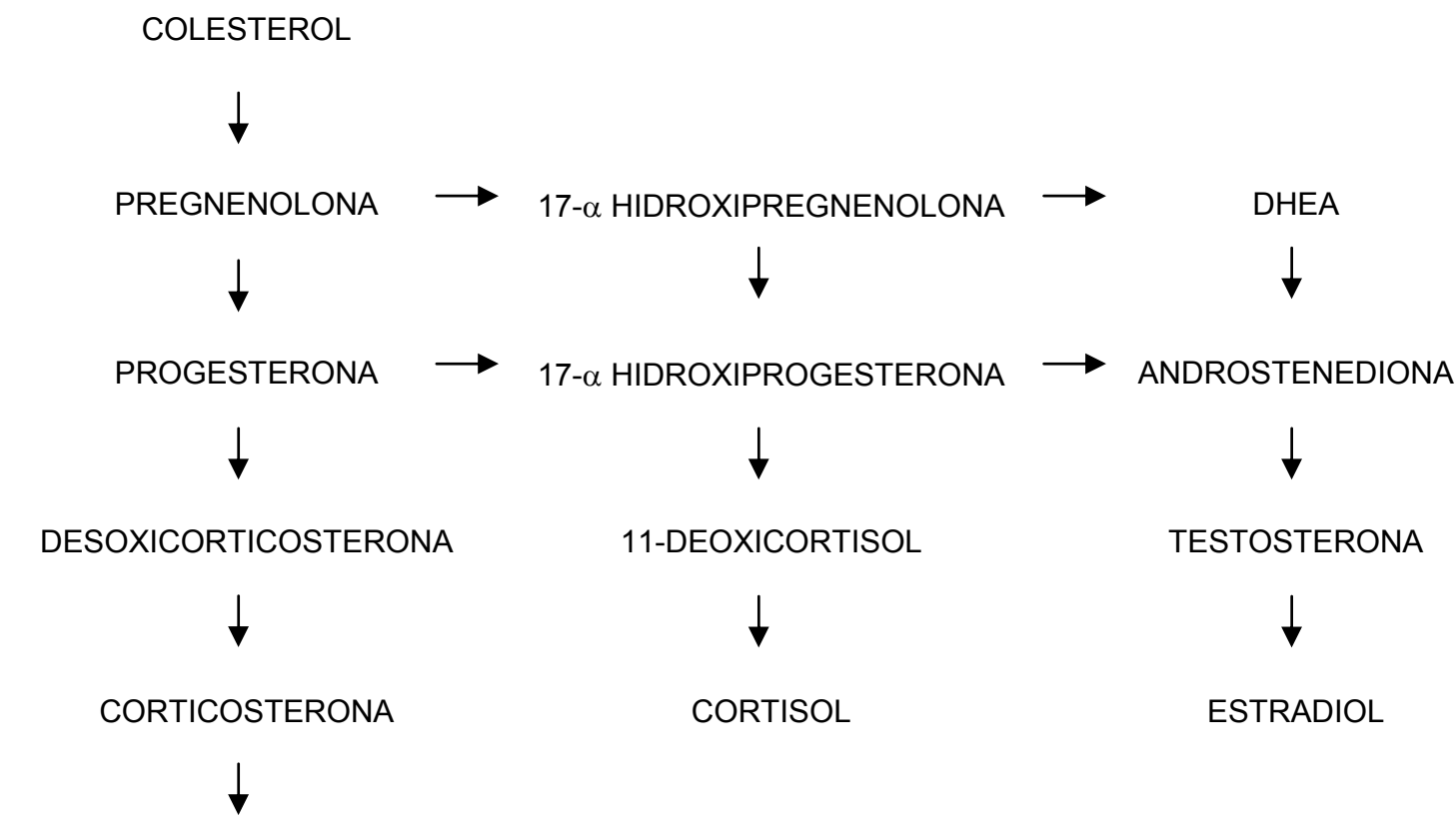

18-HIDROXICORTICOSTERONA

$\downarrow$

ALDOSTERONA

Figura 1- Biossíntese de esteróides à partir do colesterol

Nos mamíferos, existem seis famílias de hormônios esteróides que podem ser classificadas tanto por suas estruturas quanto por suas funções biológicas (hormonais). São os (1) estrógenos (esteróides sexuais femininos), (2) andrógenos (esteróides sexuais masculinos), (3) progestinas, (4) mineralocorticóides, (5) glucocorticóides, (6) vitamina D e seus metabólitos. Os ácidos biliares são estruturalmente relacionados ao colesterol e assim constituem o sétimo membro da família dos esteróides (NORMAN; LITWACK, 1997). 
Os principais tecidos que sintetizam as cinco famílias clássicas de hormônios esteróides (estrógenos, andrógenos, progestágenos, glucocorticóides e mineralocorticóides) são o córtex da adrenal, os ovários e os testículos. Durante a gestação, a unidade fetoplacentária também atua como fonte de estrógenos e alguns outros hormônios. Os locais de síntese da sexta família de esteróides, o pro-hormônio vitamina $\mathrm{D}_{3}$ e seus metabólitos são a pele, fígado e rins. Os ácidos biliares, os quais constituem a sétima família estrutural de esteróides nos mamíferos não têm sua função hormonal bem conhecida e são sintetizados principalmente no fígado (NORMAN; LITWACK, 1997).

\subsubsection{Estrogênios}

Os estrogênios são esteróides com 18 carbonos (Figura 2). São produzidos nas fêmeas pelos ovários, tanto pelo folículo quanto pelo corpo-lúteo e no caso de prenhez pela unidade feto-placentária. Nos machos, os testículos em determinadas circunstâncias podem produzir quantidades fisiologicamente significativas de estradiol. Tanto em machos como em fêmeas, o córtex da adrenal pode produzir pequenas quantidades de estrona a partir de androst-4-ene3,17-dione (NORMAN; LITWACK, 1997).

Sua estrutura é singular no que se refere ao anel A, que é benzênico, exigindo a eliminação do grupo metil no C-10. Para atividade máxima é indispensável a presença de um grupo alcoólico no C-3 e C-17ß. Uma 16 $-\mathrm{OH}$, como no estriol, reduz a atividade. O álcool no C-3 é fenólico e sua característica de ácido fraco torna os estrogênios solúveis em base diluída sendo responsável por algumas outras reações característica (FRIEDEN; LIPNER, 1975).

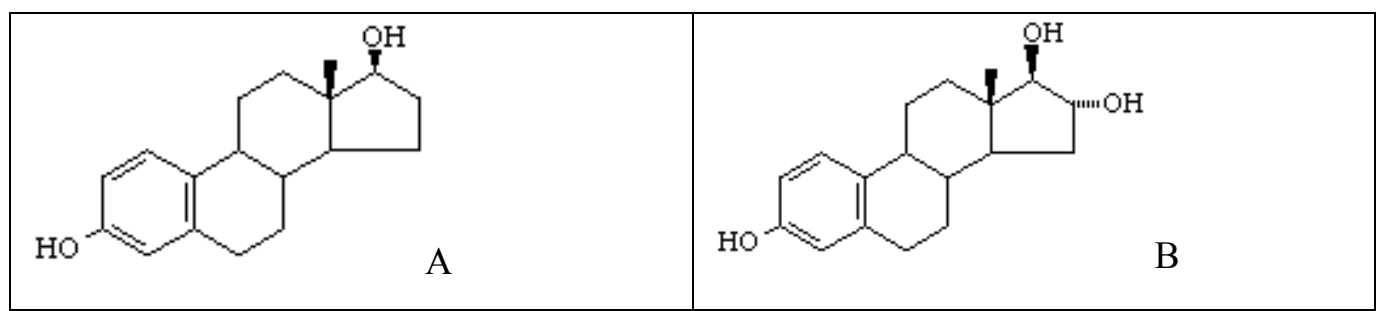

Figura 2 - Estruturas do estradiol (A) e do estriol (B) 


\subsubsection{Andrógenos}

São esteróides com 19 carbonos produzidos nos machos nos testículo e nas fêmeas pelos ovários e placenta, e em ambos os sexos, em determinadas circunstâncias, pelo córtex da adrenal que produz esteróides fracos, mas com atividade androgênica fisiologicamente significativa (Figura 3) (NORMAN; LITWACK, 1997).

Estão entre os esteróides mais simples, com grupos metílicos no C-10 e C-3, uma dupla ligação entre C-4 e C-5, um grupo cetônico no C-3, e um grupo hidroxílico no C-17. Um derivado bastante próximo, a androsterona, pode ser produzido por oxidação direta do colesterol (FRIEDEN; LIPNER, 1975).

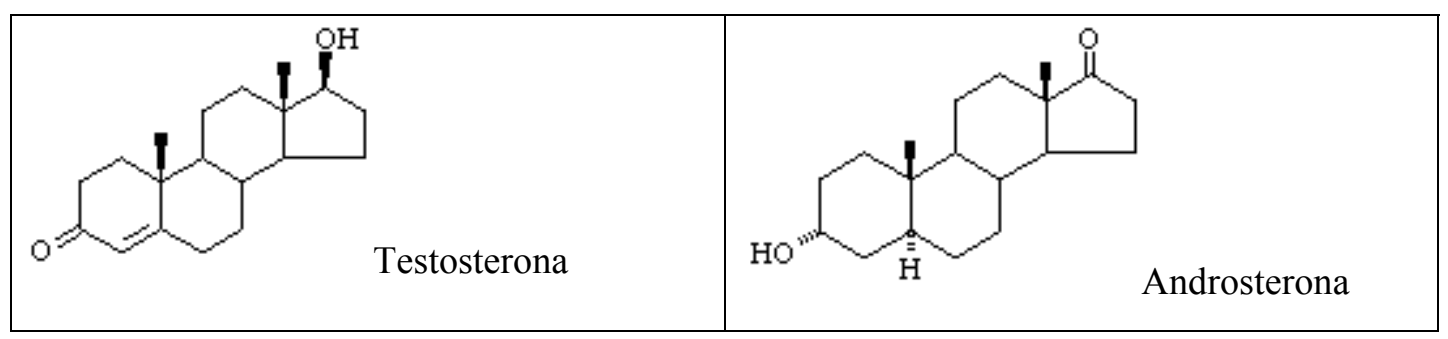

Figura 3 - Estruturas da testosterona (A) e da androsterona(B)

\subsubsection{Progestágenos}

A série do pregnano, cujo representante principal é a progesterona, é um grupo de esteróides um pouco complicado. Note-se que o esqueleto $\mathrm{C}_{21}$ da série do pregnano é característico não só dos esteróides com atividade progestagênica, mas também dos dois grupos principais de esteróides da adrenal: (1) mineralocorticóides e (2) glucocorticóides (Figura 4). A progesterona está, portanto, entre os mais simples dos esteróides $\mathrm{C}_{21}$ biologicamente ativos, com grupos cetônicos nos C-3 e C-20 e uma dupla ligação entre C-4 e C-5 (FRIEDEN; LIPNER, 1975). 


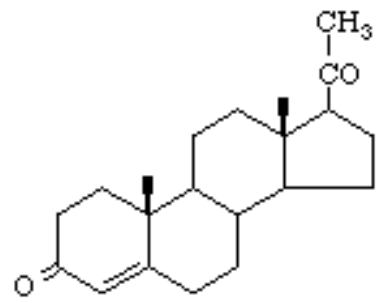

Figura 4 - Estrutura da progesterona

\subsubsection{Esteróides da Adrenal}

Mais de 45 esteróides foram isolados e quimicamente caracterizados á partir de extratos de glândula adrenal. Os corticosteróides possuem 21 carbonos, incluem os glucocorticóides e mineralocorticóides, ambos produzidos pelo córtex da adrenal (Figura 5). São caracterizados por (i) um grupo oxo no C-3 e uma dupla ligação no C-4; (ii) uma cadeia de dois carbonos no $\mathrm{C}-17$ e (iii) um grupo oxo no $\mathrm{C}-20$ e uma hidroxila no C-21. Os glucocorticóides são caracterizados pela presença ou ausência de hidroxilas nos C-11 e C-17. O principal glucocorticóide é o cortisol. Os mineralocorticóides são caracterizados por uma hidroxila no C-11 e o C-18 é oxidado com um aldeído e o principal mineralocorticóide é a aldosterona (NORMAN; LITWACK, 1997).

A atividade glucocorticóide parece depender totalmente do grupo 11-hidróxi ou 11oxi, sendo incrementada pela presença de uma 17-hidroxila e melhor ilustrada pelo cortisol, glucocorticóide natural geralmente predominante. Além do cortisol, cortisona, corticosterona, desoxicorticosterona e aldosterona, muitos outros compostos existem em quantidade significativa, inclusive a 11-desidrocorticosterona, e a 17 - hidroxidesoxicorticosterona. Enquanto que virtualmente todos estes esteróides têm algum grau de atividade glucocorticóide e mineralocorticóide, encontram-se outros esteróides com leve ação androgênica, em

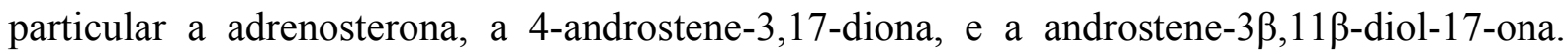
Salientando ainda a sobreposição na biossíntese de esteróides pela adrenal, acrescente-se que também a estrona, a progesterona e a 17 $\alpha$-diidroprogesterona foram localizadas entre os inúmeros esteróides da adrenal (FRIEDEN; LIPNER, 1975). 


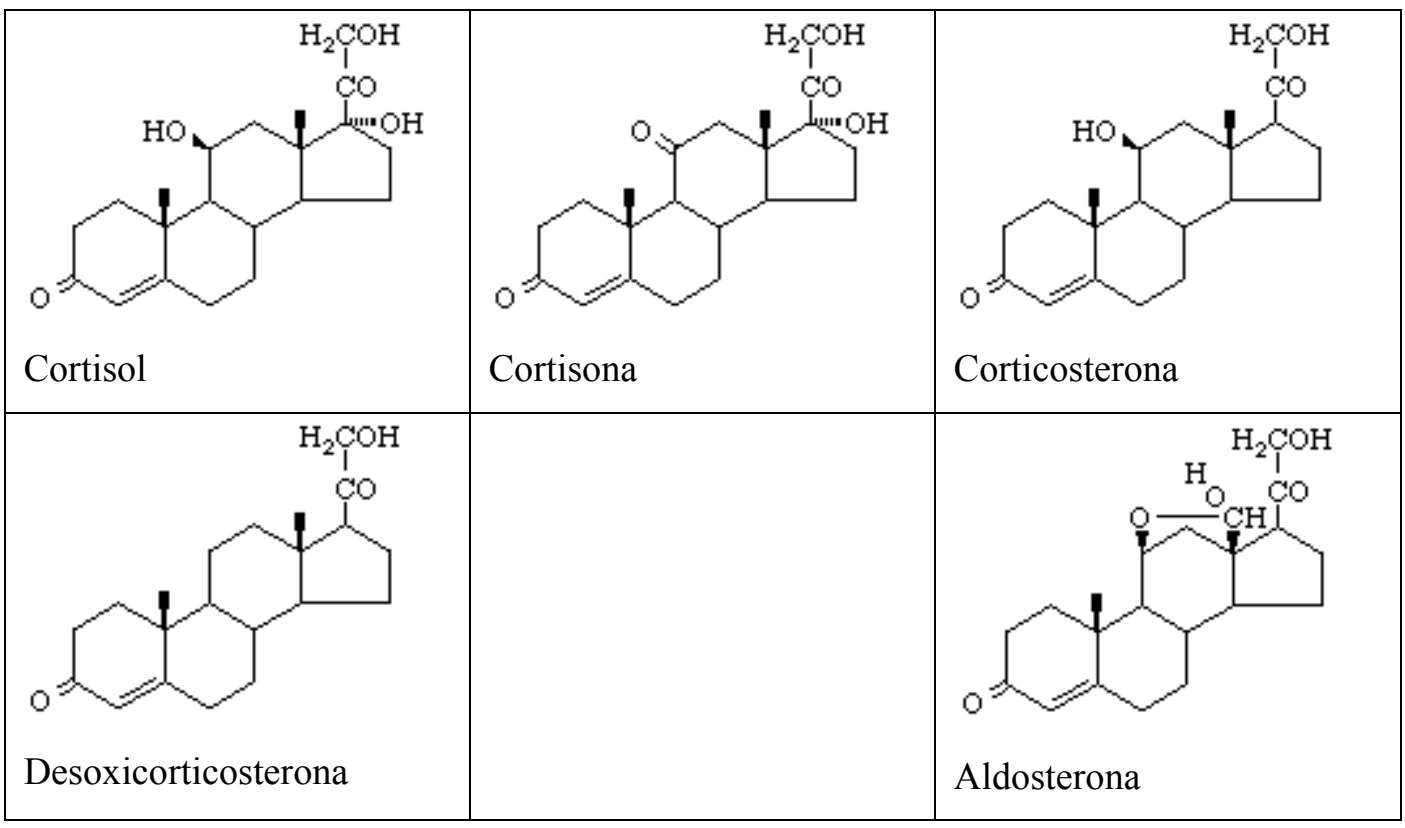

Figura 5 - Estrutura de alguns esteróides da adrenal

\subsubsection{Transporte, Catabolismo e Excreção}

A forma hormonialmente ativa da maioria dos esteróides é geralmente liberada da glândula endócrina e transportada sistemicamente a vários tecidos alvo. Um tecido alvo é definido como aquele que possui receptores específicos permitindo a acumulação do esteróide contra o gradiente de concentração, o que permite a geração de um resposta biológica apropriada no tecido alvo para um esteróide específico em questão. Assim, um fator determinante da habilidade de um tecido alvo para se ligar ao esteróide é a concentração do hormônio no sangue. A concentração de um esteróide no plasma depende de três fatores: (1) a velocidade de biossíntese; (2) a velocidade de catabolismo e (3) a força de ligação do esteróide à sua proteína de ligação carreadora (NORMAN; LITWACK, 1997).

Os hormônios esteróides são transportados dos seus locais de biossíntese aos seus órgãos alvo pelo sangue. Devido à sua intrínseca baixa solubilidade em água, seu transporte é feito por uma família de proteínas transportadoras específicas para cada grupo de esteróides. No plasma, movimentam-se no sistema circulatório ligados às suas proteínas transportadoras. Acredita-se que é a forma livre do esteróide que passa pela membrana celular da célula alvo, assim, tem sido postulado que o esteróide se desliga da proteína carreadora e se difunde 
primeiro pela parede endotelial dos capilares que contém fenestrações (NORMAN; LITWACK, 1997).

Como são compostos hidrofóbicos, vários mecanismos catabólicos não somente inativam os esteróides (reduzindo a afinidade pelo receptor) como também tornam a molécula mais hidrofílica, ou seja, aumentam a solubilidade em água. As reações catabólicas ocorrem principalmente, mas não exclusivamente, no fígado e têm natureza oxidativa. Um aumento significativo na solubilidade em água é efetuado pela conjugação do esteróide com sulfato ou glucuronídeos, estes esteróide conjugados são excretados em grandes quantidades na urina (NORMAN; LITWACK, 1997).

Nas fezes, a maioria dos esteróides apresentam-se não-conjugados, ou livres, devido à ação bacteriana da microflora intestinal que atuam na desconjugação dos metabólitos hormonais (ADLERCREUTZ, 1976).

O quadro 1 resume algumas das principais formas de excreção desses hormônios. 


\begin{tabular}{|c|c|c|c|c|}
\hline $\begin{array}{ll}\text { Classe } & \text { do } \\
\text { Esteróide } & \end{array}$ & $\begin{array}{l}\text { Esteróide } \\
\text { Precursor }\end{array}$ & Passos da Inativação & $\begin{array}{l}\text { Estrutura do } \\
\text { Excretado }\end{array}$ & $\begin{array}{l}\text { Principal } \\
\text { Conjugado }\end{array}$ \\
\hline Progestinas & Progesterona & $\begin{array}{l}\text { 1. Redução do C-20 } \\
\text { 2a. Redução do 4-ene-3- } \\
\text { one ou 2b. 3ß-esteróide } \\
\text { dehidrogenase }\end{array}$ & Pregnanediol & Glucuronídeo \\
\hline Estrógenos & Estradiol & $\begin{array}{l}\text { 1. Oxidação do } 17 \beta-\mathrm{OH} \\
\text { 2. Hidroxilação no C-2 } \\
\text { com subsequente metilação } \\
\text { 3. Outras hidroxilações ou } \\
\text { formação de cetonas em } \\
\text { várias posições, por } \\
\text { exemplo: C-6, C-7, C-14, } \\
\text { C-15, C-16, C-18 }\end{array}$ & $\begin{array}{l}\text { Um dos vários compostos } \\
\text { possíveis }\end{array}$ & Glucuronídeos \\
\hline Andrógenos & Testosterona & $\begin{array}{l}\text { 1. Redução do 4-ene-3-one } \\
\text { 2. Oxidação do C-17 oxo }\end{array}$ & Androsterona & $\begin{array}{l}\text { Glucuronídeo e } \\
\text { Sulfato }\end{array}$ \\
\hline Glucocorticóides & Cortisol & $\begin{array}{l}\text { 1. Redução do 4-ene-3-one } \\
\text { 2. Redução do grupo 20- } \\
\text { oxo } \\
\text { 3. Clivagem da cadeia } \\
\text { lateral }\end{array}$ & Allo tetrahydocortisone & Glucuronídeo \\
\hline
\end{tabular}

Quadro 1 - Formas de excreção para alguns esteróides. NORMAN; LITWACK, 1997 


\subsection{MÉTODOS NÃO-INVASIVOS DE ESTUDO DA FUNÇÃO ENDÓCRINA}

Entender como os animais se reproduzem é fundamental no manejo e conservação da vida selvagem. Historicamente, tais informações para animais domésticos recaiam na observação sistemática dos comportamentos social e reprodutivo. Com a habilidade de desenvolvimento de anticorpos específicos contra hormônios esteróides e protéicos surge o radioimunoensaio. A possibilidade de coletas seriais de sangue dos animais domesticados permitiu o estabelecimento dos padrões de secreção destes hormônios ao longo do tempo. Informações substanciais sobre o eixo hipotálamo-hipófise-gônadas em machos e fêmeas permitiu o delineamento: (1) da função gonadal baseada no sexo, idade e sazonalidade; (2) do timing da espermatogênese e ovulação; (3) do tipo de ovulação (espontânea ou induzida); (4) de metodologias para superar a infertilidade; e (5) de protocolos para reprodução assistida consistentes por meio de inseminação artificial ou transferência de embriões. Estes marcos nos animais domésticos foram possíveis pois os hormônios puderam ser medidos em amostras de sangue facilmente coletadas, em conseqüência proveram as pistas sobre como a reprodução funciona (PUKAZHENTI; WILDT, 2004).

Em contraste, é impossível e perigoso conseguir amostras seqüenciais de sangue na maioria das espécies selvagens. Iniciou-se por volta dos anos 70 o desenvolvimento das técnicas anestésicas em animais selvagens que permitiram a amostragem esporádica de sangue que produziu dados suficientes que sugeriram que os padrões hormonais nos animais selvagens era notavelmente diferente das espécies domésticas. Contudo, o problema recaía no fato de que muito poucas amostras de sangue foram colhidas de animais selvagens para plotar um perfil hormonal longitudinal. Além disso, há evidências de que o estresse da anestesia pode alterar o padrão normal de secreção hormonal no sangue do doador. Uma ferramenta alternativa era necessária (PUKAZHENTI; WILDT, 2004).

Por mais de 25 anos, laboratórios independentes desenvolveram técnicas pioneiras para avaliação de padrões hormonais em fezes e urina ( HODGES et al., 1979; BAMBERG et al., 1984; MONFORT et al., 1990; LASLEY; KIRKPATRICK 1991; GARNIERA et al., 1998; SCHWARZENBERGER et al., 1998) ou mesmo em saliva (CZEKALA; CALLISON 1996). Metabólitos hormonais excretados nas fezes e urina refletem acuradamente os padrões hormonais no sangue, com, é claro, a demora apropriada na passagem do sangue para a excreta. Se o hormônio é primariamente excretado nas fezes ou na urina é espécie dependente. Por exemplo, a maioria dos esteróides em felídeos (Brown et al., 2001ª) são excretados nas 
fezes, enquanto os mesmos metabólitos de hormônios são excretados pelos rins, na urina dos cervídeos (MONFORT et al., 1990). As fezes dos elefantes contêm a maioria dos progestágenos, mas somente $10 \%$ dos estrógenos (BROWN, 2000). Portanto, o primeiro passo crucial para aplicação desta tecnologia é determinar a razão dos metabólitos de esteróides entre urina e fezes. O estudo do metabolismo do estradiol em gatos domésticos (Felis catus) demonstrou que mais de 95\% deste esteróide é excretado nas fezes (SHILLE et al., 1990, 1984). Além do mais, muitos estudos têm sugerido que os metabólitos de estradiol e/ou a progesterona são quantificáveis em fezes de felídeos não-domésticos, guepardo, Acinonyx jubatus (CZEKALA et al., 1994, GRAHAM et al., 1993; GROSS, 1992); tigre, Panthera tigris (GRAHAM et al., 1993); leão, P. leo (GRAHAM et al., 1993); caracal, F. caracal (GRAHAM et al., 1993); serval, F. serval (SHILLE et al., 1991); lince, F. rufus (SHILLE et al., 1991).

A vantagem óbvia da utilização desta técnica é o acesso à função gonadal sem a necessidade de tocar no animal: a amostra é simplesmente coletada no chão ou piso do recinto e analisada no laboratório. Resultando em perfis hormonais com menos "ruído" que aqueles após análise de sangue pois os padrões excretórios representam um pool de metabólitos que reflete a flutuação por várias horas e não pontual como é o sangue. No entanto esta metodologia não pode ser utilizada na análise dos hormônios hipofisários que por serem protéicos são degradados rapidamente pelo metabolismo. Contudo, existem exceções onde é possível a detecção do pico de LH no panda gigante (Aiuluropoda melanoleuca) e na orca (Orcinus orca) por análise da urina por RIA ou EIA (MONFORT; BROWN, observações não publicadas apud PUKAZHENTI; WILDT, 2004). Ademais, está havendo considerável interesse em mensurar metabólitos de corticóides adrenais na urina e fezes para correlacionar o estresse e o sucesso reprodutivo tanto em zoológicos como em vida livre (MONFORT, 2003; PICKARD, 2003).

A monitoração hormonal não-invasiva tem sido extensivamente usada desde o inicio dos anos 80 para caracterizar a biologia reprodutiva de várias espécies de primatas nãohumanos, antílopes, equídeos, felídeos, canídeos, marsupiais e aves (LASLEY; KIRKPATRICK, 1991; HIRSCHENHAUSER et al., 1999; BROWN et al., 2001 a, 2001 b; Paris et al., 2002; MONFORT, 2003; PICKARD, 2003). Como perspectiva de manejo, esta tecnologia tem sido utilizada na identificação de aciclicidade, prenhez e proximidade do parto. Novos fenômenos também têm sido descobertos. Por exemplo, a monitoração de metabólitos urinários no ameaçado cervo de Eld (Cervus eldi thamin) asiático revelou que quanto ao fotoperíodo, o dia longo estimula o início do ciclo ovariano, em contraste, o dia 
curto estimula o ciclo no veado da cauda branca (Odocoileus virginianus) na América do Norte (MONFORT et al., 1990). Estudos longitudinais no guepardo (Acinonyx jubatus) indicaram que mais de $25 \%$ da população cativa não demonstra atividade ovariana (BROWN et al., 2001.a). Estudos mais recentes demonstraram que esta falha é devida a supressão pela presença de conspecíficos no mesmo recinto (WIELEBNOWISKI et al., 2002 a). Os achados fazem sentido, nas planícies da África, os guepardos são geralmente solitários. Quando colocados nos zoológicos, a atividade ovariana cessa e só retorna sob condições solitárias, sem a presença de outras fêmeas no mesmo recinto. A monitoração fecal de felídeos tem também revelado que algumas espécies são muito diferentes do gato doméstico sob o aspecto da ovulação. No gato doméstico, tigre e leão, a ovulação ocorre tipicamente após estímulo vaginal/cervical durante a cópula (ovulação induzida). Contudo, há algumas espécies de gatos, tais como a rara pantera nebulosa (Neofelis nebulosa) da Ásia, que tem relativamente alta incidência de ovulação espontânea por razões que permanecem desconhecidas (BROWN et al., 1995, 2001 a).

Talvez a maior utilidade desta técnica seja para elucidar o motivo pelo qual uma espécie falha em se reproduzir no cativeiro. A monitoração fecal não-invasiva tem revelado grandes diferenças de padrões hormonais entre as espécies de rinocerontes (HEISTERMAN et al., 1998; SCHWARZENBERGER et al., 1998; BROWN et al., 2001 b) tanto quanto em raptores (STALEY et al., 2003). Serão discerníveis variações nos padrões hormonais entre animais que têm sucesso reprodutivo comparados com os que não têm? Os achados podem ser mediados por respostas ao estresse? Estudos têm correlacionado a excreção de glucocorticóides nas fezes com potencial estresse face a condições não ideais de manejo e reprodução. Por exemplo, corticóides fecais são maiores em panteras nebulosas mantidas em recintos adjacentes a espécies predadoras ou perto do público em contraste àquelas mantidas em recintos remotos e maiores verticalmente (WIELEBNOWISKI et al., 2002 b). Assim, tais tecnologias são importantes no direcionamento do bem estar animal, direcionando o enriquecimento dos cativeiros, melhorando potencialmente o sucesso reprodutivo e o bem estar.

Há também um potencial significativo das técnicas não-invasivas para utilização em vida-livre (LASLEY, KIRKPATRICK, 1991; KIRKPATRIC et al., 1992; GARROTT et al., 1998; MONFORT, 2003), eliminando os problemas associados ao estresse da captura e contenção química, que podem levar o animal à morte (VALKENBURG et al., 1983; SEAL et al., 1985), ao bloqueio dos fenômenos reprodutivos (BALLARD; TOBEY 1981; LARSEN; GAUTHIER, 1989) e/ou a resultados confusos quanto ao status endócrino do indivíduo 
(KIRKPATRICK et al., 1979). A identificação das fezes pode ser feita associando-se dados sobre os rastros deixados pelo animal, tamanho das fezes e no caso de felídeos, confirmada pela análise dos pelos ingeridos quando da higienização própria da família (Olmos, 1993; CHAKRABORTY; CHAKRABORTY, 1996; ARANDA; SÁNCHEZ-CORDERO, 1996; FACURE; GIARETTA, 1996). Esta é uma área especialmente rica para novas descobertas combinando interesses em ecologia comportamental e fisiologia reprodutiva. Por exemplo, anos de estudos com os cães selvagens africanos (Lycaon pictus) na natureza questionavam a significância do sistema de acasalamento onde somente uma fêmea dominante se reproduz. As subordinadas falham em ficar prenhe pelo estresse imposto pela fềmea alfa? Não, ao contrário, pesquisadores estudando estes animais conseguiram coletar cuidadosamente amostras de fezes para análise subsequente. Seus achados revelaram que a fêmea dominante progenitora excreta as maiores concentrações de glucocorticóides, indicando que há um esforço adrenérgico em ser a fêmea reprodutora (CREEL et al., 1997). Estudos similares foram feitos em outras espécies, incluindo mangusto (Helogale parvula; CREEL et al., 1992), bisão (Bison bison; KIRKPATRICK et al., 1996), alce (Alces alces; BERGER et al., 1999) e ganso (Anser anser; HIRSCHENHAUSER et al., 1999), dentre outros.

Apesar da monitoração de hormônios fecais e urinários serem tão populares para estudos com animais selvagens, nada é tão valioso quanto o sangue, quando disponível, pois oferece mais rapidez na aquisição de dados no laboratório. Algumas espécies em cativeiro, notavelmente baleias, golfinhos, pandas gigantes e elefantes podem ser condicionados para coletas de sangue (PUKAZHENTI; WILDT, 2004). Em casos onde a produção de urina e fezes é grande (elefante) a coleta de sangue é muito mais prática e a análise hormonal tradicional tem revelado que pouco menos de $25 \%$ as fêmeas falham em demonstrar atividade ovariana (um fenômeno conhecido como 'flatlining'; BROWN 2000). Coletas repetidas de sangue e análises hormonais também têm sido utilizadas para inseminação artificial guiada por ultra-som. Em um dado ciclo, a elefanta produz dois picos de LH com três semanas de intervalo (BROWN et al., 1999). Sabendo o tempo do primeiro pico pode-se predizer o segundo e preparar a inseminação (BROWN, 2000). Até hoje, oito elefantas tiveram filhotes (de 12 gestações) quando a monitoração hormonal foi utilizada para coordenar a ia com o preciso dia da ovulação (PUKAZHENTI; WILDT, 2004).

As limitações dessa tecnologia são espantosamente poucas. Por exemplo, estudos recentes demonstraram que é possível gerar perfis de metabólitos de esteróides acurados pela análise de fezes do panda gigante (Aiuluropoda melanoleuca), que alimenta-se basicamente de bambu (KERSEY et al., 2003). O fato dos perfis hormonais serem produzidos por este 
material fibroso (as fezes freqüentemente contém folhas e caules) prova o crescente poder desta tecnologia. Todavia, melhorias são necessárias na extração dos metabólitos das fezes, as quais podem ser muito trabalhosas e com grande consumo de tempo e de reagentes. Pesquisas são também necessárias no desenvolvimento de técnicas que permitam acesso rápido às concentrações de hormônios gonadais e hipofisários que permitirão uma monitoração rápida e positiva (para período de acasalamento, reprodução assistida ou predição de parto); uma técnica que permita um acesso instantâneo do animal na natureza pode oferecer oportunidades excitantes para correlacionar a fisiologia de um animal com seu ambiente natural. 


\subsection{TÉCNICAS ANALÍTICAS}

\subsubsection{Eletroforese Capilar (CE)}

Eletroforese pode ser definida como o transporte de partículas eletricamente carregadas, em meio líquido, sob a influência de um campo elétrico (WEINBERGER, 1993). $\mathrm{Na}$ eletroforese clássica solutos carregados são separados através do uso de um meio líquido condutivo sobre uma superfície que permita o deslocamento das soluções de eletrólitos e dos solutos; caracteriza-se pelo uso do papel ou gel como superfície de separação, com necessidade de manipulação intensiva e longos tempos de análise. A maior limitação para a rapidez, eficiência e aumento da escala de separações eletroforéticas é a incapacidade do papel ou do gel em dissipar o calor causado pela passagem de corrente através do meio condutor, o chamado efeito Joule. Em tais condições, surgem gradientes de temperatura que induzem a gradientes de densidade, que por sua vez podem causar convecção e os fluxos convectivos misturam as bandas já separadas (Lima, 2003). Uma comparação entre os resultados da eletroforese capilar e a eletroforese em gel é apresentada na figura 6.
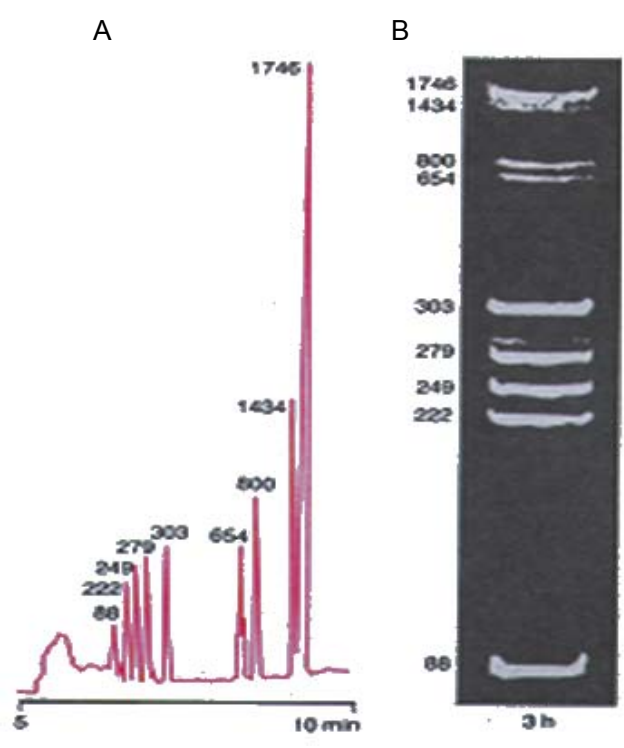

Figura 6 - Análise de DNA por eletroforese capilar (A) e eletroforese em gel (B) 
Em eletroforese capilar, a separação é conduzida em tubos de dimensões capilares, com 25 a $75 \mu \mathrm{m}$ de diâmetro interno, e 50 a $100 \mathrm{~cm}$ de comprimento, usualmente preenchidos com solução tampão (JONES; JANDIK, 1991). O uso de tubos com dimensões capilares minimiza as limitações relativas ao efeito Joule, uma vez que a geometria do capilar (elevada área superficial interna relativa ao volume) favorece a dissipação do calor. Com isso a convecção é praticamente eliminada, consequentemente, aumenta-se a eficiência da coluna por permitir a aplicação de campos elétricos mais elevados, o que resulta em uma considerável redução do tempo de análise, sendo que o consumo de amostras e solventes também e reduzido (LIMA, 2003).

A separação e análise de misturas complexas podem ser feitas usando pequenos volumes de amostra $( \pm 10 \mathrm{~nL})$ com alta resolução e eficiência. A capacidade de separação, ou seja, o número máximo de bandas separadas num determinado intervalo de tempo é alto (JONES; JANDIK, 1991), tornando a eletroforese capilar uma técnica analítica particularmente atrativa para separação de amostras complexas.

\subsubsection{Instrumentação}

Um dos aspectos mais importantes da CE é a simplicidade de sua instrumentação (Figura 7). O sistema consiste de uma fonte de alta tensão, capilares (sílica fundida é o material mais comumente empregado), eletrodos (geralmente platina), e um detector apropriado. Uma fonte cc regulada, de alta tensão, é usada para estabelecer um campo elétrico ao longo do capilar. Tais fontes podem, em geral, ser operadas à voltagem no intervalo de 0 $50 \mathrm{kV}$ e corrente de $0-200 \mu \mathrm{A}$. O operador é protegido contra um contato acidental com a alta voltagem pela inclusão do sistema inteiro, ou pelo menos o terminal de alta voltagem, numa caixa de acrílico, equipada com chaves de segurança. A fonte de alta tensão é conectada, através de eletrodos de platina, a dois reservatórios contendo uma solução de um eletrólito conveniente. Tubos capilares de sílica fundida são então preenchidos com a solução, e servem como canal de migração. As extremidades do capilar são imersas nos reservatórios da solução para completar o contato elétrico. Para minimizar efeitos térmicos, o capilar deve ser mantido à temperatura constante. Há várias possibilidades para termostatização do sistema, incluindo circulação de um líquido ou ar através de um cartucho contendo o capilar, além do uso de ventiladores e fornos (TAVARES, 1996). 


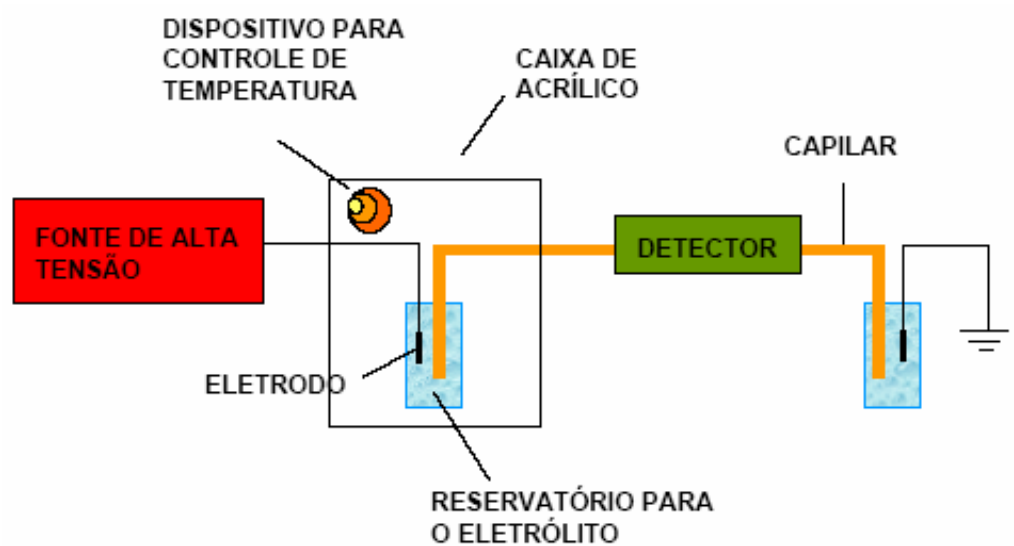

Figura 7 - Instrumentação para eletroforese capilar

\subsubsection{Modos de Injeção da Amostra}

A maneira pela qual a amostra é introduzida no capilar tem implicação direta em análises quantitativas. A reprodutibilidade da área do pico, ou altura, reflete a precisão da técnica de injeção. Em CE, amostras podem ser introduzidas no capilar por métodos eletrocinéticos ou hidrodinâmicos. $\mathrm{Na}$ injeção eletrocinética, um gradiente de potencial é estabelecido ao longo do comprimento do capilar por um período de tempo conhecido, enquanto que na injeção hidrodinâmica utiliza-se um gradiente de pressão. O gradiente de pressão pode ser estabelecido por diferentes mecanismos: pressurização ou vácuo em um dos reservatórios de solução, ou por gravidade, onde um dos reservatórios é elevados em relação ao outro e a amostra é introduzida por sifonagem. A injeção hidrodinâmica introduz no capilar uma alíquota representativa da composição do soluto na amostra. $\mathrm{O}$ volume de injeção (nL) depende do tempo de injeção, dimensões do capilar, viscosidade da solução tampão e da diferença de pressão estabelecida. Este tipo de injeção é mais precisa que a eletrocinética pois é baseada estritamente na transferência de volume. Entretanto, pode ocorrer um alargamento significativo da zona, como resultado do perfil de velocidade parabólico, característico do fluxo induzido por pressão (TAVARES, 1996).

$\mathrm{Na}$ injeção eletrocinética, a amostra é introduzida no capilar como resultado da combinação entre as velocidades eletroforética e eletrosmótica (serão explicadas posteriormente). Assim sendo, a quantidade de material injetado é uma função da mobilidade 
eletroforética do soluto, das condutividades da amostra e meio condutor, assim como da magnitude do fluxo eletrosmótico. Uma importante conseqüência deste modo de injeção é a amostragem não representativa, que resulta da discriminação entre os componentes da amostra com diferentes mobilidades. Este é particularmente um problema, quando a amostra é composta de solutos de baixa mobilidade, que podem estar presentes em concentrações próximas ao limite de detecção (TAVARES, 1996).

\subsubsection{Detecção}

Os detectores são na realidade transdutores, transformam as moléculas que chegam à câmara de detecção em um sinal elétrico (AQUINO NETO; NUNES, 2003).

Um detector ideal deve ser versátil; apresentar alta sensibilidade, monitoração contínua dos efluentes, baixo nível de ruídos, vasta linearidade de respostas, linha de base estável, insensibilidade ao fluxo e mudanças de temperatura e resposta a todos os tipos de compostos, mensurando acuradamente um pequeno volume de amostra. De todos os parâmetros ideais descritos, ruído, sensibilidade e linearidade são os requisitos utilizados na descrição da performance do detector (WESTON; BROWN, 1997).

Os detectores podem ser classificados em dois tipos: os universais e os específicos. Os detectores universais medem a diferença entre alguma propriedade do soluto em relação à solução. Assim, o sinal não depende das propriedades do soluto, mas da diferença entre as propriedades do soluto e solução. Nesta classe estão incluídos os detectores de índice de refração e condutividade, entre outros que empregam métodos indiretos. Apesar de universais, estes detectores apresentam menor sensibilidade e intervalo dinâmico. Os detectores específicos medem uma propriedade específica do soluto. A detecção é, portanto, limitada aos solutos que possuem a referida propriedade. Nesta classe estão incluídos os fotodetectores (baseados na absorção do UV/VIS, na fluorescência etc.), os espectrômetros de massas, os detectores amperométricos e os radiométricos. O uso dos detectores específicos é bastante vantajoso quando a matriz da amostra é complexa, e em situações onde é desejável minimizar interferências do background. Este tipo de detector é geralmente mais sensível que os detectores universais e fornece intervalos mais amplos de resposta linear. Além disso, a relação sinal/ruído é melhor. Conseqüentemente, os detectores específicos encontram maior uso que os universais (TAVARES, 1996). 


\subsubsection{Conceitos Básicos}

A eletroforese capilar é similar à cromatografia em vários aspectos (Quadro 2) e a maioria das palavras usadas na cromatografia são também empregadas na CE. Por exemplo, eficiência e resolução são definidas de maneira similar, contudo, algumas terminologias são diferentes, em cromatografia a coluna é usada para separar ao analitos, na eletroforese é utilizado um capilar. Na cromatografia uma bomba é usada para propelir a amostra através da coluna, na eletroforese capilar não há sistema de bomba externa, os constituintes da amostra movem-se como resultado de suas mobilidades no campo elétrico e pelo fluxo eletrosmótico, se presente (WESTON; BROWN, 1997).

\begin{tabular}{|c|c|}
\hline Eletroforese Capilar & Cromatografia \\
\hline Eletroferograma & Cromatograma \\
\hline Potencial aplicado & Velocidade do fluxo \\
\hline $\begin{array}{c}\text { Eletrólito carreador ou } \\
\text { tampão }\end{array}$ & Eluente ou fase móvel \\
\hline $\begin{array}{c}\text { Modo de injeção: } \\
\text { Hidrodinâmica ou } \\
\text { eletrocinética }\end{array}$ & $\begin{array}{c}\text { Modo de injeção: } \\
\text { Injetor }\end{array}$ \\
\hline Tempo de migração & Tempo de retenção \\
\hline Mobilidade eletroforética & Fator de capacidade da coluna \\
\hline Velocidade & ---------- \\
\hline Fluxo eletrosmótico & ------- \\
\hline Fonte de alta-voltagem & Bomba \\
\hline Capilar & Coluna \\
\hline
\end{tabular}

Quadro 2 - Comparativo entre eletroforese capilar e cromatografia.

\subsection{Mobilidade Eletroforética}

Sob a ação de um campo elétrico, um soluto carregado migra através do tampão com uma velocidade eletroforética, em $\mathrm{cm} / \mathrm{s}$ (WEINBERGER, 1993).

A mobilidade não depende somente da densidade de carga do soluto (a valência e tamanho da molécula de soluto), mas também da constante dielétrica e viscosidade do eletrólito sendo também dependente da temperatura (WESTON; BROWN, 1997). 


\subsection{Velocidade da Separação}

Em CE, a separação é baseada nas diferentes velocidades dos solutos num campo elétrico. A velocidade de migração de uma espécie química em particular é produto de sua mobilidade eletroforética e do campo elétrico (WESTON; BROWN, 1997).

\subsection{Fluxo Eletrosmótico}

Fluxo eletrosmótico (EOF) é o termo utilizado para descrever o movimento de um líquido em contato com uma superfície sólida quando um campo elétrico tangencial é aplicado. Este movimento é também conhecido como eletrosmose ou eletroendosmose. $\mathrm{O}$ EOF pode ser eliminado se necessário. Contudo o EOF é freqüentemente utilizado, quando ocorre na mesma direção que os analitos para aumentar a velocidade com a qual os analitos alcançam o detector, ou, quando flui em direção oposta aos analitos, para melhorar a resolução (WESTON; BROWN, 1997).

O EOF ocorre nos capilares de sílica fundida porque os grupos silanóis ácidos da superfície do capilar dissociam quando em contato com a solução de eletrólito (tampão) conforme a equação (WESTON; BROWN, 1997) :

$$
\mathrm{SiOH}_{(\mathrm{s})} \leftrightarrow \mathrm{SiO}_{(\mathrm{s})}^{-}+\mathrm{H}^{+}(\mathrm{aq})
$$

Cátions hidratados na solução eletrolítica são atraídos pelos grupos silanóis negativos e começam a organizarem-se em duas camadas. Uma das camadas é compacta (ligada por forças eletrostáticas) e a outra é mais frouxa ou difusa. Quando um campo elétrico é aplicado, a camada difusa se parte e move-se em direção ao cátodo, arrastando com ela um volume de solução do eletrólito, como resultado há formação de um fluxo viscoso, que é o chamado fluxo eletrosmótico (WESTON; BROWN, 1997). A figura 8 ilustra o processo. 


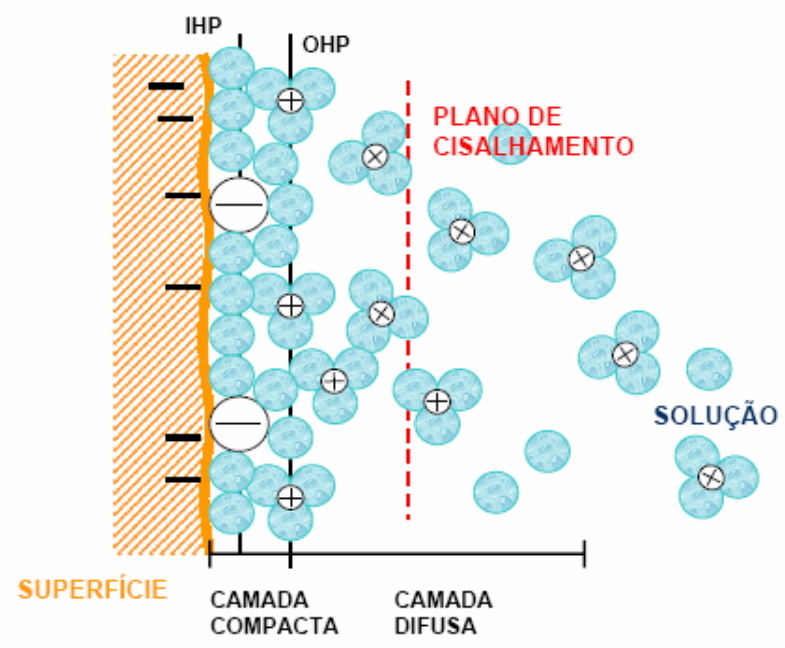

Figura 8 - Modelo para a interface capilar/solução (cortesia Profa. MarinaTavares)

\subsection{Eficiência da Separação}

Como o EOF afeta o período de tempo em que um soluto permanece no capilar, tanto a eficiência e a resolução são relacionadas à direção e fluxo do EOF. O perfil do EOF é comparativamente semelhante a uma tampa (Figura 9). Diferente do fluxo laminar característico dos fluídos sob pressão, o EOF tem mínima resistência à transferência de massa. Como resultado a contagem de pratos teóricos em capilar é muito maior que na cromatografia em coluna de comprimento semelhante ( WESTON; BROWN, 1997).
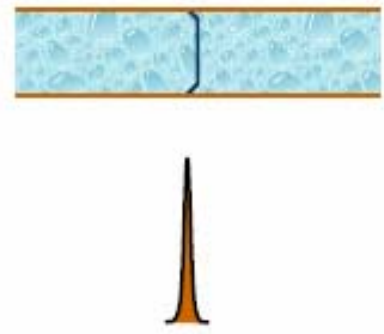

FLUXO

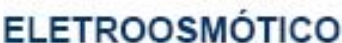

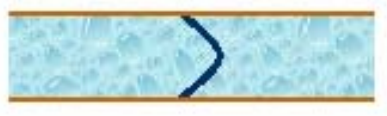

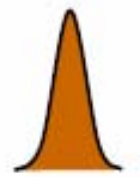

FLUXO

LAMINAR

Figura 9 - Perfil do tipo de deslocamento para um fluxo induzido por um campo elétrico (eletrosmótico) e um fluxo induzido por pressão (laminar) e o correspondente efeito no registro (Cortesia Profa. Marina Tavares) 


\subsection{Conceito de Pratos Teóricos}

A dispersão do pico é o processo fundamental que delineia a eficiência da separação. O uso do conceito de pratos teóricos para descrever a distribuição dos picos em cromatografia tem sido criticado, mas é justificado por razões práticas, fornecendo um parâmetro que caracteriza a performance da coluna. Assim foi introduzido na eletroforese capilar com o intuito de comparar o poder de separação da cromatografia coma a $\mathrm{CE}$, embora não haja nada na coluna que sugira estágios discretos (VINDEVOGEL; SANDRA, 1992).

O modelo de pratos é aplicado a todos os tipos de coluna cromatográficas. Apesar da relação ser válida para picos gaussianos, por conveniência é utilizado em picos assimétricos também. No modelo cromatográfico proposto na teoria dos pratos, a coluna cromatográfica é considerada contendo um número de finas secções ou pratos, nas quais ocorre o equilíbrio do soluto entre a fase móvel e a fase estacionária (Figura 10). O movimento de um soluto através da coluna é visto como um passo transferido de um prato teórico ao próximo. Quanto maior o número de pratos teóricos, mais eficiente é considerada a coluna. Quanto menor a altura do prato maior será o número de pratos e mais eficiente será a coluna (WESTON; BROWN, 1997). É importante salientar que os pratos não existem, são apenas utilizados didaticamente para ajudar a entender o processo.

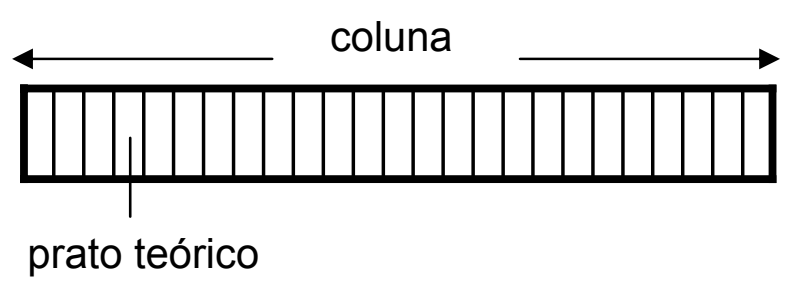

Figura 10. Desenho esquemático mostrando a divisão de uma coluna em pratos teóricos

\subsection{Modos de Separação em Eletroforese Capilar}

Vários modos de separação, com mecanismos singulares e seletividade característica são possíveis em eletroforese capilar: fronteira móvel, zona, isotacoforese e focalização isoelétrica (TAVARES, 1996). 


\subsection{Eletroforese por Fronteira Móvel}

Nesta modalidade, uma quantidade apreciável da amostra é colocada em um tubo, preenchido com solução tampão. Após o estabelecimento do campo elétrico, os componentes da amostra migram em uma dada direção, e com uma velocidade característica, dependente da mobilidade do componente. A separação completa de todos os componentes da amostra nunca é atingida. Apenas os componentes de maior mobilidade podem ser parcialmente purificados, enquanto que as outras bandas sofrem diversos graus de sobreposição (TAVARES, 1996).

\subsection{Eletroforese de Zona}

Em princípio, é também uma técnica de fronteira móvel, em que a amostra é introduzida no meio tamponado, como uma banda de pequena espessura. Quando o potencial é aplicado, cada zona migra independentemente, com velocidade constante, mas diferenciada, característica de sua própria mobilidade. As modalidades de eletroforese em solução livre, gel e micelar pertencem a esta categoria (Tavares, 1996).

\subsection{1 Cromatografia Eletrocinética Micelar (MEKC)}

Enquanto os solutos iônicos podem ser separados simplesmente com base em suas diferentes mobilidades eletroforéticas, os solutos neutros, como os esteróides, somente podem ser separados por partição entre duas fases. Dentre os métodos de separação que vêm sendo desenvolvidos para misturas contendo solutos neutros, a cromatografia eletrocinética micelar (MEKC) tem recebido cada vez mais atenção por parte dos pesquisadores (Figura 11) (BAKER, 1995).

Desenvolvida em 1984 por S. Terabe e colaboradores, a MECK é uma versão modificada de eletroforese capilar de zona, onde um surfactante não iônico é utilizado como parte da composição do eletrólito de separação. As moléculas de surfactante tendem a formar 
micelas ou agregados acima de uma concentração crítica micelar, na qual a cauda hidrofóbica é orientada para o centro e a cabeça hidrofílica e carregada eletricamente fica para fora. Quando uma alta voltagem é aplicada, a micela aniônica migra em direção ao eletrodo positivo pela sua mobilidade eletroforética. Contudo o forte fluxo eletrosmótico transporta o tampão para o eletrodo negativo. A velocidade do fluxo eletrosmótico é maior que a velocidade eletroforética da micela em direção contrária, resultando num fluxo rápido da fase aquosa e lento da fase micelar. Quando analitos neutros são injetados no pólo positivo, uma fração é incorporada dentro da micela e migra na mesma velocidade desta. A fração remanescente migra na velocidade do fluxo eletrosmótico. O equilíbrio é rapidamente estabelecido e então os analitos neutros são separados pela diferença nos coeficientes de distribuição entre a fase micelar e a fase aquosa. A ordem de migração para analitos neutros na MECK geralmente é relacionada a hidrofobicidade do analito. Analitos mais hidrofóbicos interagem mais fortemente com as micelas e migram mais lentos que os analitos hidrofílicos.

Além da separação de analitos eletricamente neutros ou não iônicos, a MECK pode aumentar a seletividade para separação de analitos iônicos pela interação iônica entre o analito e a micela (NISHI; TERABE, 1996), assim, a versatilidade da técnica em manipular materiais de diversas classes químicas em matrizes de amostras complexas são ilustradas pelas representativas aplicações nas áreas clínica, forense, ambiental, e farmacêutica (KHALEDI,1997; GÜBITZ; SCHMID, 2000; TAGLIARO; BORTOLOTTI, 2002).

Visando o aumento da seletividade das separações foram desenvolvidos métodos adicionando ciclodextrinas ao meio micelar. Este método foi denominado de Cromatografia Eletrocinética Micelar com Ciclodextrinas (MEKC-CD). Sendo neutras as ciclodextrinas migram com a velocidade eletrosmótica. A partição diferenciada de solutos entre a micela e a cavidade da ciclodextrina produz a seletividade extra requerida (TAVARES, 1997).

Solventes orgânicos também são freqüentemente usados em MEKC para reduzir a afinidade de solutos hidrofóbicos com a fase micelar. Em adição, tais solventes reduzem o fluxo eletroosmótico e conseqüentemente expandem a janela de migração (BAKER, 1995). 


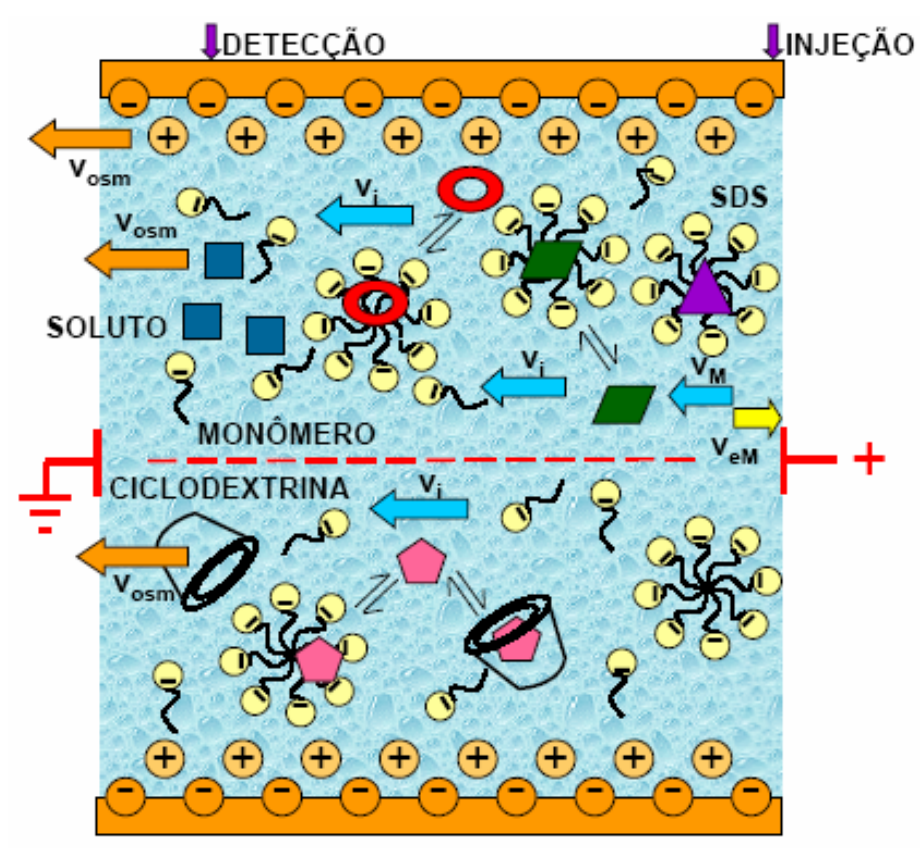

Figura 11 - Representação esquemática da migração de solutos neutros por MECK-CD em fase micelar aniônica (A) e na presença de uma fase auxiliar (B). Detalhe mostrando monômeros e micelas de SDS, ciclodextrinas e a interação de diversos solutos neutros com ambas as fases. Um soluto não retido pela micela migra com a velocidade do fluxo eletrosmótico, $\mathrm{V}_{\mathrm{OSM}}$. A velocidade eletroforética da micela é $\mathrm{V}_{\mathrm{eM}}$ enquanto que sua velocidade aparente final é $\mathrm{V}_{\mathrm{M}}$.(Cortesia Profa. Marina Tavares)

\subsection{Isotacoforese}

Neste modo, a amostra é inserida entre duas soluções diferentes, o eletrólito "líder" e o eletrólito "terminador". Ambos, cátions e ânions, podem ser analisados por esta modalidade, entretanto em misturas distintas. Por exemplo, numa separação isotacoforética de uma mistura de cátions, o eletrólito líder deve conter um cátion cuja mobilidade seja maior que a mobilidade de qualquer componente catiônico da amostra. Por outro lado, o eletrólito terminador deve conter o cátion de menor mobilidade. Quando o campo elétrico é estabelecido, diferentes gradientes de potencial evolvem em cada banda, de tal forma que todos os cátions eventualmente migrem com velocidade constante e única. Em regiões onde cátions de menor mobilidade estão presentes, o campo elétrico é mais intenso. Estes solutos, entretanto, movem-se com a mesma velocidade que os solutos de maior mobilidade, estes últimos submentidos a campos elétricos mais fracos. Portanto, as velocidade das bandas individuais são auto-normalizadas (TAVARES, 1996). 


\subsection{Eletroforese por Focalização Isoelétrica}

A focalização isoelétrica envolve a separação de solutos anfotéricos em um gradiente de $\mathrm{pH}$. Sob a influência do campo elétrico, um soluto negativamente carregado migra em direção ao anodo. Durante sua migração, o soluto experimenta regiões de $\mathrm{pH}$ progressivamente menor. Assim, uma fração cada vez maior do soluto torna-se protonada, e desta forma, a carga efetiva é alterada durante a migração. Eventualmente, a carga total do soluto torna-se zero, e sua migração é interrompida. Cada componente da amostra migra para uma região de $\mathrm{pH}$ igual ao seu ponto isoelétrico, e permanecerá nesta posição enquanto o campo elétrico for operante (TAVARES, 1996).

\subsubsection{Cromatografia a Gás (GC)}

O termo cromatografia abriga técnicas de separação nas quais compostos são separados com base na partição ou distribuição dos analitos entre duas fases em um sistema dinâmico. Na cromatografia gasosa (GC) temos um gás como fase móvel e um líquido ou sólido como fase estacionária. Quando a fase móvel é um líquido temos a cromatografia líquida (cromatografia líquida de alta performance [HPLC], por exemplo) (FOWLIS, 1999).

A GC constitui um sistema no qual os analitos são particionados ou distribuídos entre uma fase estacionária (líquida ou sólida) e uma fase móvel gasosa, portanto, os compostos a serem analisados têm que ser suficientemente voláteis para que estejam sob forma de gás em condições experimentais para que possam ser transportados pela coluna. A volatilidade do analito é um dos fatores limitantes para a aplicação da técnica (FOWLIS, 1999).

Um esquema da instrumentação para GC é apresentado na figura 12. 


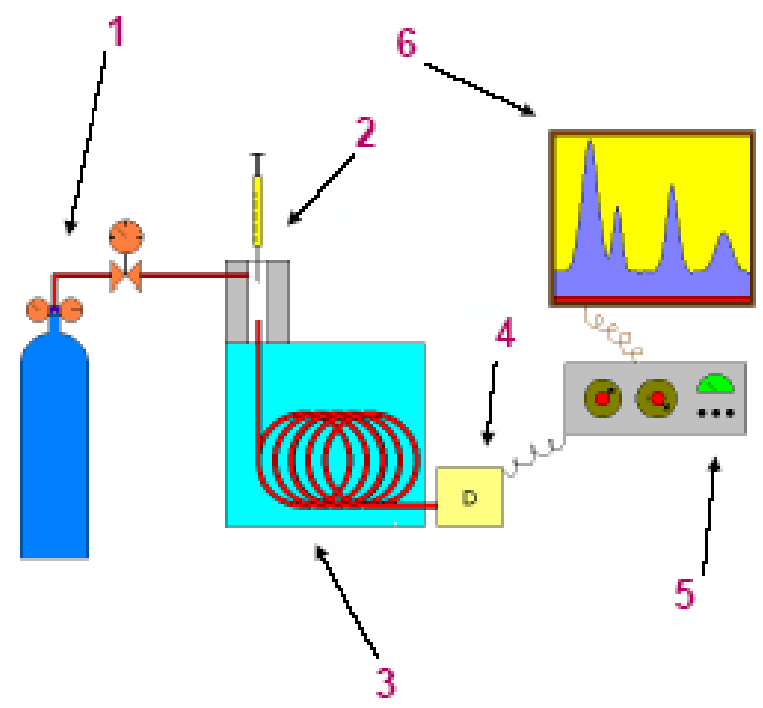

Figura 12 - Diagrama esquemático de um cromatográfo a gás. Reservatório de gás e controladores de pressão (1); injetor da amostra (2); coluna cromatográfica e forno da coluna (3); detector (4); sistema eletrônico de tratamento do sinal (5) e registrador ou computador para registro do sinal (5)(Cortesia Profa. Marina Tavares)

Algumas amostras precisam passar por uma etapa de derivatização antes de serem analisadas por GC. O objetivo da derivatização é aumentar a volatilidade do analito. Compostos que possuem ligações do tipo pontes de hidrogênio usualmente têm elevados pontos de ebulição, a eliminação das pontes de hidrogênio aumenta a volatilidade do composto. Por outro lado, se a derivatização constitui a única alternativa para análise por GC, talvez seja melhor a utilização de outro método analítico. A derivatização é um modo excelente de tornar um composto suficientemente volátil para análise, mas para análises quantitativas precisas, a derivatização introduz níveis adicionais de performance no método que precisam ser validados, sendo factível para uma amostra, mas para repetidas análises torna-se prudente a investigação de alternativas (FOWLIS, 1999).

$\mathrm{Na}$ GC, a amostra é vaporizada e introduzida em um fluxo de um gás adequado denominado de fase móvel ou gás de arraste. Esse fluxo de gás com a amostra vaporizada passa por um tubo contendo a fase estacionária (coluna cromatográfica), onde ocorre a separação da mistura. A fase estacionária pode ser um sólido adsorvente (Cromatografia GásSólido) ou, mais comumente, um filme de um líquido pouco volátil, suportado sobre um sólido inerte (Cromatografia Gás-Líquido com Coluna Recheada) ou sobre a própria parede do tubo (Cromatografia Gasosa de Alta Resolução). Na cromatografia gás-líquido, os dois fatores que governam a separação dos constituintes de uma amostra são governados pela solubilidade do composto na fase estacionária (quanto maior a solubilidade ,mais lentamente 
ele caminha pela coluna) e pela volatilidade (quanto mais volátil a substância, ou seja, quanto maior a pressão de vapor), maior a sua tendência de permanecer vaporizada e mais rapidamente caminha pelo sistema. As substâncias separadas saem da coluna dissolvidas no gás de arraste e passam por um detector; dispositivo que gera um sinal elétrico proporcional à quantidade de material eluido. O registro deste sinal em função do tempo é o cromatograma, sendo que as substâncias aparecem nele como picos com área proporcional à sua massa, o que possibilita a análise quantitativa (FOWLIS, 1999).

\subsubsection{Detectores}

O detector por ionização em chama (FID) é dos mais comumente utilizados. Fornece respostas como um detector universal para compostos orgânicos. Possuem boa linearidade permitindo análises quantitativas acuradas e alta sensibilidade, o que favorece análise de traços em misturas complexas. No entanto apresenta limitações por não responder a água, gases nobres, monóxido de carbono, dióxido de carbono, formaldeído e ácido fórmico (Fowlis, 1999).

Neste modo de detecção o efluente da coluna é misturado com hidrogênio e oxigênio e queimado. Como numa chama de hidrogênio e oxigênio não existem íons, não há passagem de corrente elétrica. Quando um composto orgânico elui, ele também é queimado e ocorre formação de íons e a chama passa a conduzir corrente elétrica. $O$ ar e o hidrogênio são difundidos para o interior do coletor, onde se misturam ao efluente da coluna e queimam, há aplicação de uma diferença de potencial entre o flame-tip e o coletor, pela formação de íons na chama flui uma corrente elétrica que é registrada como um sinal.

A detecção por espectrometria de massas (MS) é baseada na ionização das moléculas do soluto em uma fonte de íons e a separação dos íons é gerada conforme sua relação massa/carga por uma unidade analisadora, que pode ser um analisador magnético, um filtro quadrupolo ou um sistema de ion-trap (FOWLIS, 1999).

A amostra é fragmentada e ionizada em um padrão característico da espécie química. Moléculas são bombardeadas por elétrons (electron impact, EI) ou íons (chemical ionization, CI). O íon formado se fragmenta em padrões informativos de sua estrutura. Os fragmentos resultantes são separados magneticamente de acordo com suas massas moleculares e 
contados. O gráfico do número de íons formados em função da razão massa/carga dos íons é o espectro de massas do analito.

A MS pode produzir o espectro de massa de cada componente que elui da coluna em adição a dados quantitativos. Isto fornece rápida identificação dos componentes em misturas. O espectrometro de massa é universal na resposta e pode ser seletivo conforme a demanda (FOWLIS, 1999).

\subsubsection{Cromatografia Líquida de Alta Performance (HPLC)}

A cromatografia líquida (LC) é uma técnica analítica utilizada na separação de misturas em solução em seus componentes individuais. A separação repousa no uso de duas fases diferentes ou camadas miscíveis, uma das quais é mantida estacionária e a outra movimenta-se sobre a primeira. LC é o nome genérico da cromatografia aonde a fase móvel é um líquido. A separação ocorre porque, sob um estado ótimo de várias condições, cada componente numa amostra vai interagir com as duas fases de formas diferentes e diferentes também em relação a outros componentes da mistura. HPLC designa a cromatografia líquida na qual a fase móvel é mecanicamente bombeada através de uma coluna que contém a fase estacionária. Um equipamento de HPLC consiste de um injetor, de uma bomba, de uma coluna e um detector (Figura 13) (WESTON; BROWN, 1997). 


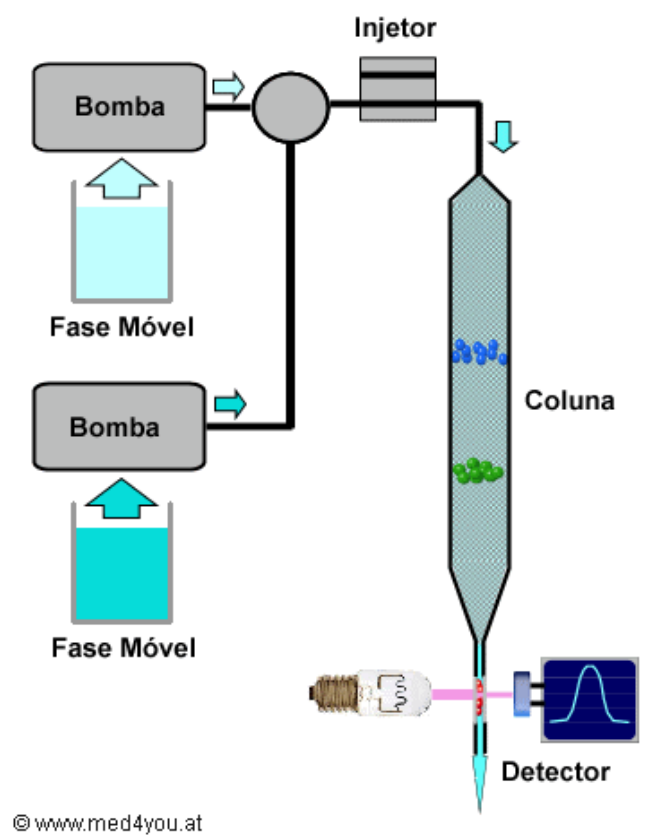

Figura 13. Instrumentação para cromatografia líquida de alta eficiência.

Os métodos utilizados em cromatografia líquida podem ser classificados conforme o mecanismo de retenção, ou seja, pelo modo que o analito interage com a fase estacionária. $\mathrm{Na}$ cromatografia por adsorção os analitos interagem com a fase estacionária conforme a premissa de que semelhante atrai semelhante, assim solutos polares serão mais retidos por fases estacionárias mais polares. Nesta modalidade as moléculas do soluto estão em contato tanto com a fase estacionária como com a fase móvel. Já no modo de partição ocorre competição entre as fases móvel e estacionária, ambas são líquidos. Na troca iônica o que rege a separação é a atração entre opostos; pode ser aplicada a qualquer soluto que adquira carga em solução, a alteração do $\mathrm{pH}$ da solução pode carregar eletricamente os solutos. $\mathrm{Na}$ modalidade por exclusão as partículas da fase estacionária são manufaturadas com vários tamanhos de poros o que a faz se comportar como uma peneira, assim os solutos são separados conforme seus tamanhos, sendo os maiores primeiro eluídos. Por fim, na cromatografia por afinidade a separação é regida pelo mecanismo de chave-fechadura, prevalente em sistemas biológicos. O mecanismo de retenção é mais específico, por outro lado a técnica é mais demorada e também tem elevado custo econômico (WESTON; BROWN, 1997).

$\mathrm{Na}$ cromatografia líquida existem ainda outros mecanismos de sorção que causam separação, dependendo da escolha de um líquido ou de um sólido como fase estacionária, ou 
do tipo de sólido utilizado. A cromatografia líquido-líquido utiliza uma fase estacionária líquida revestindo um suporte sólido inerte. A separação neste caso é devida às diferenças nos coeficientes de partição dos solutos entre as fases estacionária e móvel líquidas. $\mathrm{Na}$ cromatografia líquido-líquido de fase normal, a fase estacionária é relativamente polar e a fase móvel é relativamente apolar, enquanto que na cromatografia líquido-líquido de fase reversa a fase estacionária é apolar e a fase móvel é polar (LINDSAY, 1992). Na cromatografia de fase reversa os componentes mais polares eluem primeiro pela sua maior solubilidade na fase móvel, aumentando-se a polaridade da fase móvel aumenta-se o tempo de eluição; é utilizada para compostos orgânicos ionizáveis. Na cromatografia de fase normal o componente menos polar elui primeiro, pela sua maior solubilidade na fase móvel, aumentando-se a polaridade da fase móvel, o tempo de eluição diminui, utilizada para solutos não iônicos. 


\subsection{PANTHERA ONCA: DADOS BIOLÓGICOS}

A onça pintada é o maior felino das Américas, e único representante atual do gênero Panthera no Novo Mundo (GONYEA, 1976). Pertence à subfamília Pantherinae e à linhagem Panther, juntamente com outros grandes felídeos (JOHNSON; O’BRIEN, 1997). A distribuição histórica desta espécie se estendia do Arizona, Novo México e Texas no sul dos Estados Unidos da América ao Rio Negro $\left(40^{\circ} \mathrm{S}\right)$ ou Rio Santa Cruz $\left(50^{\circ} \mathrm{S}\right)$ na Argentina (ARRA, 1974; CARMAN, 1984). Atualmente ela está oficialmente extinta nos Estados Unidos, é muito rara no México, mas ainda pode ser encontrada na América do Sul (HILTON-TAYLOR, 2000) (Figura 14) A destruição de habitats aliada à perseguição, devido principalmente ao alegado prejuízo econômico causado às criações de animais domésticos, faz com que as populações venham sendo severamente reduzidas, estando então classificada pela IUCN (União Internacional para Conservação da Natureza) como espécie vulnerável à extinção e inclusa na Lista Oficial da Fauna Ameaçada de Extinção do IBAMA.

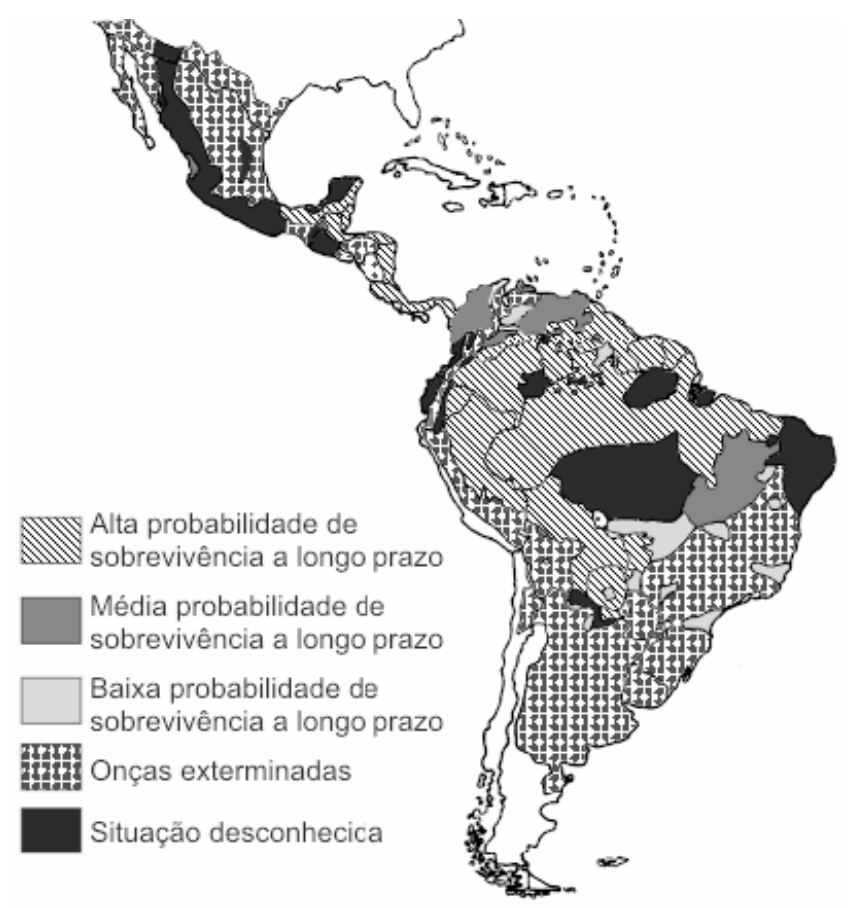

Fonte: Ângelo, Cláudio. Biotecnologia pode salvar onças-pintadas. Folha de S. Paulo, São Paulo, 6 fev. 2002. Folha Ciência, p. A 16.

Figura 14 - Distribuição geográfica de Panthera onca

Os nomes comuns da espécie são onça-pintada, onça, onça-preta, jaguar, jaguarcanguçu, jaguaretê, canguçu (ROSSI, 2002) 
Seus hábitos são solitários e territorialistas, podendo formar casais durante o período reprodutivo (OLIVEIRA, 1994). Suas atividades de deslocamento e caça ocorrem principalmente à noite, sendo que nas demais horas do dia apresentam atividade local (RABINOWITZ; NOTTIGHAM, 1986).

Possuem membros curtos e musculosos adaptados para escalar, nadar, rastejar e capturar presas como queixadas (Tayassu pecari), jacarés (Caiman spp), e cervídeos (gêneros Mazama, Blastocerus e Ozotocerus) (Wildlife Conservation Society 2002).

Predam também antas (Tapyrus terrestris), catetos (Tayassu tajacu) e capivaras (Hidrochoerus hidrochaeris) (EMMONS, 1990; LEITE, 2002). Foi observado que em áreas limítrofes de parques e reservas com regiões de intensa atividade agropecuária ocorre utilização de animais domésticos como fonte de alimento, principalmente quando o acesso a esse é facilitado pela ausência de barreiras, como cercas (LEITE ${ }^{1}, 2002$ apud VIAU, 2003)

O corpo é robusto, compacto e musculoso, tendo tamanho médio de 132,7 cm (110,5 a 175,4 cm). As pernas também são fortes e musculosas, as patas são bem grandes. A cauda é relativamente curta, com 57,6 cm (40 a $68 \mathrm{~cm})$, o peso é em média 61,4 kg (35 a 130,5 kg) (OLIVEIRA; CASSARO, 1999) e pode variar em função do habitat, sexo e presas disponíveis. O comprimento do corpo das fêmeas é em média 10 a $20 \%$ menor que dos machos (Wildlife Conservation Society 2002).

A coloração varia entre amarelo bem claro e castanho-ocráceo, tendendo mais a amarelo-acastanhado. O corpo é completamente revestido por pintas negras, que chegam a formar rosetas dos mais diversos tamanhos, mas geralmente grandes e com um ou mais pontos negros no seu interior. Segundo Dittrich (1979) indivíduos melânicos não são raros, ocorrem por herança dominante. Por seu tamanho e padrão de coloração difere de todas as outras espécies de felinos neotropicais (ROSSI, 2002) (Figura 14).

\footnotetext{
${ }^{1}$ : LEITE, M. R. P.; OLIVEIRA, T. C.; PAULA, R. C.; INDRUSIAK, C. Por que promover a conservação de carnívoros? In: (Ed.). Manual de identificação, preservação e controle de predação por carnívoros. Brasília, IBAMA: 2002. Por que promover a conservação de carnívoros?, p.83
} 


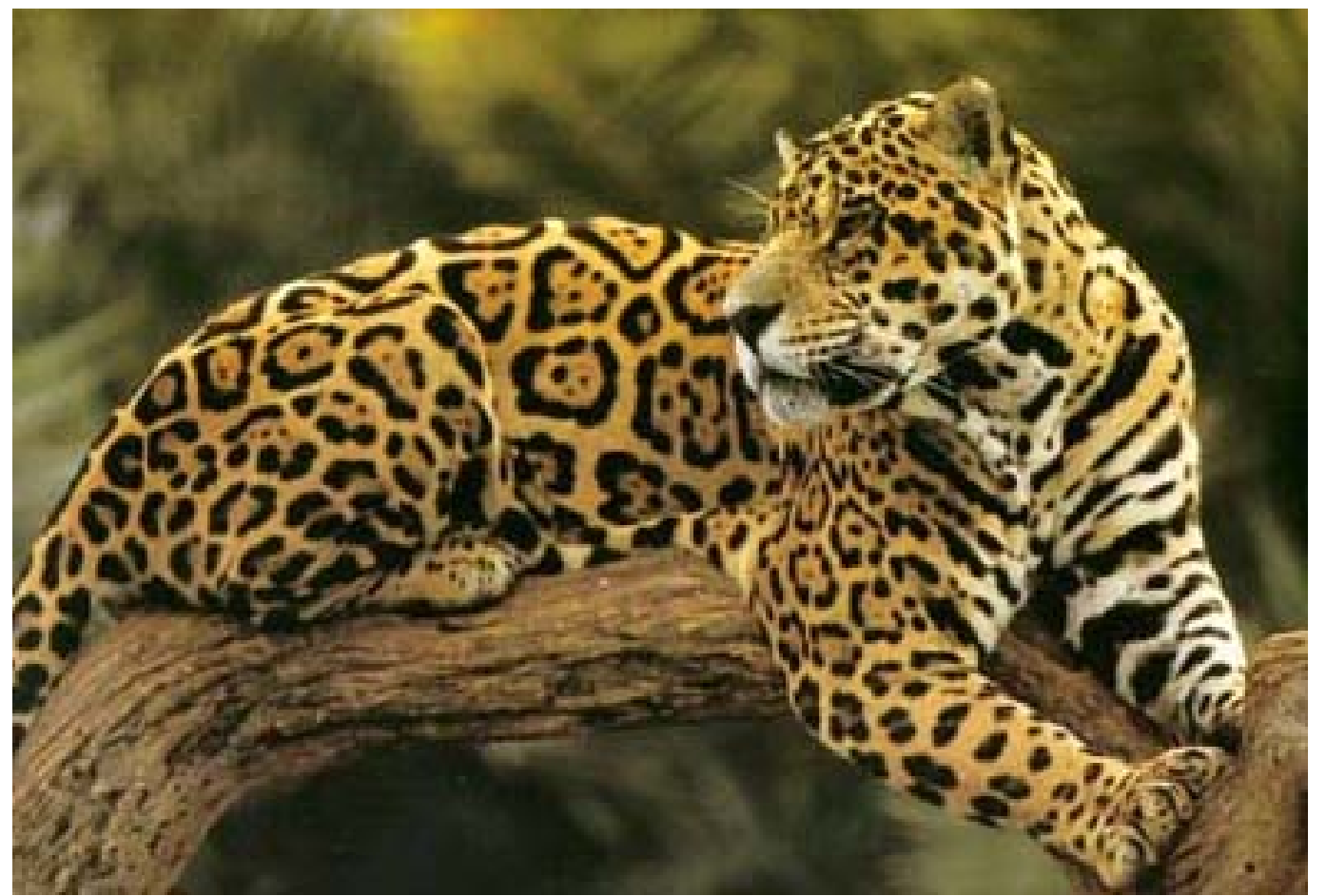

Figura 15 - Onça-pintada (Panthera onca). Fonte: http://lynx.uio.no/lynx/catsgportal/cat-website/20_catwebsite/home/index_en.htm

As onças que habitam florestas são, em geral, mais escuras e consideravelmente menores do que os animais que habitam áreas abertas; a diferença de tamanho pode ser devido à grande abundância de espécies de presas de grande porte existente na maioria dos ambientes abertos (NOWELL; JACKSON, 1996).

Com base em observações comportamentais alguns autores sugerem que a maturidade sexual ocorra entre 24 e 30 meses para fêmeas e entre 36 e 40 meses para machos (WILDT et al., 1979; RABINOWITZ; NOTTINGHAM, 1986), no entanto, em estudo da função ovariana por meio de métodos não invasivos, Viau (2003) constatou que a puberdade começa por volta dos 20 meses (18-20 meses de idade) e pode estar relacionada a parâmetros sazonais, indicando uma possível concentração da atividade reprodutiva durante a primavera. Esta diferença em relação aos dados de observações comportamentais está provavelmente relacionada com a não manifestação do estro no início da atividade ovariana.

Ainda segundo Viau (2003), o estro de fêmeas mantidas em cativeiro pode ocorrer durante 7 a 15 dias e o inter-estro de 28 a 31 dias.

Durante a fase de estro, a fêmea atrai um ou mais machos por sinais olfatórios e auditivos e em poucos dias ocorrem muitas cópulas que, segundo Eaton (1978), chegam a 
mais de 100 vezes por dia. O comportamento de cópula para essa espécie ainda não foi descrito, porém muito provavelmente deva ser semelhante ao descrito para outras espécies de felídeos selvagens (MELLEN, 1993) e domésticos (FELDMAN; NELSON, 1996). O macho imobiliza a fêmea receptiva por trás, mordendo primeiramente a região da nuca para em seguida realizar a monta, primeiro com o auxílio dos membros torácicos e depois com os membros pélvicos. A fêmea assume posição de lordose e desvia a cauda lateralmente. O macho inicia movimentos copulatórios rápidos que duram poucos segundos (EATON, 1978). Em seguida a fêmea se desprende do macho e inicia um vigoroso rolamento em decúbito dorsal que dura alguns segundos, seguido, tanto no macho como na fêmea, por lambedura da própria região urogenital (FELDMAN; NELSON, 1996)

O período de gestação dura de 90 a 111 dias, com número médio de dois filhotes $(1$ a 4), que param de mamar quando atingem 5-6 meses de idade e permanecem com a mãe até um ano e meio (SEYMOUR, 1989).

A longevidade para a espécie é em média 12 anos em vida livre e 20 em cativeiro (SEYMOUR, 1989; NOWELL; JACKSON, 1996 apud ADANIA et al., 2005). 
MATERIAL E MÉTODOS 


\section{MATERIAL E MÉTODOS}

\subsection{ANIMAIS}

Neste estudo foram utilizadas amostras de fezes de Panthera onca (adultas) remanescentes do projeto de pesquisa, nível mestrado, realizado no Laboratório de Dosagens Hormonais - VRA - FMVZ - USP, que avaliou a atividade ovariana em onças mantidas em cativeiro pela quantificação de estrógenos e progestágenos por meio de radioimunoensaio, que gerou a dissertação: "Estudo da função ovariana em fêmeas de onça-pintada (Panthera onca Linnaeus, 1758) mantidas em cativeiro, por meio da extração e quantificação de esteróides fecais", Viau (2003).

\subsection{COLHEITA, ARMAZENAMENTO, QUANTIFICAÇÃO POR RADIOIMUNOENSAIO E SELEÇÃO DAS AMOSTRAS FECAIS}

As amostras fecais foram colhidas 2 a 7 vezes por semana, normalmente no período da manhã, durante 16 a 18 meses. O material fecal recolhido foi devidamente identificado quanto ao animal e a data, e acondicionado em coletores plásticos próprios que permaneceram armazenados em freezer $\left(-20^{\circ} \mathrm{C}\right)$ até o processamento.

A primeira etapa do processamento foi a liofilização conforme técnica descrita por Wasser (1991). Este procedimento garante a ausência de ação bacteriana e permite a padronização do peso do material a ser utilizado. O processo de liofilização foi executado em aproximadamente $12 \mathrm{~h}$ com o auxílio do aparelho evaporador giratório Speed Vac (Speed Vac - Sc110, Savant).

À partir da liofilização as amostras foram submetidas ao protocolo de extração hormonal desenvolvido por Brown et al. (1994) e analisadas por radioimunoensaio em fase sólida, por meio de conjunto diagnóstico comercial (COAT-A-COUNT, Diagnostic Products Corporation, Los Angeles, CA, USA) desenvolvido para avaliação quantitativa de progesterona $\left(\mathrm{P}_{4}\right)$ e estradiol $\left(\mathrm{E}_{2}\right)$ no soro humano, segundo o protocolo do fabricante, utilizando-se como elemento traçador o $\mathrm{I}^{125}$. 
Baseando-se nos resultados obtidos por Viau (2003) foram selecionadas amostras de uma fêmea que recebeu tratamento para superovulação, que não entraram no experimento citado anteriormente. Este material foi utilizado nos testes de desenvolvimento dos protocolos de extração e recuperação, como também para o desenvolvimento da metodologia analítica.

\subsection{PADRÕES E REAGENTES}

Os padrões de hormônios esteróides foram selecionados conforme revisão de literatura abrangendo trabalhos publicados nos últimos dez anos nos quais foram pesquisados hormônios encontrados em diversas matrizes biológicas (fezes, urina, soro etc.) por meio de diferentes técnicas análiticas. Vale ressaltar que a aquisição dos padrões envolve trâmites burocráticos excessivos, o que impediu aquisição de mais dezesseis outros padrões pelo Laboratório de Cromatografia e Eletroforese Capilar-IQ-USP. As estruturas dos padrões são mostradas na quadro 3 .

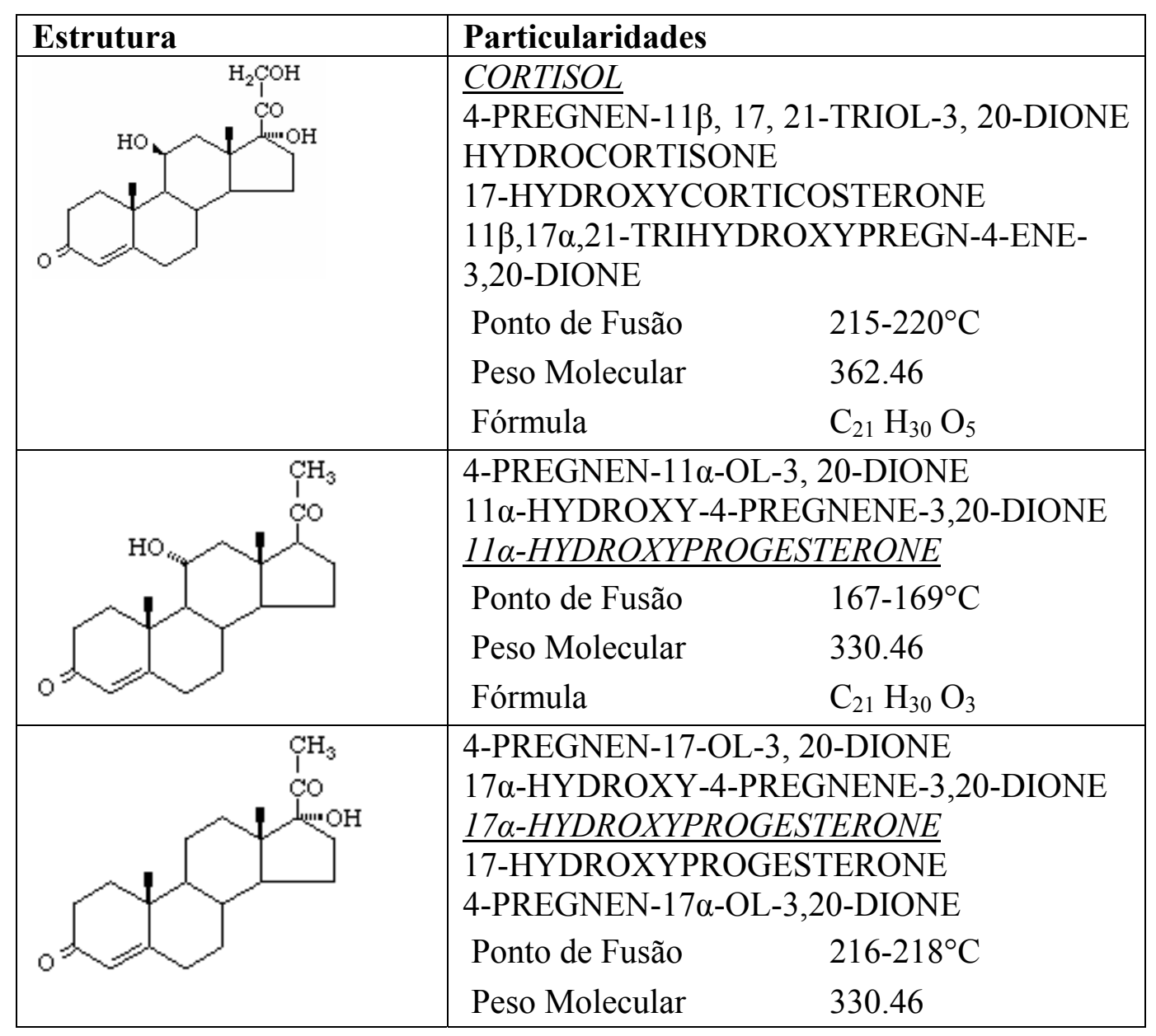




\begin{tabular}{|c|c|}
\hline & $\mathrm{C}_{21} \mathrm{H}_{30} \mathrm{O}_{3}$ \\
\hline & 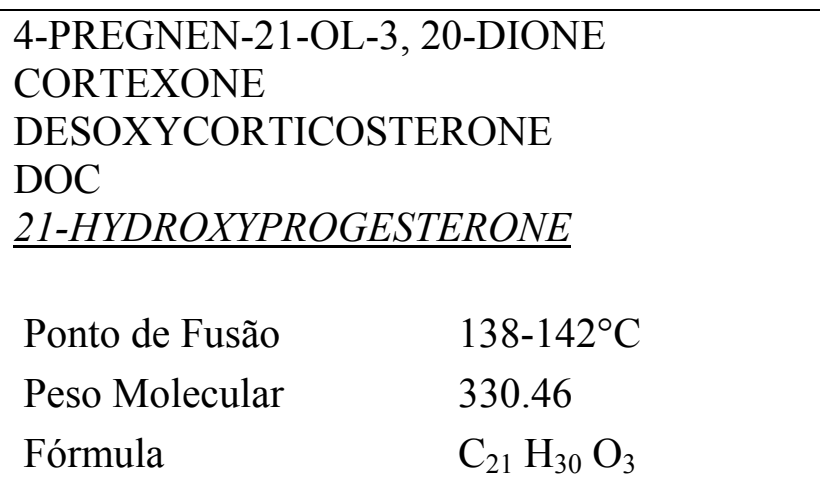 \\
\hline & 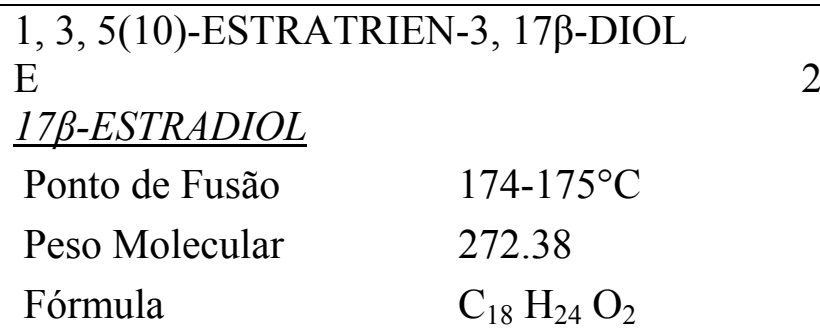 \\
\hline & 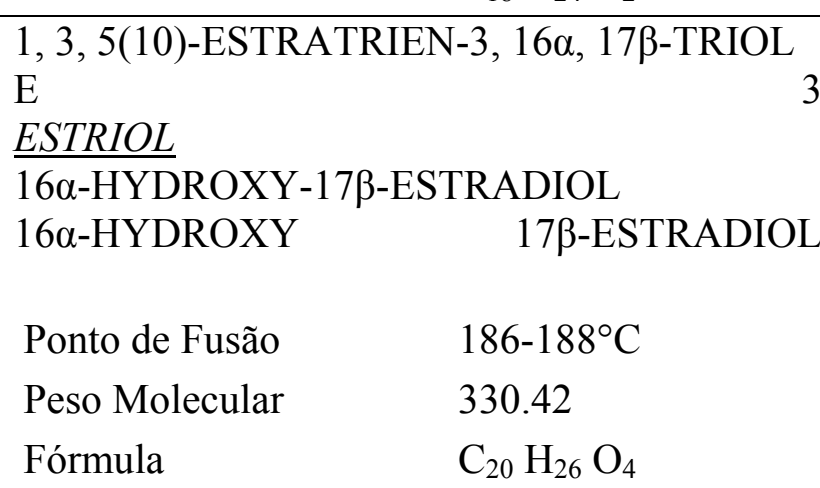 \\
\hline & 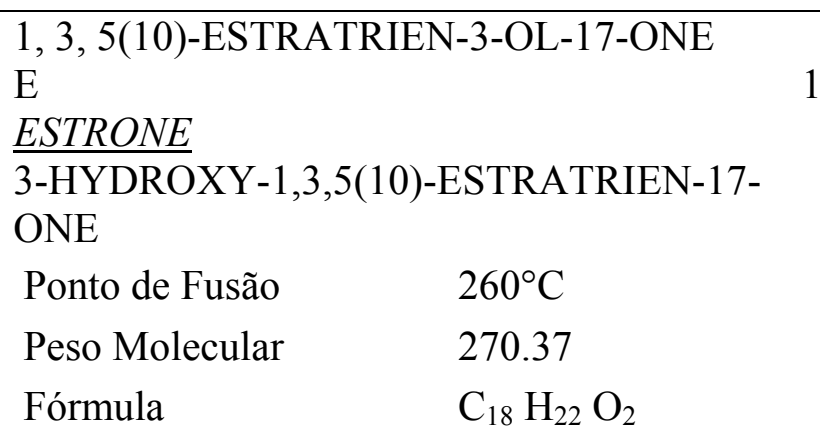 \\
\hline & 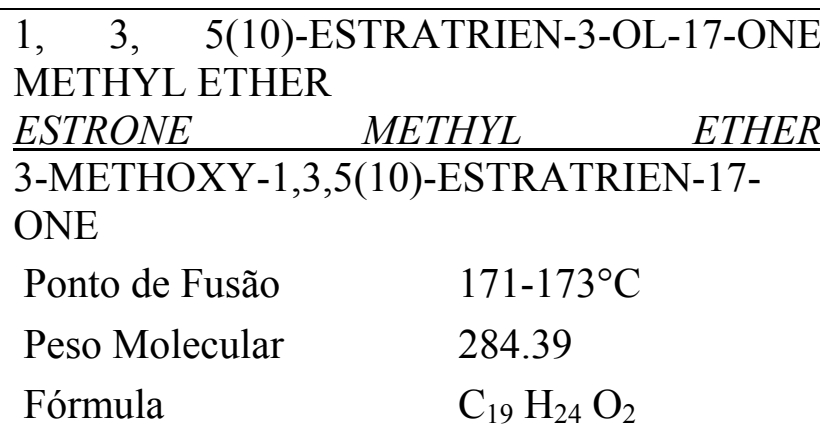 \\
\hline
\end{tabular}




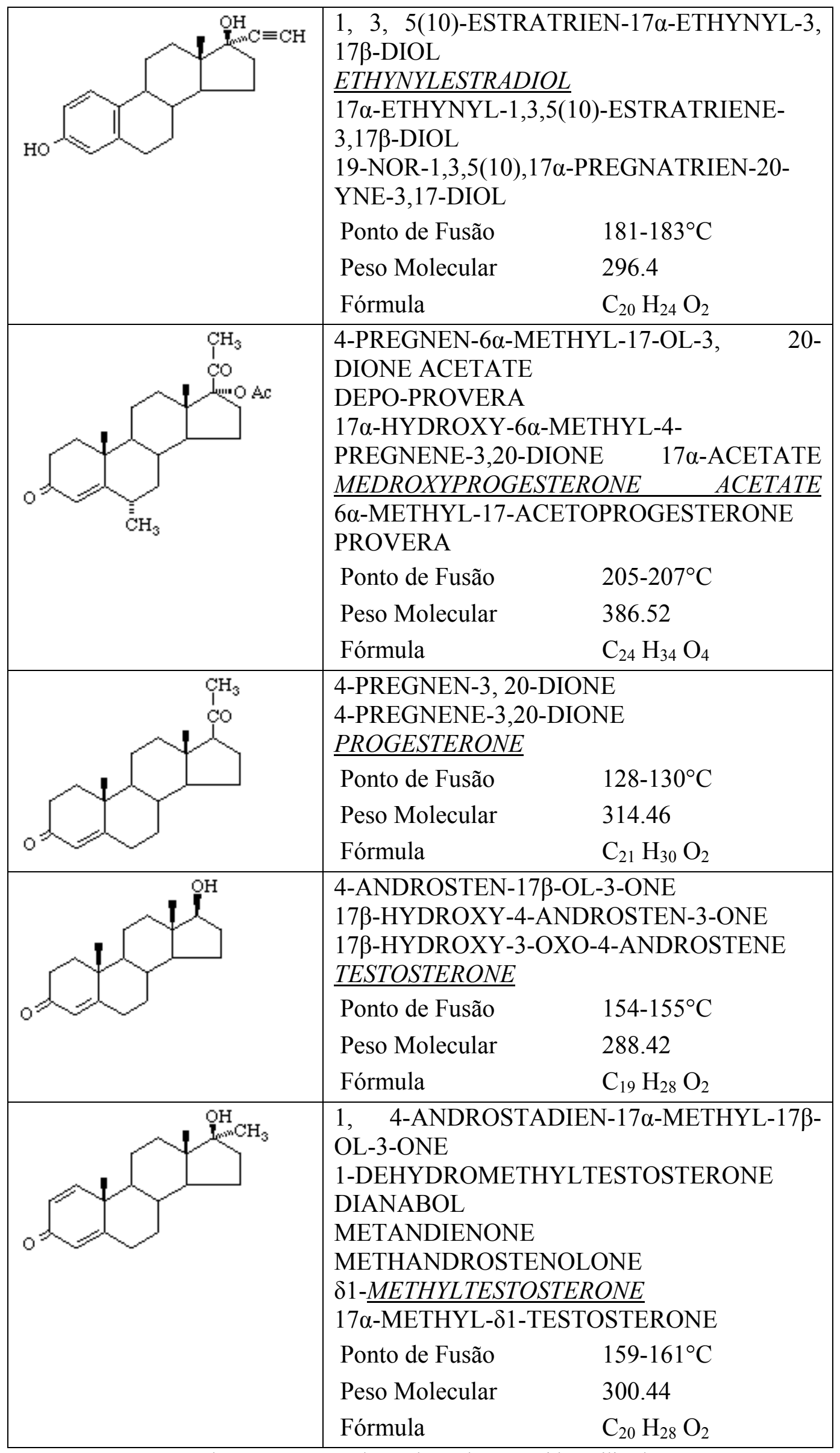

Quadro 3 - Estruturas dos padrões dos esteróides utilizados. 
As soluções estoque de cada hormônio $\left(2000 \mu \mathrm{g} \mathrm{mL}^{-1}\right)$, foram preparadas dissolvendose quantidades apropriadas dos padrões em metanol. Todas as soluções foram armazenadas a temperatura de $-20{ }^{\circ} \mathrm{C}$.

Todos os reagentes e solventes utilizados foram de grau analítico, os padrões, a $\beta$-ciclodextrina ( $\beta$-CD) e o tetraborato de sódio foram obtidos da Aldrich/Sigma (St. Louis, MO, USA). Dodecil sulfato de sódio (SDS) foi obtido da Riedel Haen (Seelze, Germany). Metanol, etanol e acetonitrila, de grau HPLC, foram obtidas da Merck (Darmstadt,Germany). O agente derivatizante ativado n-metil-n-trimetilsililtrifluoroacetamida (MSTFA) foi obtido da Fluka (St. Louis, MO, USA).

Quando necessário, os solventes, eletrólitos e amostras foram filtrados em sistema da Millipore.

Soluções estoques de SDS e tetraborato foram preparadas na concentração de 100 mmol L ${ }^{-1}$.

A água foi purificada pelo sistema de deionização (Milli-Q Purification System, Millipore Corp., Bedford, MA, USA).

Os cartuchos de extração em fase sólida (SPE) contendo a fase reversa Strata X (60 $\mathrm{mg} / 3 \mathrm{~mL})$ e $\mathrm{C}_{18}(60 \mathrm{mg} / 3 \mathrm{~mL})$ foram obtidos da Phenomenex (Milford, MA).

\subsection{EXTRAÇÕES}

Uma das etapas mais críticas envolvidas na análise de matrizes complexas consiste na extração e no isolamento dos analitos de interesse, de forma que seja efetuada sua determinação qualitativa e quantitativa por intermédio de uma técnica analítica adequada. A extração visa à remoção do(s) analito(s) da matriz, enquanto a etapa de isolamento (clean-up) focaliza-se na eliminação de interferentes (LANÇAS, 2004).

Foram testados sete tratamentos para as amostras: quatro protocolos de extração líquido-líquido, um de hidrólise ácida e dois protocolos de extração em fase sólida (SPE). A extração líquido-líquido é um processo de separação que se baseia na solubilidade relativa dos solutos em solventes. O soluto dissolve-se mais prontamente e torna-se mais concentrado no solvente que tem uma solubilidade mais elevada. Para uma extração líquido-líquido ser 
bem sucedida, o analito deve ser extraído quantitativamente da amostra pela fase orgânica (LIMA, 2003).

Desde os primórdios das análises de esteróides a extração líquido-líquido é a técnica predominantemente utilizada no processamento de matrizes biológicas, mas sua popularidade vem decrescendo em favor de outras tecnologias mais eficientes. Sendo utilizada como alternativa para o pré-tratamento da amostra, a polaridade dos esteróides e sua capacidade de ligação a proteínas são aspectos importantes na seleção dos solventes para o procedimento de extração. Assim, para extração quantitativa do(s) analito(s), o solvente escolhido deve não só dissolver os compostos de interesse completamente, mas também ser capaz de romper as associações com proteínas (APPELBLAD; IRGUM, 2002).

A hidrólise ácida é um procedimento de desconjugação dos hormônios e eliminação de interferentes da amostra (JI et al., 1995).

O princípio da extração em fase sólida envolve a partição entre duas fases (um sólido e um líquido). $\mathrm{O}$ composto a ser analisado, deve ter maior afinidade com a fase sólida do que com a matriz líquida (retenção ou adsorção). O composto retido deve então ser removido em um estágio posterior por eluição com um solvente no qual este tenha maior afinidade do que pela fase sólida (eluição ou desorção). Dentre as técnicas de preparo de amostras, tanto quando se deseja concentrar um composto ou eliminar interferentes, a SPE é uma das mais utilizadas quando uma rotina de trabalho é necessária.

Todos os procedimentos que serão descritos a seguir foram testados quanto à recuperação hormonal pós-extração por adição dos padrões dos esteróides às amostras. As amostras que receberam alíquotas dos padrões foram denominadas "dopadas" e aquelas sem adição foram denominadas "brancas". As amostras dopadas receberam $40 \mu \mathrm{L}$ da solução estoque (2000 $\mathrm{\mu gmL}^{-1} \mathrm{em}$ metanol) de cada padrão e foram secas em banho-maria sob fluxo de ar comprimido ou de nitrogênio. Para comparação, uma solução dos mesmos padrões foi preparada com os mesmos $40 \mu \mathrm{L}$ de cada padrão e $1560 \mu \mathrm{L}$ de metanol a $10 \%$ em água deionizada.

\subsubsection{Protocolo 01: Extração com Etanol/Metanol}

Conforme a técnica descrita por Brown et al. (1994), Brown et al. (1995) e Brown et al. (1996) uma alíquota de 0,2g de fezes (liofilizadas) foi fervida em 5ml de etanol (Etanol, 
P.A. Merck) 90\% (90\% etanol: 10\% água destilada) por 25 minutos. Durante este tempo o etanol evaporado foi gradativamente reposto para que nenhuma amostra ressecasse, desta forma ao final desta etapa o volume inicial foi mantido. O material foi homogeneizado em aparelho vórtex (PHOENIX, MOD AT 56) e em seguida centrifugado por 15 minutos a 500g (Quimis), o sobrenadante foi recuperado e o pellet resultante ressuspendido em $5 \mathrm{ml}$ de etanol (90\%) e homogeneizado em aparelho vórtex e recentrifugado. Os dois sobrenadantes foram combinados e secos completamente em banho-maria com fluxo de ar comprimido (Láctea) e armazenados até a diluição mais adequada e posterior injeção para análise.

Este protocolo foi submetido a análise por cromatografia a gás e eletroforese capilar.

\subsubsection{Protocolo 02: Hidrólise Ácida}

A hidrólise ácida foi conduzida conforme Ji e colaboradores (1995). Aos tubos (amostras brancas e dopadas) contendo $0,2 \mathrm{~g}$ de fezes foram adicionados $3 \mathrm{~mL}$ de metanol e $450 \mu \mathrm{L}$ de ácido acético. A seguir as amostras ficaram 1hora em estufa pré-aquecida a $100^{\circ} \mathrm{C}$. Após o tempo na estufa as amostras foram deixadas em temperatura ambiente até que esfriassem. Foi adicionado então $10 \mathrm{~mL}$ de diclorometano, tomando-se cuidado com a formação de gás, neste momento é importante a utilização de luvas e óculos de segurança. As amostras foram então passadas no vórtex por 2 minutos e deixadas sob refrigeração por 10 minutos antes de serem centrifugadas por 5 minutos. A seguir a fase aquosa foi removida com a utilização de pipeta e foi adicionado $1 \mathrm{~mL}$ de uma solução de hidróxido de sódio/bicarbonato de sódio $(0,1 \mathrm{~mol})$, foi feita uma nova passagem no vórtex por 2 minutos seguida pela centrifugação e mais uma vez a fase aquosa foi descartada. Por fim adicionou-se $1 \mathrm{~mL}$ de água deionizada à fase orgânica, seguida por uma passagem no vórtex e centrifugação e a última fase aquosa foi descartada. A fase orgânica restante foi seca em banho-maria a $45^{\circ} \mathrm{C}$ sob fluxo de nitrogênio. $\mathrm{O}$ extrato seco foi ressuspendido em $500 \mu \mathrm{L}$ de metanol, passado no vórtex por 1 minuto e foi adicionado então $1500 \mu \mathrm{L}$ de água deionizada (Milli-Q).

Este protocolo foi submetido a análise por eletroforese capilar. 


\subsubsection{Protocolo 03: Extração com Diclorometano/Metanol}

Aos tubos (brancas e dopadas) contendo $0,2 \mathrm{~g}$ de fezes foram adicionados $4 \mathrm{~mL}$ da solução de diclorometano/metanol (volume/volume), a seguir as amostras ficaram 30 minutos no ultrasom, foram passadas no vórtex por 1 minuto e então centrifugadas por 5 minutos. $\mathrm{O}$ sobrenadante foi transferido para outro tubo e seco em banho-maria a $45^{\circ} \mathrm{C}$ sob fluxo de ar comprimido ou nitrogênio. $\mathrm{O}$ extrato seco foi ressuspendido em $500 \mu \mathrm{L}$ de metanol, passado no vórtex por 1 minuto e foi adicionado então $1500 \mu \mathrm{L}$ de água deionizada (Milli-Q).

Este protocolo foi submetido a análise por eletroforese capilar.

\subsubsection{Protocolo 04: Extração com Acetonitrila/Etanol}

Aos tubos (brancas e dopadas) contendo $0,2 \mathrm{~g}$ de fezes foram adicionados $4 \mathrm{~mL}$ da solução de acetonitrila/etanol (volume/volume), a seguir as amostras ficaram 30 minutos no ultrasom, foram passadas no vórtex por 1 minuto e então centrifugadas por 5 minutos. $\mathrm{O}$ sobrenadante foi transferido para outro tubo e seco em banho-maria a $45^{\circ} \mathrm{C}$ sob fluxo de ar comprimido ou nitrogênio. $\mathrm{O}$ extrato seco foi ressuspendido em $500 \mu \mathrm{L}$ de metanol, passado no vórtex por 1 minuto e foi adicionado então $1500 \mu \mathrm{L}$ de água deionizada (Milli-Q).

Este protocolo foi submetido a análise por eletroforese capilar.

\subsubsection{Protocolo 05: Extração com Acetonitrila}

Aos tubos (brancas e dopadas) contendo $0,2 \mathrm{~g}$ de fezes foram adicionados $4 \mathrm{~mL}$ da solução de acetonitrila (100\%), a seguir as amostras ficaram 30 minutos no ultrasom, foram passadas no vórtex por 1 minuto e então centrifugadas por 5 minutos. O sobrenadante foi transferido para outro tubo e seco em banho-maria a $45^{\circ} \mathrm{C}$ sob fluxo de ar comprimido ou nitrogênio. $\mathrm{O}$ extrato seco foi ressuspendido em $500 \mu \mathrm{L}$ de metanol, passado no vórtex por 1 minuto e foi adicionado então $1500 \mu \mathrm{L}$ de água deionizada (Milli-Q).

Este protocolo foi submetido a análise por eletroforese capilar. 


\subsubsection{Protocolo 06: Extração em Fase Sólida (SPE-SX)}

A uma alíquota de $0.2 \mathrm{~g}$ de fezes liofilizadas foram adicionados $4,0 \mathrm{~mL}$ de acetonitrila (Acetonitrila, P.A. Merck), a seguir as amostras ficaram 30 minutos no ultra-som, foram passadas no vórtex por 1 minuto e então centrifugadas por 5 minutos. O sobrenadante foi transferido para outro tubo e seco em banho-maria a $45^{\circ} \mathrm{C}$ sob fluxo de ar comprimido ou nitrogênio. $\mathrm{O}$ extrato seco foi ressuspendido em $500 \mu \mathrm{L}$ de metanol, passado no vórtex por 1

minuto e foi adicionado então $1500 \mu \mathrm{L}$ de água deionizada. Os cartuchos de SX foram condicionados com $5 \mathrm{~mL}$ de metanol, seguido de $5 \mathrm{~mL}$ de água deionizada. Após o condicionamento, o extrato fecal foi introduzido no cartucho. Após a passagem da amostra o cartucho foi lavado com $1 \mathrm{~mL}$ de uma solução contendo $5 \%$ de metanol em água e o eluato descartado, na sequência o cartucho foi novamente lavado com $1 \mathrm{~mL}$ de metanol mas na concentração de $100 \%$ e o eluato foi recolhido. Este extrato foi seco em banho-maria com fluxo de ar comprimido e o resíduo foi dissolvido em $500 \mu \mathrm{L}$ de metanol, homogenizado durante 2 minutos no vórtex, sendo o volume completado para $2 \mathrm{~mL}$ com água deionizada.

Este protocolo foi submetido a análise por eletroforese capilar.

\subsubsection{Protocolo 07: Extração em Fase Sólida (SPE-C18):}

A uma alíquota de 2,0g de fezes liofilizadas foram adicionados $8,0 \mathrm{~mL}$ de acetonitrila (Acetonitrila, P.A. Merck), este material foi previamente homogeneizado em aparelho vórtex e em seguida mantido em banho ultra-sônico por 20 minutos, em seguida foi ajustado em aparelho homogeneizador (Homogeneizador de Sangue AP 22-Phoenix) por 12 horas. Após este tempo os tubos foram colocados no aparelho multi-vórtex (Multi-Tube Vortexer VX 2.500 - VNR Scientific Products) por 1 minuto e então centrifugados por 15 minutos a 500g. O sobrenadante foi recolhido e seco em banho-maria com fluxo de ar comprimido. O extrato foi ressuspendido em $500 \mu \mathrm{L}$ de metanol, passado no vórtex por 1 minuto e foi adicionado então $1500 \mu \mathrm{L}$ de água deionizada passando novamente pelo vórtex. A seguir o extrato ressuspendido é passado no extrator em fase sólida $\mathrm{C} 18$, condicionado com $5 \mathrm{~mL}$ de metanol, seguido de $5 \mathrm{~mL}$ de água deionizada. Após o condicionamento, o extrato fecal foi introduzido no cartucho. Após a passagem da amostra, o cartucho foi lavado com $1 \mathrm{~mL}$ de uma solução 
contendo $5 \%$ de metanol em água e o eluato descartado, na sequência o cartucho foi novamente lavado com $1 \mathrm{~mL}$ de metanol mas na concentração de $100 \%$ e o eluato foi recolhido. Após a passagem no cartucho de C18 o eluído foi seco em banho-maria com fluxo de ar comprimido e armazenado até a diluição mais adequada e injeção para análise.

Este protocolo foi submetido a análise por eletroforese capilar e cromatografia líquida de alta eficiência.

Para análise em CE, as amostras submetidas a este protocolo tiveram seus resíduos dissolvidos em $125 \mu \mathrm{L}$ de metanol, homogeneizados durante dois minutos (vórtex) e os volumes completados para $0,5 \mathrm{~mL}$ com água deionizada.

Para análise por HPCL o resíduo foi dissolvido em $1 \mathrm{~mL}$ de acetonitrila para posterior injeção.

\subsection{METODOLOGIA ANALÍTICA}

\subsubsection{Eletroforese Capilar}

Os experimentos foram realizados nos equipamentos P/ACE ${ }^{\mathrm{TM}}$ System MDQ da Beckman Coulter, (Laboratório de Cromatografia e Eletroforese Capilar [LACE] do Instituto de Química coordenado pela Prof ${ }^{\natural}$ Marina Franco Maggi Tavares) e Hewlett-Packard (HP) 3D CE - Agilent (Instituto de Química - Departamento de Química Analítica - Núcleo de Desenvolvimento de Combustíveis - Unesp-Araraquara coordenado pelo Prof. Arnaldo Alves Cardoso) ambos equipados com detector arranjo de diodos, com operação na faixa de 190-600 $\mathrm{nm}$, controlador de temperatura e programa de aquisição e tratamento de dados. Os capilares de sílica fundida utilizados foram adquiridos da Polymicro Technologies, Phoenix, AZ, com dimensões de $75 \mu \mathrm{m}$ d.i. e comprimento total 48,5 cm (40,5 cm até o detector). A janela de detecção de aproximadamente $0,3 \mathrm{~cm}$ foi aberta pela remoção do revestimento de poliimida do capilar. As amostras foram injetadas pelo modo hidrodinâmico com pressão de $50 \mathrm{mBar} x$ $3 \mathrm{~s}$ e detectadas em $214 \mathrm{~nm}$ e $254 \mathrm{~nm}$.

O condicionamento do capilar foi feito através da passagem de solução de hidróxido de sódio $1,0 \mathrm{~mol} \mathrm{~L}^{-1}$ durante $5 \mathrm{~min}$, seguida de água deionizada durante 5 min e solução de 
eletrólito (40 min), no início de cada dia ou quando foi efetuada mudança de condição de análise. Entre as corridas o capilar foi condicionado com eletrólito durante $3 \mathrm{~min}$.

$\mathrm{Na}$ primeira parte dos experimentos, efetuados no equipamento P/ACE ${ }^{\mathrm{TM}}$ System MDQ, para estabelecimento do eletrólito utilizou-se de um fatorial $2^{3}$, ou seja, de dois níveis $(+,-)$ (Tabela 1) e três variáveis, que neste caso são as concentrações de acetonitrila (ACN), SDS e $\beta$-CD, para otimizar a separação dos esteróides.

Tabela 1 - Parâmetros experimentais investigados.

\begin{tabular}{|lllll|}
\hline Fatores & & $\mathbf{( - 1 )}$ & $\mathbf{( + 1 )}$ & $\mathbf{0}$ \\
\hline $\mathrm{A}$ & $\beta-\mathrm{CD}\left(\mathrm{mmolL}^{-1}\right)$ & 5 & 10 & 7,5 \\
$\mathrm{~B}$ & $\mathrm{SDS}\left(\mathrm{mmolL}^{-1}\right)$ & 20 & 30 & 25 \\
$\mathrm{C}$ & Acetonitrila $(\%)$ & 10 & 15 & 12,5 \\
\hline
\end{tabular}

Todos os experimentos foram realizados em duplicata, entretanto, de modo a facilitar a realização dos trabalhos, as análises não foram feitas de forma aleatória. Os ensaios estão dispostos na tabela 2 .

Tabela 2 - Ensaios experimentais em todos os níveis de cada fator com ponto central.

\begin{tabular}{|lllllll|}
\hline \multicolumn{3}{l}{ Ensaio } & \multicolumn{3}{l}{ Fatores } & \multicolumn{4}{c|}{ Variáveis (conc.) } \\
\hline & $\mathrm{A}$ & $\mathrm{B}$ & $\mathrm{C}$ & $\beta-\mathrm{CD}$ & $\mathrm{SDS}$ & $\mathrm{ACN}$ \\
1 & - & - & - & 5 & 20 & 10 \\
2 & + & - & - & 10 & 20 & 10 \\
3 & - & + & - & 5 & 30 & 10 \\
4 & + & + & - & 10 & 30 & 10 \\
5 & - & - & + & 5 & 20 & 15 \\
6 & + & - & + & 10 & 20 & 15 \\
7 & - & + & + & 5 & 30 & 15 \\
8 & + & + & + & 10 & 30 & 15 \\
9 & 0 & 0 & 0 & 7,5 & 25 & 12,5 \\
\hline
\end{tabular}

Como o equipamento $\mathrm{P} / \mathrm{ACE} \mathrm{TM}^{\mathrm{T}}$ System MDQ precisou ser enviando para manutenção, os experimentos foram transferidos para o equipamento HP 3D CE - Agilent do LACE e posteriormente para um equipamento igual a este último, mas pertencente ao Núcleo de Desenvolvimento de Combustíveis (Unesp-Araraquara). Quando da mudança de equipamento, as condições para a separação tiveram que ser novamente investigadas e 
procedeu-se a uma série de nove experimentos, nos quais se variou as concentrações de SDS, tetraborato de sódio, acetonitrila, etanol e adição de $\beta$-ciclodextrinas no intuito de se obter o eletrólito para separação dos esteróides mais eficiente.

Para a construção das curvas analíticas foram utilizadas as soluções padrão dos hormônios. Etinilestradiol e medroxiprogesterona foram empregados como padrão interno (5 $\left.\mu \mathrm{g} \mathrm{mL}{ }^{-1}\right)$. Concentrações no intervalo de 2,5 a $20 \mu \mathrm{g} \mathrm{mL}^{-1}$ para, estriol, estrona, estradiol, testosterona e progesterona foram obtidas. As curvas de calibração foram construídas utilizando a concentração de cada hormônio versus a razão das áreas dos picos (analito/padrão interno).

Para determinar a exatidão do método, ensaios de recuperação foram realizados. As amostras de fezes foram dopadas em três diferentes níveis de concentração de estriol, estrona, estradiol, progesterona e testosterona e uma concentração fixa dos padrões internos. A porcentagem de recuperação foi determinada por intermédio da comparação das respostas de amostras extraídas de matrizes dopadas com concentração baixa, média e alta, em triplicata, com aquelas obtidas para as soluções padrão não extraídas, as quais representam $100 \%$ de recuperação.

\subsubsection{Cromatografia a Gás}

Para análise estrutural dos componentes foram realizados experimentos com GC-FID.

Tais experimentos foram realizados no equipamento HP 6850 - Agilent (Instituto de Química - Departamento de Química Analítica Unesp-Araraquara - Núcleo de Desenvolvimento de Combustíveis coordenado pelo Prof. Arnaldo Alves Cardoso), equipado com detector de ionização de chama (FID). A separação foi conduzida em uma coluna capilar HP-5 (5\% difenil e 95\% dimetilpolisiloxano) com dimensões de 30m x 0,250 mm x 0,25 m e hélio usado como gás de arraste com velocidade linear de $25 \mathrm{~mL} / \mathrm{min}$. A Programação de temperatura do forno foi a seguinte: temperatura inicial de $150{ }^{\circ} \mathrm{C}$ por $2 \mathrm{~min}$, aumentando 20 ${ }^{\circ} \mathrm{C} / \mathrm{min}$ até $220^{\circ} \mathrm{C}$ e mantida por $1 \mathrm{~min}$, aumentando $3{ }^{\circ} \mathrm{C} / \mathrm{min}$ até $280{ }^{\circ} \mathrm{C}$ e mantida por 15 min. As temperaturas do injetor e detector foram mantidas em $270^{\circ} \mathrm{C}$ e $290{ }^{\circ} \mathrm{C}$, respectivamente. O modo de injeção utilizado foi splitless volume de $1 \mu \mathrm{L}$. A aquisição e tratamento dos dados foram feitas utilizando o software da HP Chemstation. 


\subsubsection{Derivatização}

Como dito anteriormente, o objetivo da derivatização é aumentar a volatilidade do analito. Alguns dos esteróides e muitos de seus metabólitos, devido a grupos hidroxilas ou cetônicos em sua estrutura, necessitam para a análise por cromatografia a gás, uma prévia derivatização, diminuindo a estabilidade ao calor apresentada por estes compostos. Pela derivatização, introduz-se na molécula do esteróide um grupo de alto peso molecular, propiciando maior seletividade e especificidade à técnica cromatográfica. O agente derivatizante mais utilizado, no caso dos esteróides é o n-metil-ntrimetilsililtrifluoroacetamida (MSTFA). Esse agente possui a vantagem de poder ser utilizado como solvente e assim ser introduzido diretamente no GC. Entretanto, o uso somente do MSTFA não é efetivo na silanização de esteróides que possuem 17ß-hidroxi-grupos. Desta forma, é necessário o uso de iodeto de amônio $\left(\mathrm{NH}_{4} \mathrm{I}\right)$ na constituição da solução o que permite a formação efetiva de grupos trimetilsilil (TMS) nesses esteróides. Além disso, a adição de um agente redutor, como o etanotiol evita a formação de iodeto sob ação da luz, estabilizando a solução derivatizante.

Uma alíquota de $25 \mu \mathrm{L}$ de cada hormônio, preparado em metanol, foi evaporada e o resíduo foi dissolvido em $200 \mu \mathrm{L}$ do agente derivatizante MSTFA ativado $\left(\mathrm{NH}_{4} \mathrm{I}+\right.$ etanotiol). Os frascos, devidamente fechados, foram mantidos em estufa $\left(80^{\circ} \mathrm{C}\right)$ por duas horas. Após este período os frascos foram então retirados da estufa e mantidos por 5 min a temperatura ambiente para posterior injeção.

\subsubsection{Silanização dos Tubos de Derivatização}

Os frascos utilizados para a derivatização devem ser tratados com agente silanizante antes de serem utilizados. O procedimento de tratamento envolve diversas etapas:

1. Lavagem dos frascos com extran, enxagüe com água destilada, secagem em estufa.

2. Manutenção dos tubos por 5 min em solução potássica alcoólica (10\%).

3. Lavagem dos tubos em água corrente e enxagüe com água destilada. 
4. Manutenção dos tubos em metanol por 30 min. Retira-se os tubos do metanol deixando-os escorrendo em papel toalha por 3 min.

5. Secagem dos tubos por 30 min em estufa $\left(60^{\circ} \mathrm{C}\right)$.

6. Manter os tubos em temperatura ambiente por $5 \mathrm{~min}$. Adiciona-se o agente silanizante (solução de diclorodimetillsilano a $10 \%$ em tolueno). Deixa-se por uma hora.

7. Retira-se o agente silanizante, escorre-se em papel toalha e adiciona-se metanol (grau HPLC) por $30 \mathrm{~min}$.

8. Retira-se o metanol, deixa-se escorrer em papel toalha por $3 \mathrm{~min}$.

9. Secagem por $30 \mathrm{~min}$ em estufa $\left(60^{\circ} \mathrm{C}\right)$.

10. Adiciona-se acetona por $30 \mathrm{~min}$.

11. Retira-se a acetona, deixando que os tubos escorram em papel toalha por $3 \mathrm{~min}$.

12. Secagem por $30 \mathrm{~min}$ em estufa $\left(60^{\circ} \mathrm{C}\right)$.

13. Os tubos então são fechados até serem utilizados para a reação de derivação.

\subsubsection{Cromatografia Líquida de Alta Eficiência}

Aproveitamos a oportunidade de proceder análises no equipamento de HPLC do Laboratório de Andrologia, do Dep. de Reprodução Animal (coordenado pela Profa. Valquíria H. Barnabe) a título de comparação com os resultados obtidos pela CE e também com intuito de desenvolvimento de protocolo de metodologia para análise em cromatografia líquida acoplada a espectrometria de massas (LC-MS).

Os experimentos foram realizados no equipamento HP - Agilent equipado com detector de arranjo de diodos, sistema de bombeamento e injetor automático. O volume de amostra injetado foi de $20 \mu \mathrm{L}$ e a separação foi conduzida em uma coluna zorbax $\mathrm{XDB}_{8}(15$ m x 4,6 mm), utilizando como fase móvel 1:1 v/v acetonitrila/água. A aquisição e tratamento e dados foram feitas utilizando o software da HP Chemstation. 


\section{RESULTADOS E DISCUSSÃO}

\subsection{COMPOSIÇÃO DO ELETRÓLITO}

\subsubsection{Desenvolvimento do Método do Equipamento P/Ace ${ }^{\mathrm{Tm}}$ System Mdq da Beckman} Coulter

A princípio estudou-se a separação simultânea de uma mistura-teste constituída pelos esteróides: 17- $\alpha$-metiltestosterona, estriol, estrona, estronametileter, etinilestradiol, cortisol, medroxiprogesterona, progesterona, testosterona; utilizando o método MEKC, uma vez que os analitos não apresentam carga.

Durante experimentos preliminares observou-se que somente a interação do analito/SDS não era suficiente para que ocorresse a separação (Figura 16), neste caso, a resolução poderia ser melhorada pela adição de outras substâncias no tampão de análise, como é o caso dos solventes orgânicos (ex. metanol, etanol ou acetonitrila) ou seletores quirais (ciclodextrinas) (SCHIMITT et al, 1997).

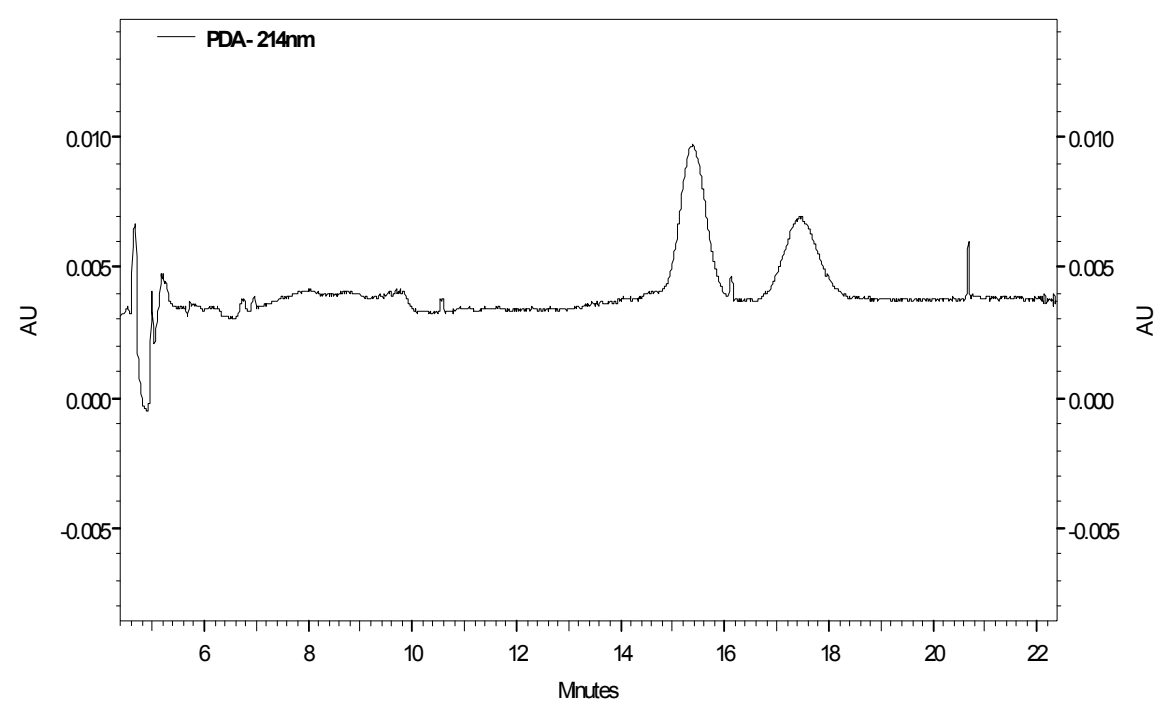

Figura 16 - Separação da mistura-teste de esteróides utilizando sistema de micelar constituído por $30 \mathrm{mmolL}^{-1}$ SDS, e tampão tetraborato $20 \mathrm{mmolL}^{-1}$, pH 9,2 um capilar de sílica fundida de 40,2 cm x $75 \mu \mathrm{m}$ d.i. (30 $\mathrm{cm}$ até o detector), os analitos foram injetados hidrodinamicamente, com pressão de $0,3 \mathrm{psi} / 3 \mathrm{~s}$. A tensão aplicada foi de $20 \mathrm{kV}$, temperatura $23^{\circ} \mathrm{C}$ e detecção em $214 \mathrm{~nm}$. 
As ciclodextrinas (CDs) apresentam em sua cavidade interna características hidrofóbicas, enquanto que a sua parte externa características hidrofílicas, devido aos grupos hidroxila ali presentes. A melhora na separação ocorre devido à interação do grupo hidrofóbico do analito no interior de cavidade hidrofóbica da $\mathrm{CD}$ e também às interações externas com os grupos hidroxila que estão dispostos na estrutura das CDs, interações do tipo dipolo-dipolo. As ciclodextrinas possuem diferentes graus de afinidade pelo analito, desta forma, o analito terá seu tempo de migração alterado podendo assim, ser diferenciado de seu par crítico.

Como apresentado anteriormente na seção de metodologia, para otimizar a separação utilizou-se de um fatorial $2^{3}$, ou seja, de dois níveis $(+,-)$ e três variáveis, as concentrações de acetonitrila (ACN), SDS e $\beta$-CD.

Para se obter uma separação completa das bandas eletroforéticas dos nove padrões em questão, foi realizada previamente uma triagem das variáveis que poderiam influenciar os experimentos através de "corridas exploratórias" (Figura 17), as quais indicaram que a concentração de aditivo orgânico (acetonitrila), concentração de SDS e de seletor quiral (ciclodextrinas) influenciavam na separação. 

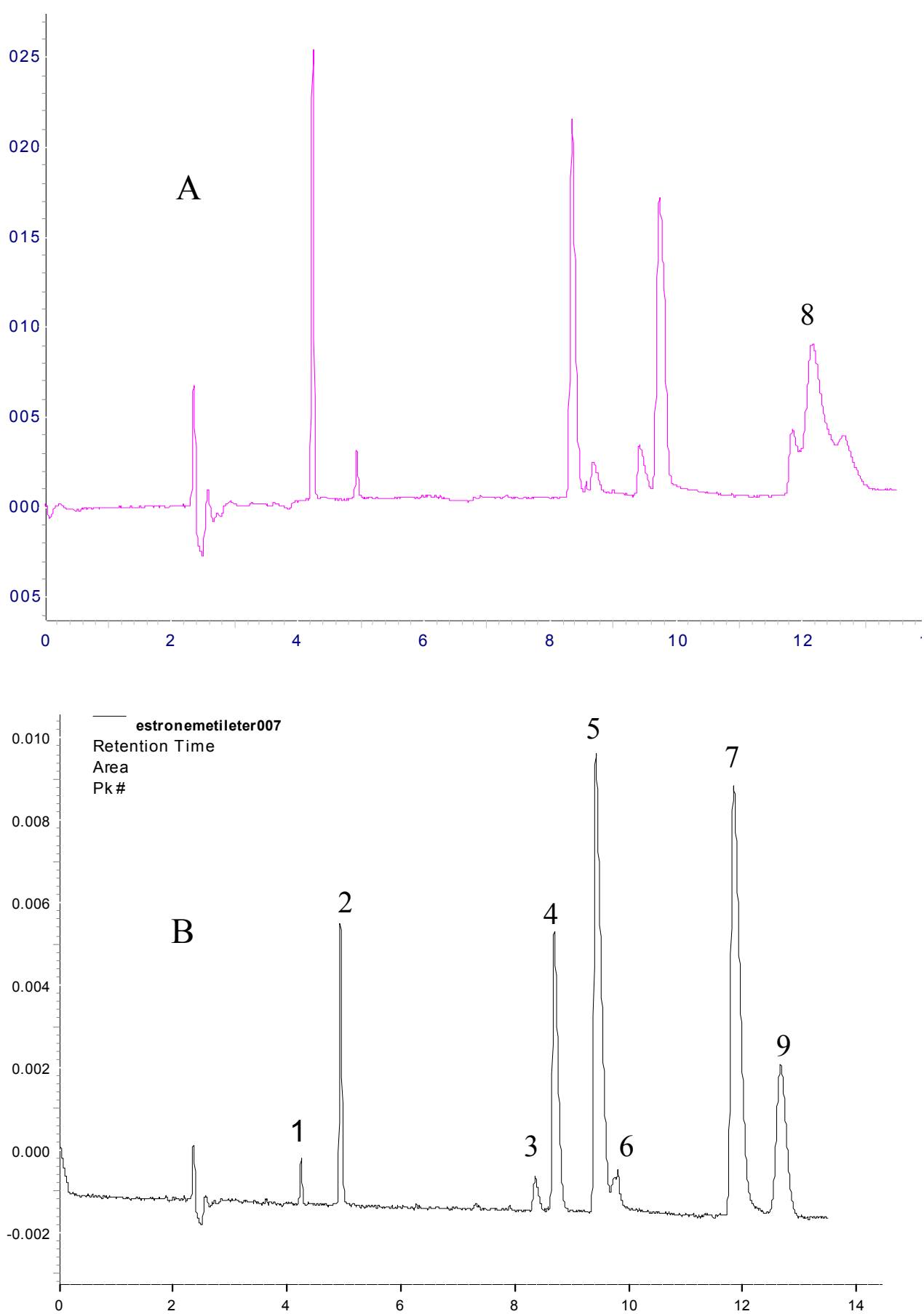

Figura 17 - Separação dos esteróides utilizando sistema de micelar constituído por $25 \mathrm{mmolL}^{-1} \mathrm{SDS}, 12 \% \mathrm{ACN}$, $10 \mathrm{mmolL}^{-1} \beta$-Ciclodextrina e tampão tetraborato $20 \mathrm{mmolL}^{-1}, \mathrm{pH} 9,2$ um capilar de sílica fundida de $40,2 \mathrm{~cm} \times 75 \mu \mathrm{m}$ d.i. ( $30 \mathrm{~cm}$ até o detector), os analitos foram injetados hidrodinamicamente, com pressão de $0,3 \mathrm{psi} / 3 \mathrm{~s}$. A tensão aplicada foi de $22 \mathrm{kV}$, temperatura $22{ }^{\circ} \mathrm{C}$ e detecção em $200 \mathrm{~nm}$ (A) e 254nm (B). 1) Estriol, 2) Cortisol, 3)Estrona, 4)testosterona, 5)Metiltestosterona, 6)Etinilestradiol, 7)Progesterona 8)Estronametileter, 9) Medroxiprogesterona

O tempo do último pico e as resoluções entre pares críticos foram as respostas investigadas neste estudo. Estes parâmetros foram escolhidos a fim de se obter um tempo menor de análise com a resolução completa dos pares críticos, os quais apresentavam 
dificuldade na separação durante os experimentos prévios. Observou-se que quando se aumenta a concentração de $\beta$-CD no eletrólito de separação os pares críticos tornam-se bem resolvidos, independente da variação individual da concentração de SDS e ACN, no entanto, podemos observar que a interação entre $\beta$-CD/SDS, $\beta-\mathrm{CD} / \mathrm{ACN}$ e $\beta$-CD/SDS/ACN também influenciavam a resolução dos pares críticos.

Após a realização dos ensaios observou-se que a separação dos esteróides utilizando sistema micelar constituído por $25 \mathrm{mmolL}^{-1} \mathrm{SDS}, 12,5 \% \mathrm{ACN}, 7,5 \mathrm{mmolL}^{-1} \beta$-ciclodextrina e tampão tetraborato $20 \mathrm{mmolL}^{-1}$, $\mathrm{pH} 9,2$, foi o meio no qual se obteve uma melhor resposta em relação resolução dos pares críticos (Figura 18).

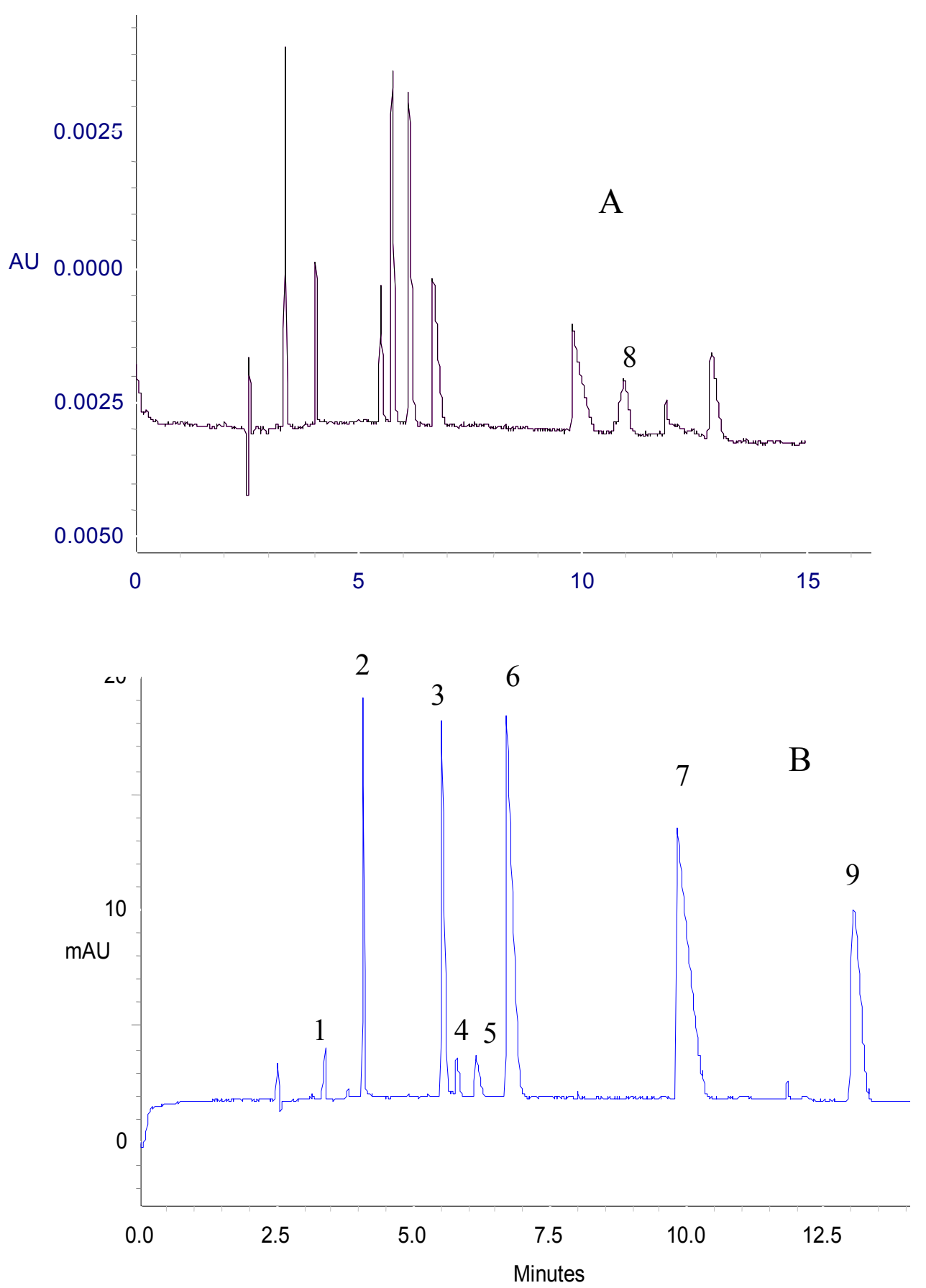


Figura 18 - Separação dos esteróides utilizando sistema de micelar constituído por $25 \mathrm{mmolL}^{-1} \mathrm{SDS}, 12,5 \%$ ACN, 7,5 $\mathrm{mmolL}^{-1} \beta$-Ciclodextrina e tampão tetraborato $20 \mathrm{mmolL}^{-1}, \mathrm{pH} \mathrm{9,2} \mathrm{um} \mathrm{capilar} \mathrm{de} \mathrm{sílica}$ fundida de 40,2 $\mathrm{cm} \times 75 \mu \mathrm{m}$ d.i. (30 $\mathrm{cm}$ até o detector), os analitos foram injetados hidrodinamicamente, com pressão de $0,3 \mathrm{psi} / 3 \mathrm{~s}$. A tensão aplicada foi de $22 \mathrm{kV}$, temperatura $22{ }^{\circ} \mathrm{C}$ e detecção em 214 nm (A) e 242nm (B). 1) Estriol, 2) Cortisol, 3)Estrona, 4)Testosterona, 5)Metiltestosterona, 6)Etinilestradiol, 7)Progesterona 8)Estronametileter, 9)Metoxiprogesterona

Infelizmente não pudemos continuar a série experimental neste equipamento, que foi enviado para manutenção. Assim os experimentos passaram a ser conduzidos no equipamento HP 3D CE - Agilent.

\subsubsection{Desenvolvimento do Método no Equipamento Hewlett-Packard 3d Ce - Agilent.}

Estudos preliminares demostraram que as condições pré-otimizadas no MDQ não foram satisfatórias quando aplicadas ao equipamento da HP. Assim, uma nova série de experimentos foi procedida (nove experimentos). Nesta fase utilizou-se os seguintes padrões: estriol, cortisol, 11- $\alpha$-hidróxiprogesterona (11- $\alpha-\mathrm{HP})$, estrona, testosterona, estradiol, 17- $\alpha$ metiltestosteona (17- $\alpha$-MT), 17- $\alpha$-hidróxiprogesterona (17- $\alpha$-HP), 21- $\alpha$-hidróxiprogesterona (21- $\alpha$-HP) e progesterona. Cada parâmetro analítico foi avaliado separadamente, com o objetivo de escolher as melhores condições para a otimização das etapas seguintes. No primeiro experimento avaliou-se o efeito da concentração de borato no sistema de separação, mantendo-se as concentrações de SDS e do solvente constantes. Os resultados obtidos estão ilustrados nas Figuras 19 e 20. 

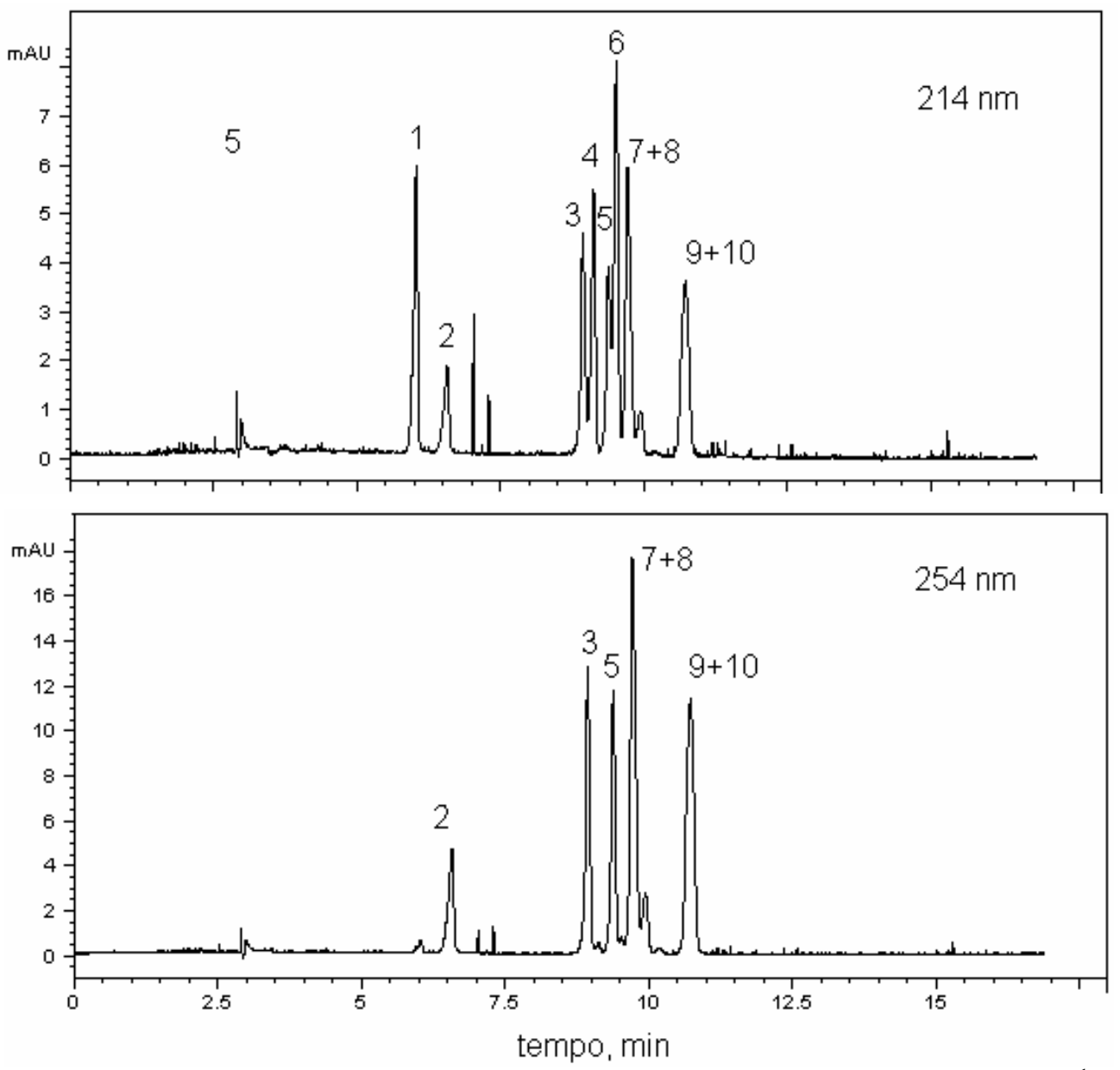

Figura 19 - Eletroferograma de uma mistura padrão. Concentração de cada hormônio: $20 \mu \mathrm{g} \mathrm{mL}{ }^{-1}$. Condições de separação: Capilar de $75 \mu \mathrm{m}$ x 48,5 cm comprimento total (40 cm até o detector). Eletrólito: $30 \mathrm{mmol}$ $\mathrm{L}^{-1} \mathrm{SDS}$ contendo $10 \mathrm{mmol} \mathrm{L}^{-1}$ de tetraborato de sódio $10 \%$ acetonitrila, $\mathrm{pH} 9,2$; tensão: $20 \mathrm{kV}$; injeção: $3 \mathrm{~s} \mathrm{x} 50$ mbar; temperatura: $22^{\circ} \mathrm{C}$, Identificação dos picos: 1. Estriol, 2. Cortisol, 3. 11- $\alpha$-HP, 4. Estrona, 5. Testosterona, 6. Estradiol, 7. 17- $\alpha$-MT, 8 17- $\alpha$-HP, 9. 21- $\alpha$-HP e 10. progesterona. 


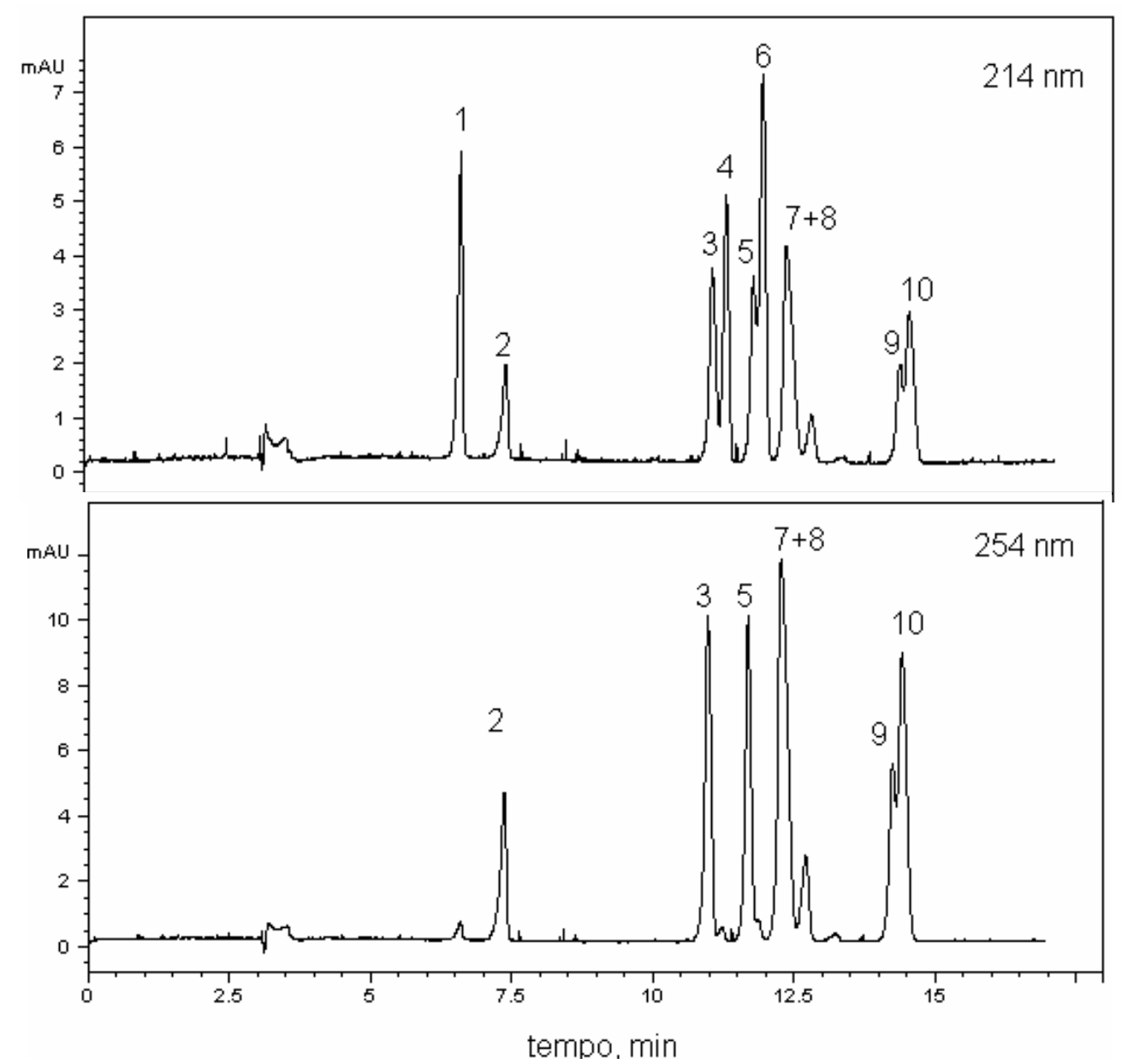

Figura 20 - Eletroferograma de uma mistura padrão. Concentração de cada hormônio: $20 \mu \mathrm{g} \mathrm{mL}{ }^{-1}$. Condições de separação: Capilar de $75 \mu \mathrm{m}$ x 48,5 cm comprimento total (40 cm até o detector). Eletrólito: $30 \mathrm{mmol}$ $\mathrm{L}^{-1}$ SDS contendo $20 \mathrm{mmol} \mathrm{L}^{-1}$ de tetraborato de sódio e $10 \%$ acetonitrila, $\mathrm{pH}$ 9,2; tensão: $20 \mathrm{kV}$; injeção: $3 \mathrm{~s} \mathrm{x} 50$ mbar; temperatura: $22^{\circ} \mathrm{C}$, Identificação dos picos: 1. Estriol, 2. Cortisol, 3. 11- $\alpha$-HP, 4. Estrona, 5. Testosterona, 6. Estradiol, 7. 17- $\alpha-\mathrm{MT}, 8$. 17- $\alpha-\mathrm{HP}, 9.21-\alpha-\mathrm{HP}$ e 10. progesterona.

O sistema de eletrólito selecionado proporcionou uma separação parcial dos analitos investigados. $\mathrm{O}$ aumento da concentração de borato não proporcionou mudanças significativas na separação do par crítico 17- $\alpha$-HP, 17- $\alpha-\mathrm{MT}$, mas proporcionou uma pequena melhora na resolução do par crítico 21- $\alpha$-HP, progesterona.

No segundo experimento avaliou-se a adição de $\beta$ - ciclodextrina. A adição de 5 mmol $\mathrm{L}^{-1} \beta-\mathrm{CD}$ proporcionou melhor resolução entre os pares 17- $\alpha-\mathrm{MT}, 17-\alpha-\mathrm{HP}, 11-\alpha-\mathrm{HP}$, estrona e 21- $\alpha-H P$, progesterona (Figura 21). Mas ocorreram mudanças na ordem de eluição pela adição de ciclodextrina. 


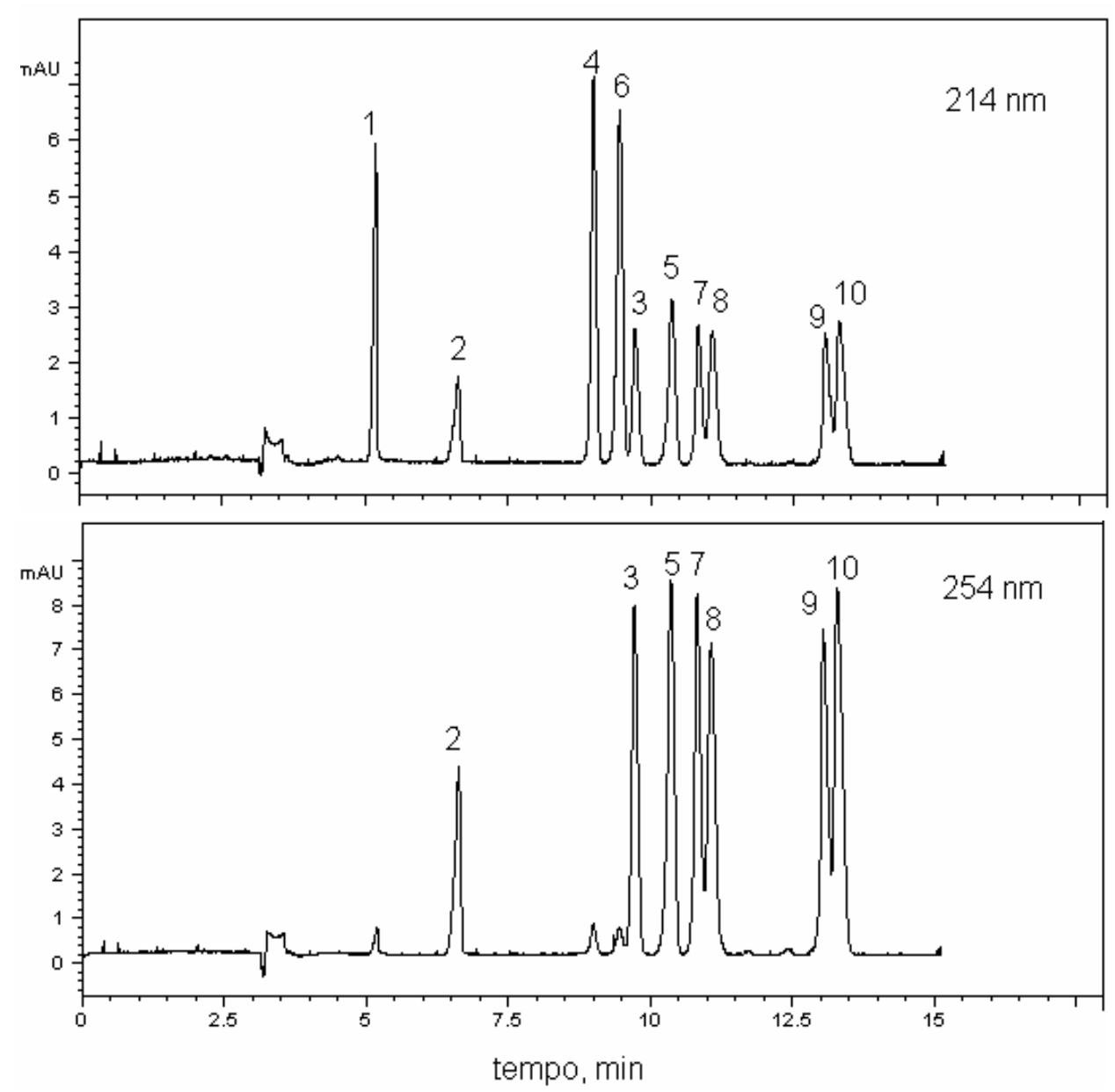

Figura 21 - Efeito da adição de $\beta$-CD o sistema de separação. Concentração de cada hormônio: $20 \mu \mathrm{g} \mathrm{mL}^{-1}$. Condições de separação: Capilar de $75 \mu \mathrm{m}$ x 48,5 cm comprimento total (40 cm até o detector). Eletrólito: $30 \mathrm{mmol} \mathrm{L}^{-1} \mathrm{SDS}$ contendo $20 \mathrm{mmol} \mathrm{L}^{-1}$ de tetraborato de sódio, $10 \%$ acetonitrila e 5 mmol L ${ }^{-1}$ de $\beta-\mathrm{CD}$, pH 9,2; tensão: $20 \mathrm{kV}$; injeção: $3 \mathrm{~s} \mathrm{x} 50$ mbar; temperatura: $22^{\circ} \mathrm{C}$, Identificação dos picos: 1. Estriol, 2. Cortisol, 3. 11- $\alpha$-HP, 4. Estrona, 5. Testosterona, 6. Estradiol, 7. 17- $\alpha$-MT, 8. 17- $\alpha-H P, 9.21-\alpha-H P$ e 10. progesterona.

No terceiro experimento, para otimizar a resolução entre pares críticos uma maior porcentagem de acetonitrila foi adicionada ao eletrólito. Solventes orgânicos são freqüentemente usados em MEKC para reduzir a afinidade de solutos hidrofóbicos com a fase micelar. Em adição, solventes orgânicos reduzem o fluxo eletroosmótico e conseqüentemente expandem a janela de migração (Baker, 1995). O aumento da concentração de acetonitrila promoveu a separação completa do par crítico progesterona, 21- $\alpha-\mathrm{HP}$, mas proporcionou coeluição parcial dos pares estradiol, 11- $\alpha$-HP e 17- $\alpha$-MT, 17- $\alpha$-HP (Figura 22). 


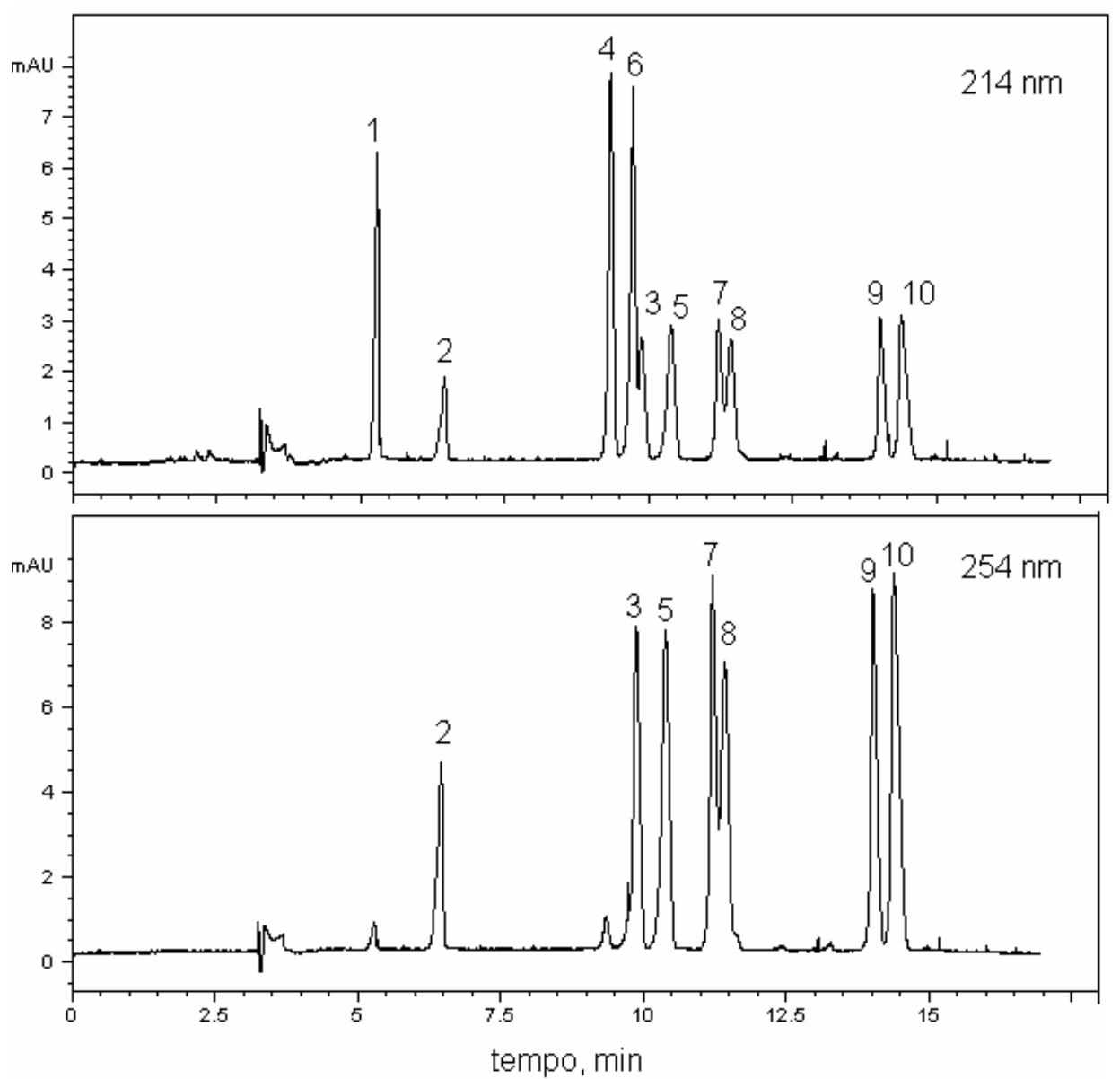

Figura 22 - Efeito da concentração de acetonitrila no sistema de separação. Concentração de cada hormônio: 20 $\mu \mathrm{g} \mathrm{mL}{ }^{-1}$. Capilar de $75 \mu \mathrm{m} \times 48,5 \mathrm{~cm}$ comprimento total $(40 \mathrm{~cm}$ até o detector). Eletrólito: $30 \mathrm{mmol}$ $\mathrm{L}^{-1} \mathrm{SDS}$ contendo $20 \mathrm{mmol} \mathrm{L}^{-1}$ de tetraborato de sódio, $12 \%$ acetonitrila e $5 \mathrm{mmol} \mathrm{L}^{-1} \mathrm{de} \beta-\mathrm{CD}$, pH 9,2; tensão: $20 \mathrm{kV}$; injeção: $3 \mathrm{~s} \mathrm{x} 50$ mbar; temperatura: $22^{\circ} \mathrm{C}$, Identificação dos picos: 1 . Estriol, 2. Cortisol, 3. 11- $\alpha$-HP, 4. Estrona, 5. Testosterona, 6. Estradiol, 7. 17- $\alpha$-MT, 8. 17- $\alpha$-HP, 9. 21- $\alpha$-HP e 10. progesterona.

O quarto experimento avaliou o efeito do aumento da concentração de $\beta$-CD no sistema de separação. Foi observada a separação completa dos pares críticos $17-\alpha-\mathrm{MT}, 17-\alpha-$ HP e progesterona, 21- $\alpha$-HP, mas por outro lado foi observada a perda de resolução entre os picos do estradiol e 11- $\alpha$-HP (Figura 23). 


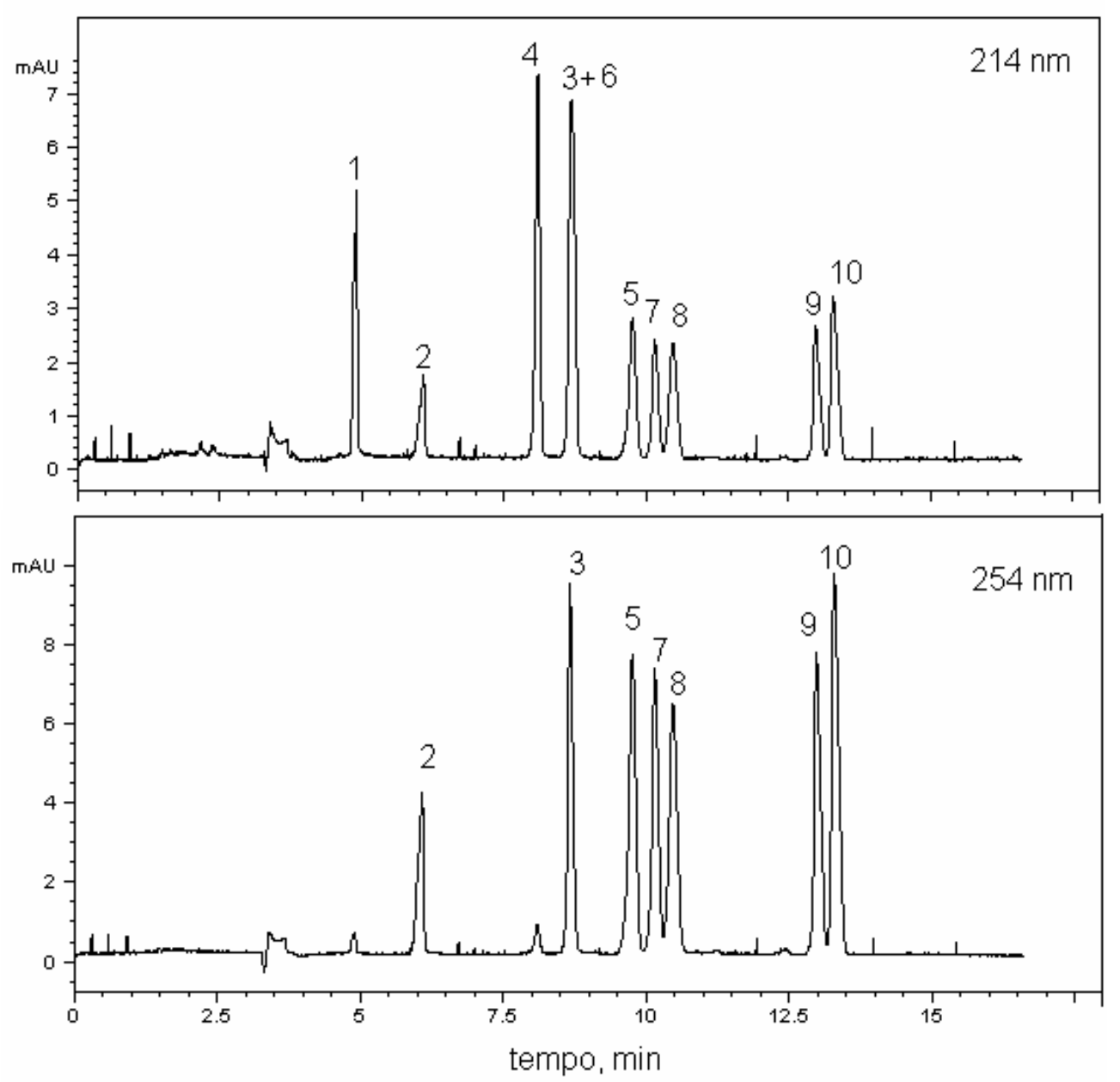

Figura 23 - Efeito da concentração de $\beta$-CD no sistema de separação. Concentração de cada hormônio: $20 \mu \mathrm{g}$ $\mathrm{mL}^{-1}$. Capilar de $75 \mu \mathrm{m} \times 48,5 \mathrm{~cm}$ comprimento total $\left(40 \mathrm{~cm}\right.$ até o detector). Eletrólito: $30 \mathrm{mmol} \mathrm{L}^{-1}$ SDS contendo $20 \mathrm{mmol} \mathrm{L}^{-1}$ de tetraborato de sódio, $12 \%$ acetonitrila e $7,5 \mathrm{mmol} \mathrm{L}^{-1}$ de $\beta-\mathrm{CD}, \mathrm{pH}$ 9,2; tensão: $20 \mathrm{kV}$; injeção: $3 \mathrm{~s} \mathrm{x} 50$ mbar; temperatura: $22^{\circ} \mathrm{C}$, Identificação dos picos: 1. Estriol, 2. Cortisol, 3. 11- $\alpha$-HP, 4. Estrona, 5. Testosterona, 6. Estradiol, 7. 17- $\alpha-\mathrm{MT}, 8$. 17- $\alpha-\mathrm{HP}, 9.21-\alpha-\mathrm{HP}$ e 10. progesterona.

Com o objetivo de reduzir o número de variáveis no sistema de separação a otimização passou a ser feita com base na mistura de solventes orgânicos no quinto experimento. De acordo com a literatura (PEREIRA, 2005) a seletividade do sistema pode aumentar quando acetonitrila é usada em combinação com pequenas quantidades de etanol. $\mathrm{O}$ efeito da adição de diferentes proporções acetonitrila/etanol ao eletrólito foi investigado, mantendo constantes a concentração do eletrólito, tensão aplicada e temperatura. $\mathrm{O}$ uso de solvente orgânico reduz o fluxo e com isso uma melhor resolução pode ser obtida, mas a concentração do solvente deve ser selecionada para proporcionar melhor resolução em um menor tempo de análise. 
Para não aumentar de forma significativa o tempo de análise em função do aumento da concentração de acetonitrila/etanol, a concentração de borato foi reduzida.

Para estes experimentos a 17- $\alpha-\mathrm{MT}$, inicialmente selecionada como padrão interno, foi substituído por outros dois padrões internos sintéticos: etinilestradiol $(214 \mathrm{~nm})$ e medroxiprogesterona $(254 \mathrm{~nm})$. A separação foi conduzida utilizando como eletrólito uma mistura contendo $30 \mathrm{mmol} \mathrm{L}^{-1} \mathrm{SDS}, 15 \mathrm{mmol} \mathrm{L}^{-1}$ de tetraborato de sódio, $15 \%$ acetonitrila e $2,5 \%$ de etanol. A figura 24 apresenta os resultados obtidos.
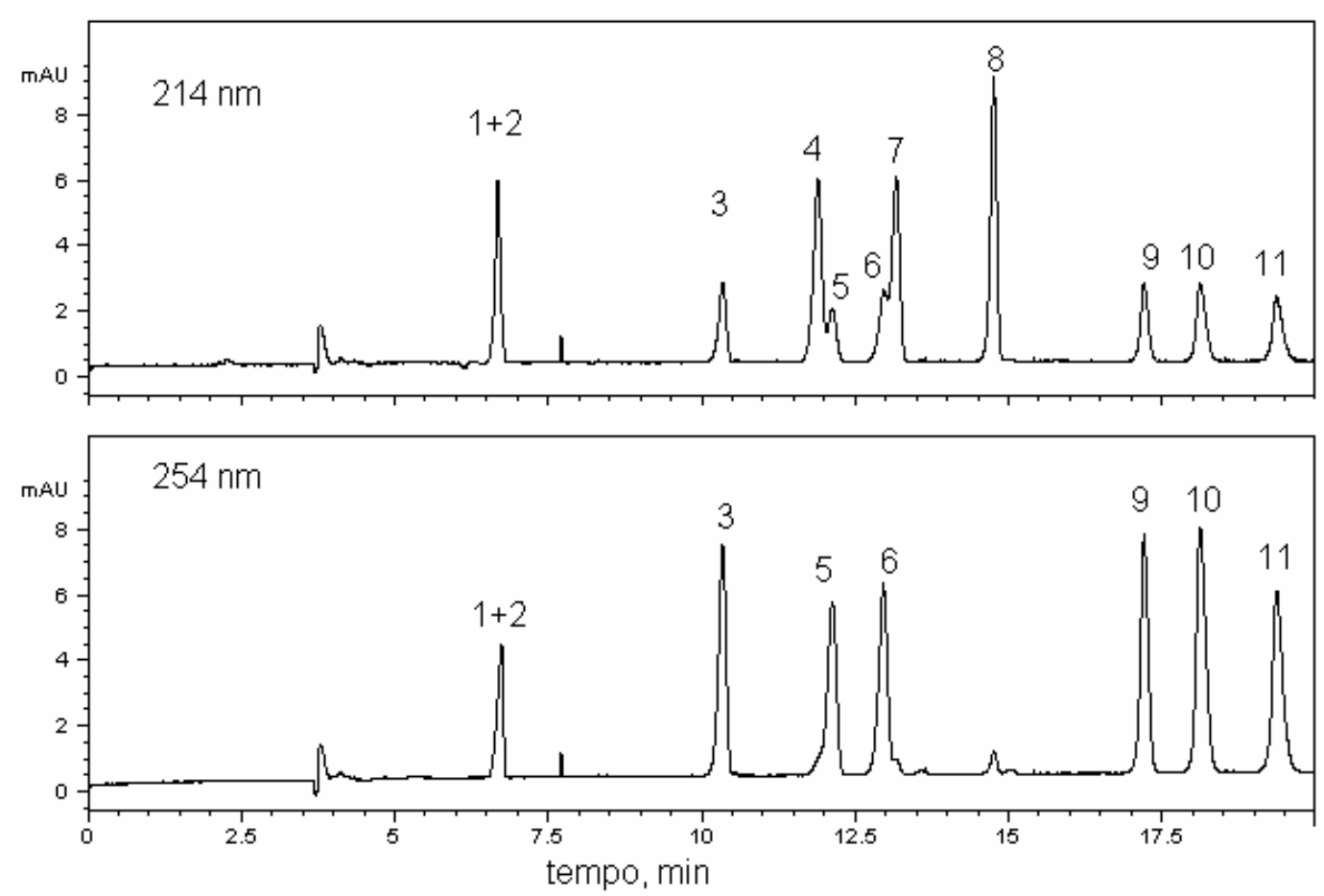

Figura 24 - Efeito da mistura acetonitrila/etanol no sistema de separação. Concentração de cada hormônio: $20 \mu \mathrm{g}$ $\mathrm{mL}^{-1}$. Capilar de $75 \mu \mathrm{m} \times 48,5 \mathrm{~cm}$ comprimento total $\left(40 \mathrm{~cm}\right.$ até o detector). Eletrólito: $30 \mathrm{mmol} \mathrm{L}^{-1}$ SDS contendo $15 \mathrm{mmol} \mathrm{L}^{-1}$ de tetraborato de sódio, $15 \%$ acetonitrila e $2,5 \%$ de etanol, $\mathrm{pH} \mathrm{9,2;}$ tensão: $20 \mathrm{kV}$; injeção: $3 \mathrm{~s} \mathrm{x} 50$ mbar; temperatura: $22^{\circ} \mathrm{C}$, Identificação dos picos: 1. Estriol, 2. Cortisol, 3. 11- $\alpha$-HP, 4. Estrona, 5. Testosterona, 6. 17- $\alpha$-HP, 7. Estradiol, 8. etinilestradiol, 9. 21- $\alpha-$ HP, 10. progesterona e 11. medroxiprogesterona.

Como mostra a figura 24, foi possível separar completamente seis dos onze hormônios estudados. Como o aumento da proporção acetonitrila/etanol torna-se inviável devido ao grande aumento no tempo de análise, a etapa seguinte (sexto experimento) foi avaliar individualmente o efeito do solvente no sistema, mantendo as outras variáveis constantes. A redução da concentração de acetonitrila para $12,5 \%$ proporcionou a separação dos pares críticos estriol, cortisol, estrona e testosterona, mas houve coeluição do par 17- $\alpha$-HP, estradiol (Figura 25). 

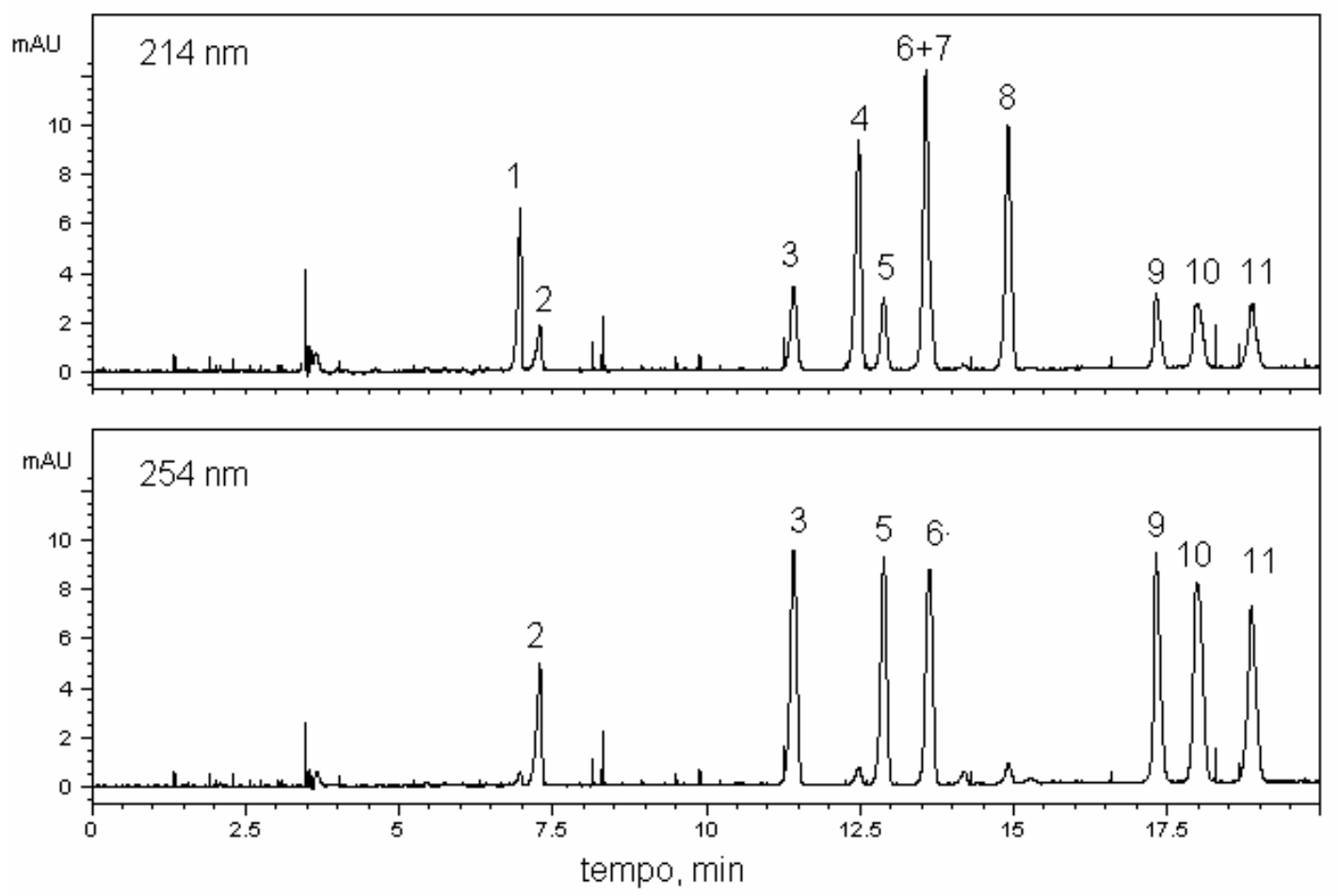

Figura 25 - Efeito da concentração de acetonitrila no sistema de separação. Concentração de cada hormônio: 20 $\mu \mathrm{g} \mathrm{mL}{ }^{-1}$. Capilar de $75 \mu \mathrm{m} \times 48,5 \mathrm{~cm}$ comprimento total ( $40 \mathrm{~cm}$ até o detector). Eletrólito: $30 \mathrm{mmol}$ $\mathrm{L}^{-1} \mathrm{SDS}$ contendo $15 \mathrm{mmol} \mathrm{L}^{-1}$ de tetraborato de sódio, $12,5 \%$ acetonitrila e $2,5 \%$ de etanol, $\mathrm{pH}$ 9,2; tensão: $20 \mathrm{kV}$; injeção: $3 \mathrm{~s} \mathrm{x} 50$ mbar; temperatura: $22^{\circ} \mathrm{C}$, Identificação dos picos: 1 . Estriol, 2. Cortisol, 3. 11- $\alpha$-HP, 4. Estrona, 5.Testosterona, 6. 17- $\alpha$-HP, 7. Estradiol, 8. etinilestradiol, 9. 21- $\alpha-$ HP, 10. progesterona e 11. medroxiprogesterona.

No sétimo experimento a concentração de acetonitrila foi reduzida para $10 \%$, sendo observada uma melhora na separação do par 17- $\alpha$-HP, estradiol, mas perda de resolução entre os picos da 21- $\alpha$-HP, progesterona e medroxiprogesterona (Figura 26). 

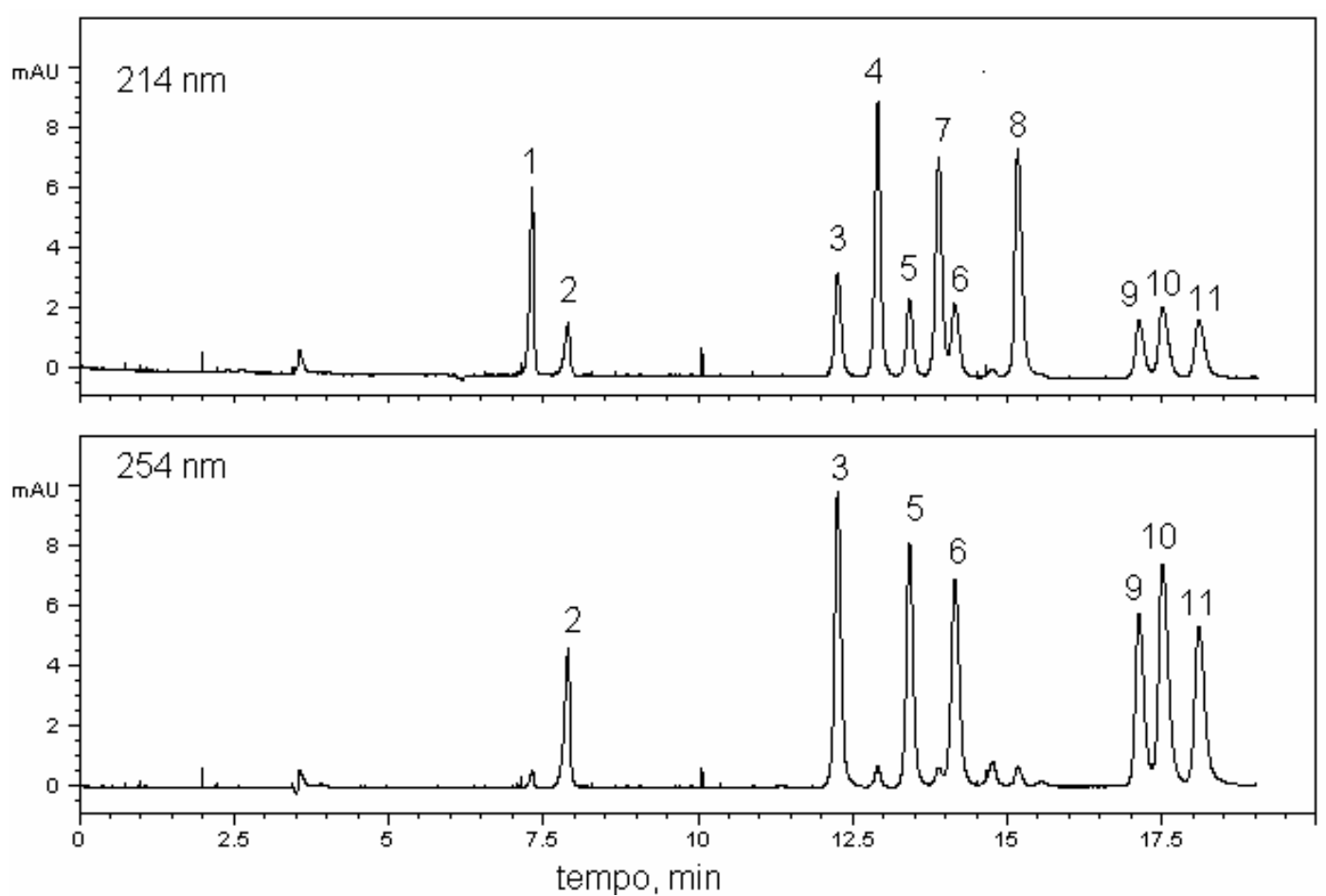

Figura 26 - Efeito da concentração de acetonitrila no sistema de separação. Concentração de cada hormônio: 20 $\mu \mathrm{g} \mathrm{mL}{ }^{-1}$. Capilar de $75 \mu \mathrm{m} \times 48,5 \mathrm{~cm}$ comprimento total ( $40 \mathrm{~cm}$ até o detector). Eletrólito: $30 \mathrm{mmol}$ $\mathrm{L}^{-1} \mathrm{SDS}$ contendo $15 \mathrm{mmol} \mathrm{L}^{-1}$ de tetraborato de sódio, $10 \%$ acetonitrila e $2,5 \%$ de etanol, pH 9,2; tensão: $20 \mathrm{kV}$; injeção: $3 \mathrm{~s} \mathrm{x} 50$ mbar; temperatura: $22^{\circ} \mathrm{C}$, Identificação dos picos: 1. Estriol, 2. Cortisol, 3. 11- $\alpha$-HP, 4. Estrona, 5. Testosterona, 6. 17- $\alpha$-HP, 7. Estradiol, 8. etinilestradiol, 9. 21- $\alpha-$ HP, 10. Progesterona e 11. medroxiprogesterona.

Como não foram obtidos resultados satisfatórios com relação à concentração de acetonitrila, o oitavo experimento avaliou o efeito da concentração de etanol no sistema de separação. A figura 27 apresenta os resultados obtidos. 

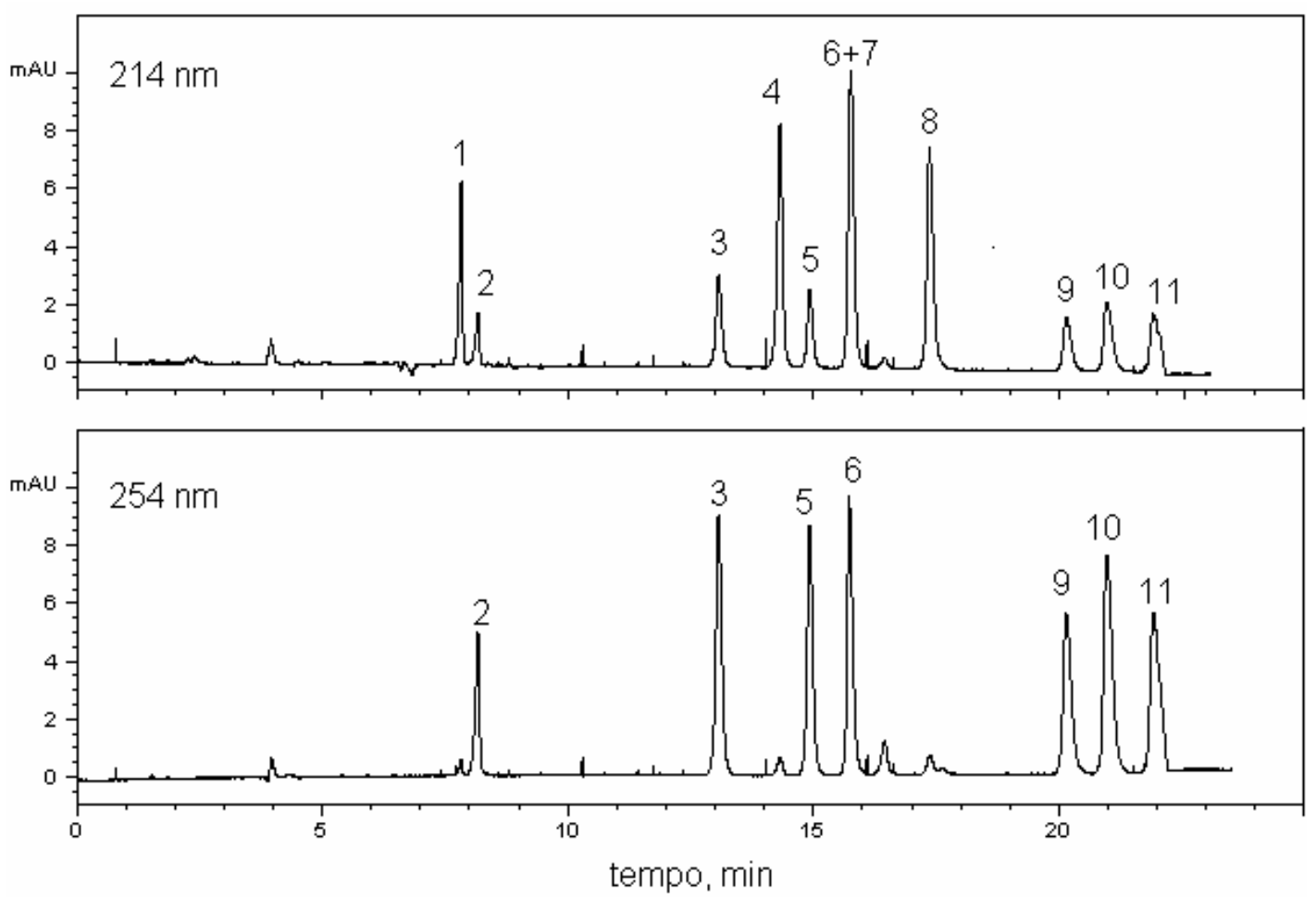

Figura 27 - Efeito da concentração de etanol no sistema de separação. Concentração de cada hormônio: $20 \mu \mathrm{g}$ $\mathrm{mL}^{-1}$. Capilar de $75 \mu \mathrm{m} \times 48,5 \mathrm{~cm}$ comprimento total $\left(40 \mathrm{~cm}\right.$ até o detector). Eletrólito: $30 \mathrm{mmol} \mathrm{\textrm {L } ^ { - 1 }}$ SDS contendo $15 \mathrm{mmol} \mathrm{L}^{-1}$ de tetraborato de sódio, $10 \%$ acetonitrila e $5 \%$ de etanol, pH 9,2; tensão: $20 \mathrm{kV}$; injeção: $3 \mathrm{~s} \mathrm{x} 50$ mbar; temperatura: $22^{\circ} \mathrm{C}$, Identificação dos picos: 1. Estriol, 2. Cortisol, 3.

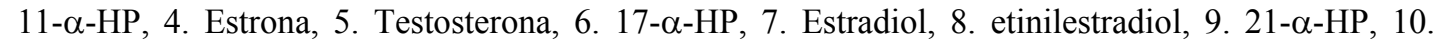
progesterona e 11. medroxiprogesterona.

O aumento da concentração de etanol proporcionou uma melhor resolução entre os picos da 21- $\alpha-H P$, progesterona e medroxiprogesterona, entretanto foram observados coeluição do par estradiol, 17- $\alpha$-HP longos tempos de análise (superior a $20 \mathrm{~min}$ ).

Geralmente, o uso de altas concentrações de solvente orgânico não é recomendado porque acima de $20 \%$ as estruturas das micelas são rompidas (BOWSER, 1998). Com base neste comportamento, uma concentração máxima de $20 \%$ de solvente orgânico foi estabelecida para o nono experimento. Como o uso individual dos solventes já tinha sido testado, foi avaliado o comportamento do sistema de separação utilizando uma mistura contendo $10 \%$ acetonitrila/ $10 \%$ etanol. Para otimizar o tempo de análise a concentração do tetraborato de sódio foi novamente reduzida. A adição de uma mistura contendo $10 \%$ de acetonitrila e $10 \%$ de etanol ao eletrólito promoveu a resolução completa dos onze hormônios avaliados (Figura 28) 

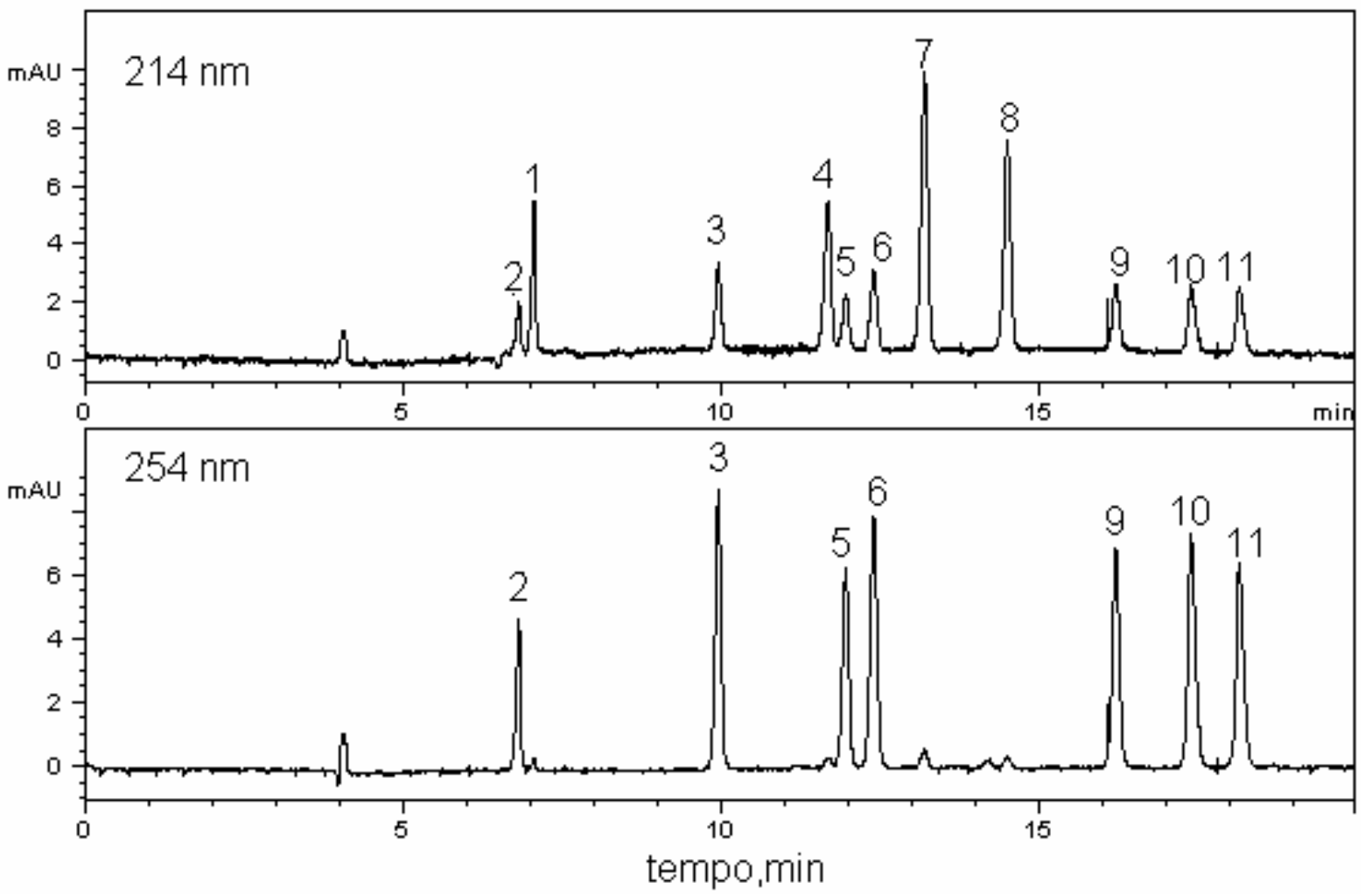

Figura 28 - Eletroferograma da mistura padrão sob condições otimizadas. Concentração de cada hormônio: 20 $\mu \mathrm{g} \mathrm{mL}{ }^{-1}$. Capilar de $75 \mu \mathrm{m}$ x 48,5 cm comprimento total ( $40 \mathrm{~cm}$ até o detector). Eletrólito: $30 \mathrm{mmol}$ $\mathrm{L}^{-1} \mathrm{SDS}$ contendo $10 \mathrm{mmol} \mathrm{L}^{-1}$ de tetraborato de sódio, $10 \%$ acetonitrila e $10 \%$ de etanol, $\mathrm{pH} \mathrm{9,2}$; tensão: $20 \mathrm{kV}$; injeção: $3 \mathrm{~s} \mathrm{x} 50$ mbar; temperatura: $22^{\circ} \mathrm{C}$, Identificação dos picos: 1. Estriol, 2. Cortisol, 3. 11- $\alpha$-HP, 4. Estrona, 5. Testosterona, 6. 17- $\alpha$-HP, 7. Estradiol, 8. etinilestradiol, 9. 21- $\alpha-$ HP, 10. progesterona e 11. medroxiprogesterona

\subsection{PROCEDIMENTOS DE EXTRAÇÃO}

\subsubsection{Protocolo 01: Extração com Etanol/Metanol}

À partir do estabelecimento da composição do eletrólito procedeu-se à análise por CE de uma amostra submetida ao Protocolo 01 de extração (Figura 29). 

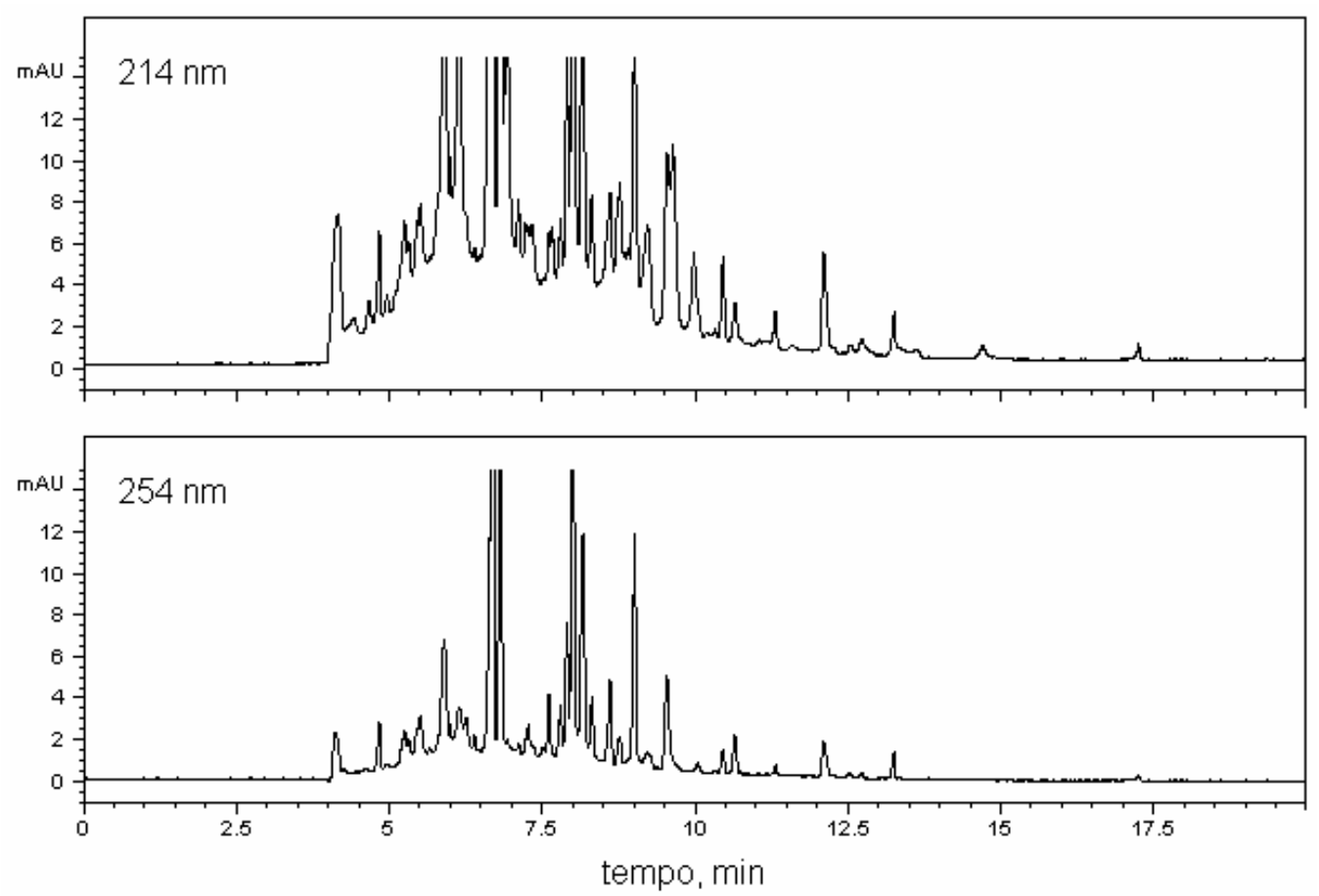

Figura 29 - Eletroferograma de uma amostra fecal extraída à partir do protocolo 01. Capilar de $75 \mu \mathrm{m} \times 48,5 \mathrm{~cm}$ comprimento total $\left(40 \mathrm{~cm}\right.$ até o detector). Eletrólito $30 \mathrm{mmol} \mathrm{L}^{-1} \mathrm{SDS}$ contendo $10 \mathrm{mmol} \mathrm{L}^{-1} \mathrm{de}$ tetraborato de sódio, $10 \%$ acetonitrila e $10 \%$ de etanol, $\mathrm{pH} 9,2$; tensão: $20 \mathrm{kV}$; injeção: $3 \mathrm{~s} \mathrm{x} 50$ mbar; temperatura: $22^{\circ} \mathrm{C}$.

Por se tratar de uma amostra complexa, com grande variação na sua composição, o protocolo 01 mostrou-se inadequado a este tipo de análise demonstrando a presença de muitos interferentes, sendo necessária a investigação de outros protocolos de extração para procedimentos em CE.

À partir do mesmo protocolo de extração procedeu-se a experimentação em cromatografia a gás com deteç̧ão por ionização em chama como descrito anteriormente. Infelizmente em nenhuma das amostras avaliadas foi confirmada a presença dos padrões investigados (Figura 30). 

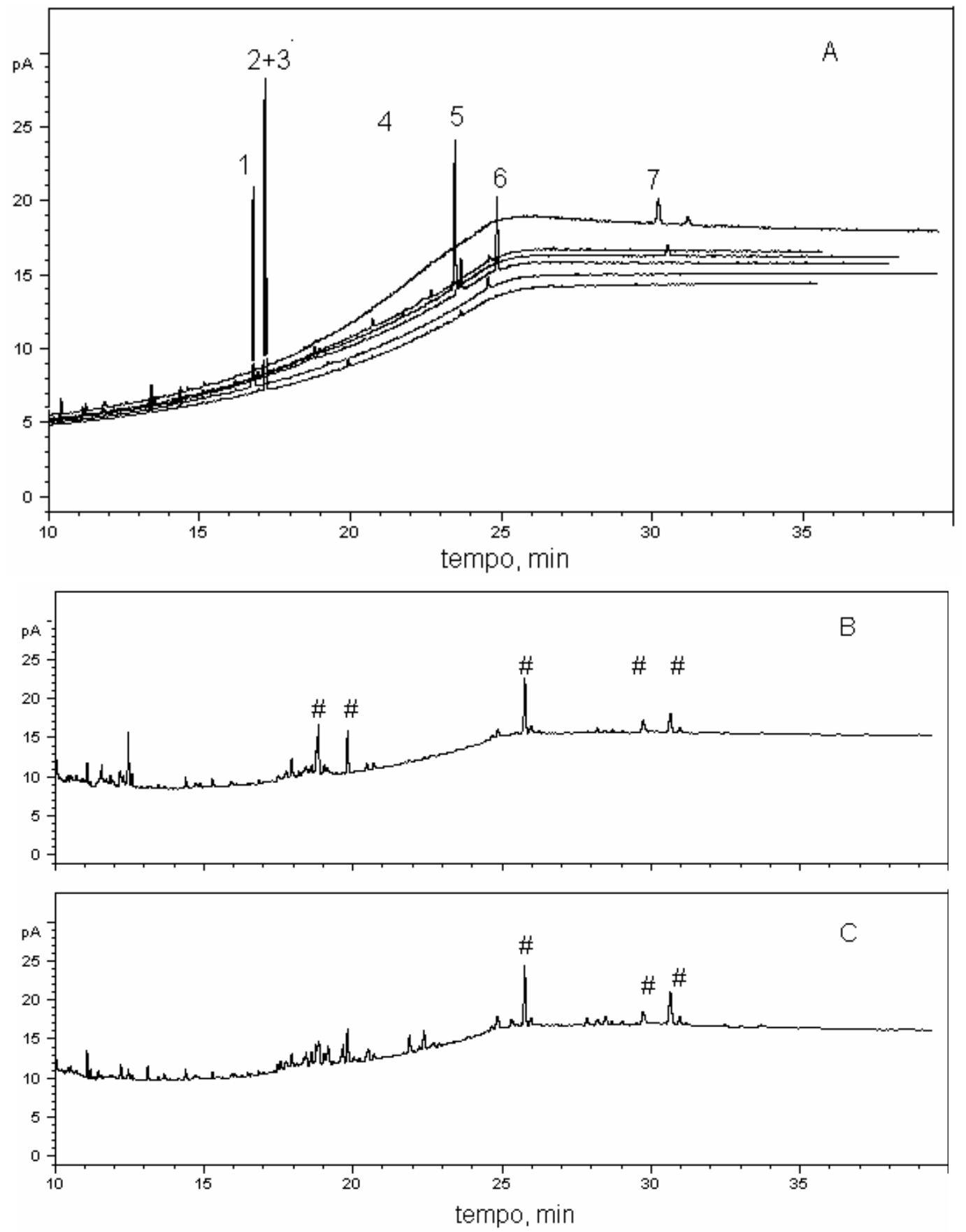

Figura 30 - Cromatograma dos hormônios analisados por CG-FID como descrito na seção experimental. A. padrão, B. amostra 1 e C. amostra 2. Identificação dos picos: 1.estrona, 2. testosterona, 3. estradiol, 4. estriol, 5.17 - $\alpha$ - HP, 6. 11 - $\alpha$ - HP, 7. cortisol e \# não identificado.

A maior dificuldade encontrada em relação aos experimentos conduzidos em GC foi o processo de derivatização. De 10 amostras derivatizadas somente duas puderam ser analisadas, uma vez que este procedimento torna o composto muito sensível à umidade (em 8 amostras ocorreu a formação de cristais). Além disso, o processo de tratamento do material e vidraria utilizado na derivatização é moroso e consome muito tempo. 
Com base nestes resultados e nos resultados preliminares obtidos na meck optamos por abandonar a cromatografia a gás e investir na otimização do método analítico com a CE.

\subsubsection{Protocolo 02: Hidrólise Ácida}

A hidrólise ácida foi procedida à semelhança do protocolo desenvolvido por Ji (1995) com intuito de descojungar os esteróides, retirar da amostra resíduos de proteínas e outras substâncias que causam ruído no eletroferograma, ou seja, o objetivo da hidrólise foi limpar a amostra. Ao final do processamento o extrato seco apresentava-se castanho escuro, com grumos aderidos ao vidro do tubo, a solubilização em metanol foi muito difícil, necessitando de várias passagens no vórtex e ultra-som e ainda assim não houve dissolução completa dos grumos. Ao ser adicionada a água deionizada houve a formação de um precipitado levando à necessidade de se filtrar o extrato antes da injeção. Foi programada uma seqüência de injeção de uma solução com os padrões, seguida pelas amostras submetidas à hidrólise (dopada e branca) e então obtivemos os eletroferogramas apresentados na figura 31. 

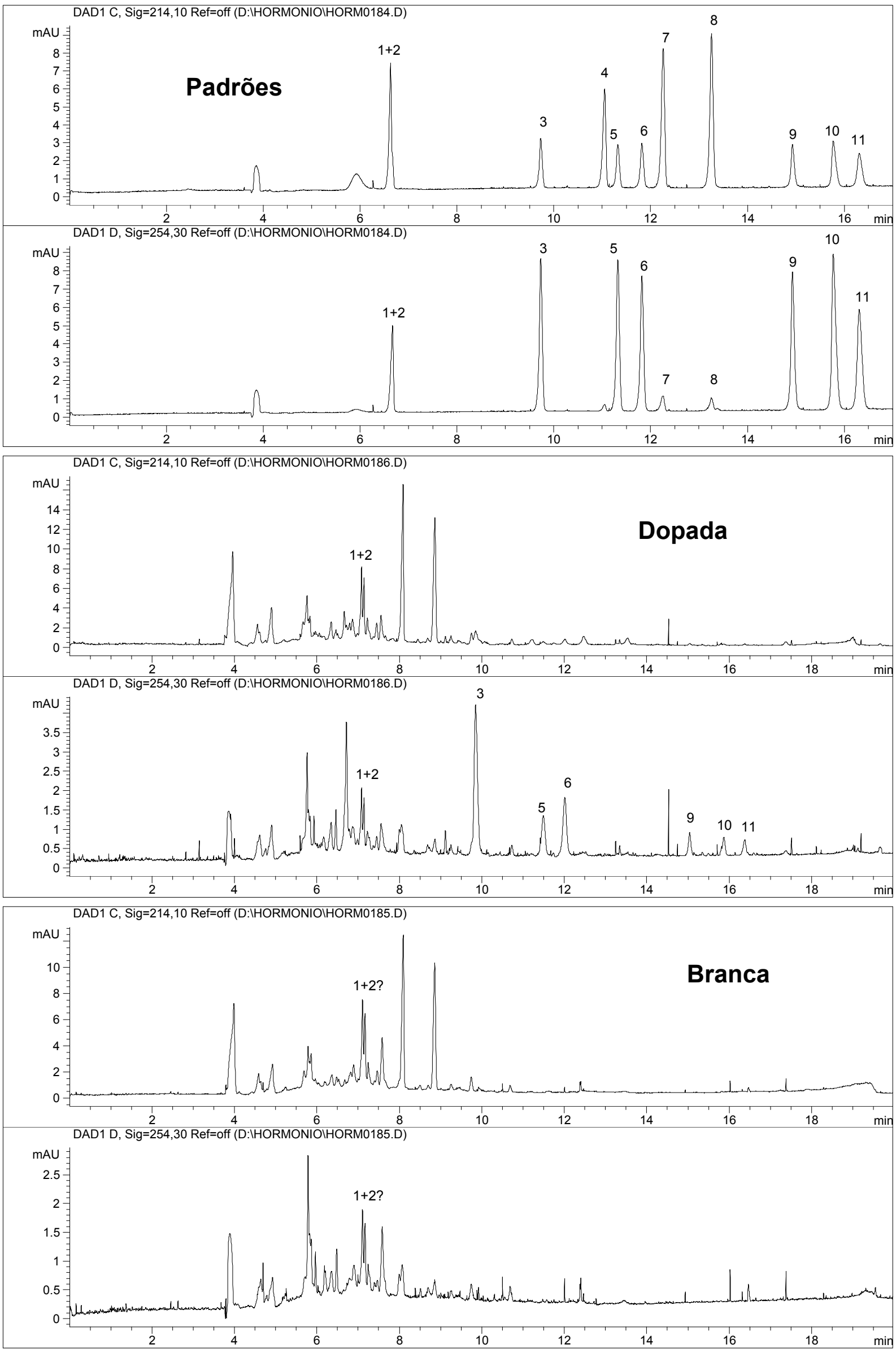
Figura 31 - Efeito da hidrólise ácida na extração de esteróides à partir de fezes de onça pintada. Capilar de $75 \mu \mathrm{m} \times 48,5 \mathrm{~cm}$ comprimento total $(40 \mathrm{~cm}$ até o detector). Eletrólito 30 mmol L-1 SDS contendo $10 \mathrm{mmol} \mathrm{L}^{-1}$ de tetraborato de sódio, $10 \%$ acetonitrila e $10 \%$ de etanol, pH 9,2; tensão: $20 \mathrm{kV}$; injeção: $3 \mathrm{~s} \mathrm{x} 50$ mbar; temperatura: $22^{\circ} \mathrm{C}$

O resultado da hidrólise não foi satisfatório, nos eletroferogramas observa-se que houve perda de padrões.

Quanto à avaliação da recuperação dos padrões adicionados à amostra obteve-se o resultado apresentado na tabela 3 .

Tabela 3 - Recuperação apresentada pelo protocolo de hidrólise ácida

\begin{tabular}{|l|c|}
\hline Padrões & Recuperação \\
\hline Estriol & nc \\
\hline 11 -alfa $h p$ & $9,0 \%$ \\
\hline Estrona & $13,0 \%$ \\
\hline Testosterona & $26,6 \%$ \\
\hline 17 -alfa $\mathrm{hp}$ & $46,1 \%$ \\
\hline Estradiol & $8,8 \%$ \\
\hline 21 -alfa $\mathrm{hp}$ & $9,8 \%$ \\
\hline Progesterona & $7,5 \%$ \\
\hline \multicolumn{2}{|c|}{ nc: não foi possivel calcular } \\
\hline \multicolumn{2}{|l}{} \\
\hline
\end{tabular}

Além da baixa eficiência este protocolo apresentou consumo elevado de tempo e descarte de grande volume de reagentes, formação de grande quantidade de grumos e necessidade de filtragem do extrato.

\subsubsection{Protocolo 03 : Diclorometano/Metanol}

Neste protocolo o resíduo seco obtido, tal qual o da hidrólise apresentava-se escuro e com grumos, no entanto a coloração era mais clara e era menor a quantidade de grumos. A ressuspensão em metanol foi rápida e completa, mas a solução tornou-se turva ao ser adicionada a água deionizada, fazendo-se necessária a passagem por um filtro antes da injeção. A figura 32 mostra os eletroferogramas da solução de padrões e da amostra dopada respectivamente. 

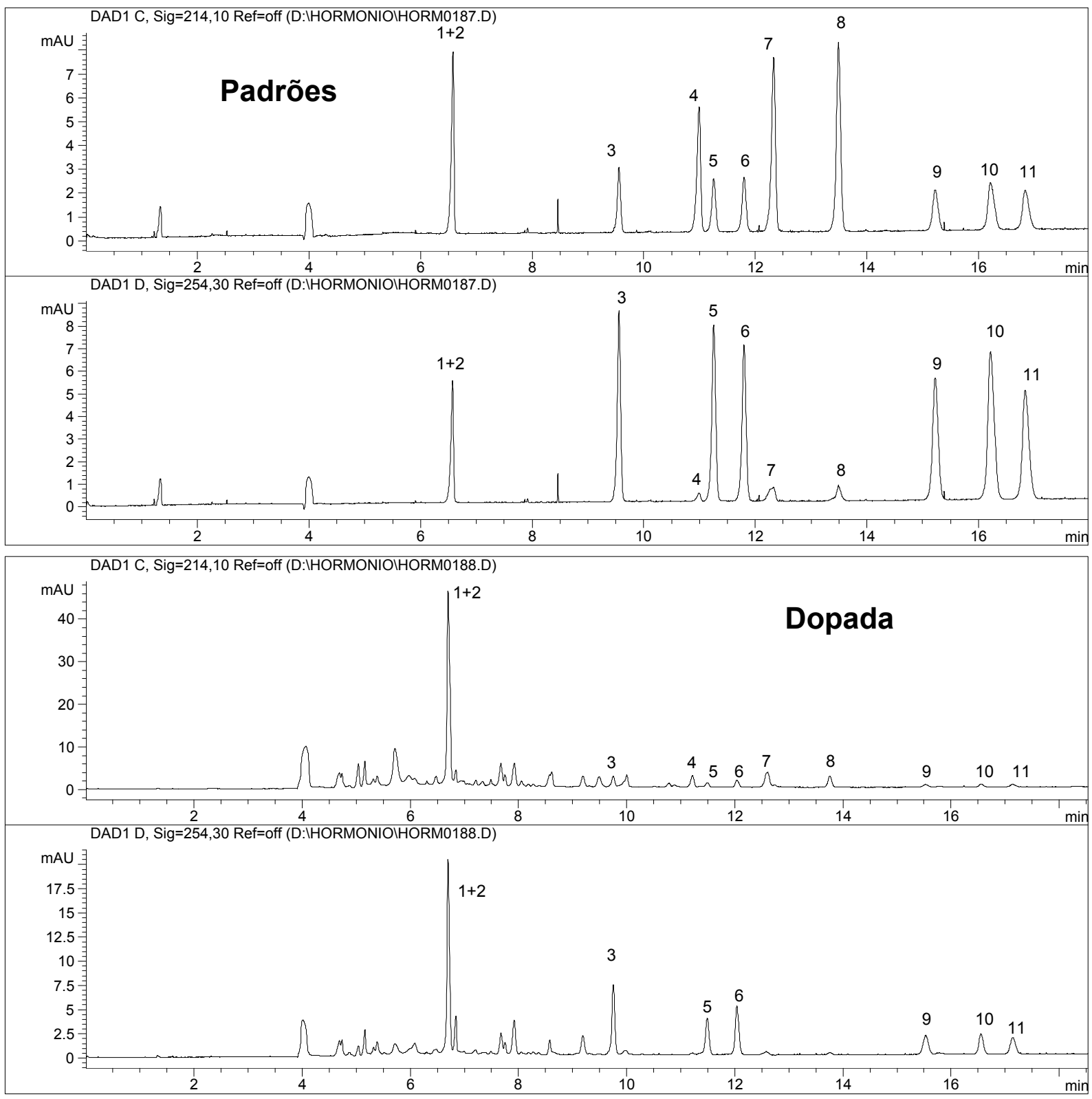

Figura 32 - Resultado da extração com diclorometano/metanol. Capilar de $75 \mu \mathrm{m}$ x $48,5 \mathrm{~cm}$ comprimento total ( $40 \mathrm{~cm}$ até o detector). Eletrólito $30 \mathrm{mmol} \mathrm{L}^{-1} \mathrm{SDS}$ contendo $10 \mathrm{mmol} \mathrm{L}^{-1}$ de tetraborato de sódio, $10 \%$ acetonitrila e $10 \%$ de etanol, pH 9,2; tensão: $20 \mathrm{kV}$; injeção: $3 \mathrm{~s} \mathrm{x} 50$ mbar; temperatura: $22^{\circ} \mathrm{C}$.

Apesar de apresentar maior eficiência que o protocolo anterior, as taxas de recuperação não foram satisfatórias. A tabela 4 mostra a recuperação obtida por este protocolo. 
Tabela 4 - Recuperação apresentada pelo protocolo de extração em diclorometano/metanol.

\begin{tabular}{|l|c|}
\hline Padrões & Recuperação \\
\hline Estriol & nc \\
\hline 11 -alfa hp & $77,4 \%$ \\
\hline Estrona & $47,2 \%$ \\
\hline Testosterona & $36,6 \%$ \\
\hline 17 -alfa hp & $64,0 \%$ \\
\hline Estradiol & $48,1 \%$ \\
\hline 21-alfa hp & $35,3 \%$ \\
\hline Progesterona & $24,4 \%$ \\
\hline \multicolumn{2}{|c|}{ nc: não foi possivel calcular }
\end{tabular}

Do ponto de vista do processamento laboratorial vale ressaltar que o diclorometano é um líquido muito volátil, irritante paras as mucosas e cancerígeno, tornando o manuseio perigoso para um número elevado de amostras no caso de análises rotineiras.

\subsubsection{Protocolo 04: Acetonitrila/Etanol}

O resíduo após a etapa de secagem apresentou-se amarelo citrino, sem grumos, no entanto foi necessária a permanência em banho ultra-sônico por vinte minutos até a dissolução completa. A solução ficou turva após a adição da água deionizada, mas como não houve formação de grumos não foi necessária a filtragem do extrato. A figura 33 mostra respectivamente os eletroferogramas dos padrões, da amostra branca e da amostra dopada deste protocolo. 

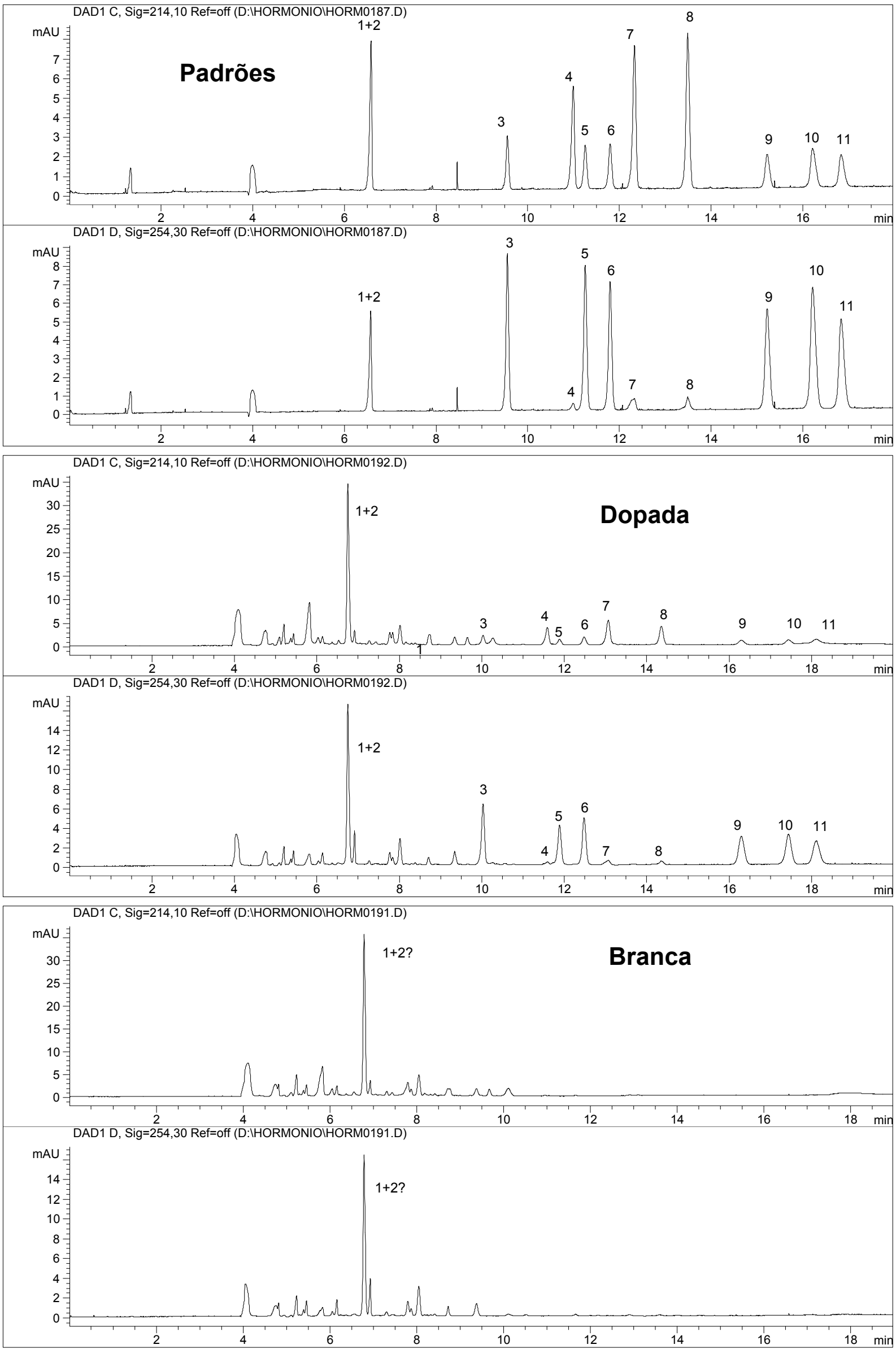
Figura 33 - Resultado da extração com acetonitrila/etanol. Capilar de $75 \mu \mathrm{m} x 48,5 \mathrm{~cm}$ comprimento total (40 cm até o detector). Eletrólito $30 \mathrm{mmol} \mathrm{L}^{-1} \mathrm{SDS}$ contendo $10 \mathrm{mmol} \mathrm{L}^{-1}$ de tetraborato de sódio, $10 \%$ acetonitrila e $10 \%$ de etanol, pH 9,2; tensão: $20 \mathrm{kV}$; injeção: $3 \mathrm{~s}$ x 50 mbar; temperatura: $22^{\circ} \mathrm{C}$.

A mistura dos dois solventes promoveu um bom resultado,comprovado pelo eletroferograma da amostra dopada. O cálculo da recuperação obtida por este protocolo está demonstrado na tabela 5 .

Tabela 5 - Recuperação apresentada pelo protocolo de extração em acetonitrila/etanol

\begin{tabular}{|l|c|}
\hline Padrões & Recuperação \\
\hline Estriol & nc \\
\hline 11 -alfa $h p$ & $97,1 \%$ \\
\hline Estrona & $89,4 \%$ \\
\hline Testosterona & $53,4 \%$ \\
\hline 17 -alfa hp & $85.4 \%$ \\
\hline Estradiol & $93,4 \%$ \\
\hline 21 -alfa hp & $78,5 \%$ \\
\hline Progesterona & $56,6 \%$ \\
\hline \multicolumn{2}{|c|}{ nc: não foi possivel calcular }
\end{tabular}

\subsubsection{Protocolo 05: Acetonitrila}

O extrato seco deste protocolo apresentou-se de coloração mais clara que a do protocolo com acetonitrila/etanol, ressuspendendo-se facilmente em metanol formando uma solução transparente que se turvou após a adição da água deionizada. A figura 34 mostra os eletroferogramas dos padrões, do branco e da amostra dopada deste protocolo. 

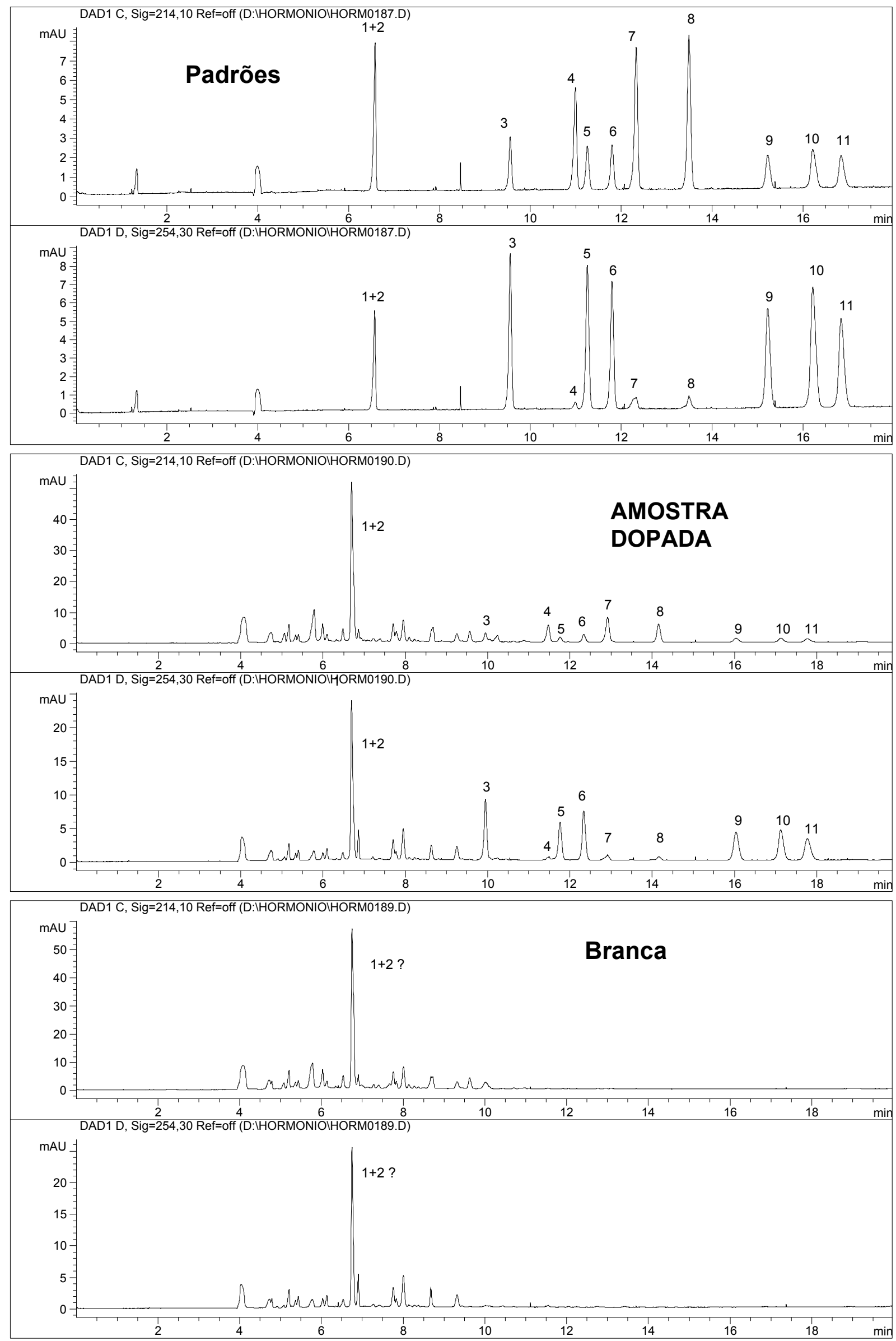
Figura 34 - Resultado da extração em acetonitrila. Capilar de $75 \mu \mathrm{m} \times 48,5 \mathrm{~cm}$ comprimento total (40 $\mathrm{cm}$ até o detector). Eletrólito $30 \mathrm{mmol} \mathrm{L}^{-1} \mathrm{SDS}$ contendo $10 \mathrm{mmol} \mathrm{L}^{-1}$ de tetraborato de sódio, $10 \%$ acetonitrila e $10 \%$ de etanol, pH 9,2; tensão: $20 \mathrm{kV}$; injeção: $3 \mathrm{~s} \mathrm{x} 50$ mbar; temperatura: $22^{\circ} \mathrm{C}$.

Como demonstrado na tabela 6, a extração em acetonitrila apresentou a melhor recuperação em relação aos outros protocolos testados neste estudo; apresentando também melhor resolução em um tempo de análise satisfatório.

Tabela 6 - Recuperação apresentada pelo protocolo de extração em acetonitrila.

\begin{tabular}{|l|c|}
\hline Padrões & Recuperação \\
\hline Estriol & nc \\
\hline 11 -alfa $h p$ & $97,3 \%$ \\
\hline Estrona & $94,3 \%$ \\
\hline Testosterona & $97,6 \%$ \\
\hline 17 -alfa hp & $99,0 \%$ \\
\hline Estradiol & $96,5 \%$ \\
\hline 21-alfa hp & $97,8 \%$ \\
\hline Progesterona & $87,3 \%$ \\
\hline \multicolumn{2}{|c|}{ nc: não foi possivel calcular }
\end{tabular}

Os melhores resultados dos protocolos com acetonitrila devem-se provavelmente ao efeito deste solvente na precipitação de proteínas.

No entanto a impossibilidade de cálculo da recuperação do estriol para este protocolo e para os demais deveu-se a presença de interferentes, além disso a altura dos picos indica que as concentrações dos hormônios nas amostras são muito baixas. Uma alternativa para eliminar estes interferentes e concentrar os analitos é a utilização da extração em fase sólida (SPE).

\subsubsection{Protocolo 06: Extração em Fase Sólida (SPE-SX)}

A partir do protocolo de extração em acetonitrila, foi feita a passagem das amostras dopada e branca no cartucho Strata-X e em seguida foi programada uma seqüência de injeções da solução de padrões, e das duas amostras. Os resultados estão expressos na figura 35 . 

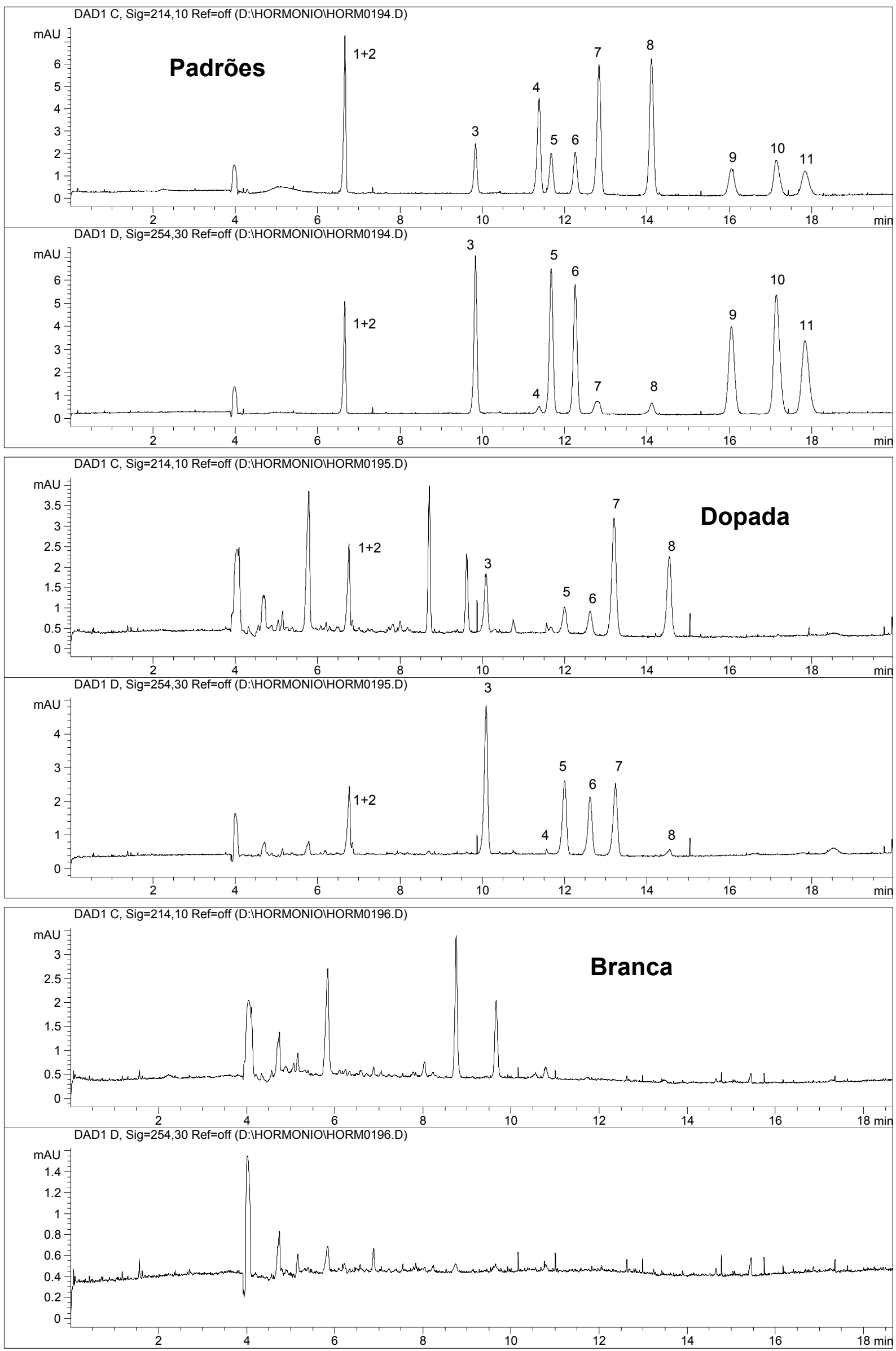
Figura 35 - Resultado da extração em fase sólida StrataX. Capilar de $75 \mu \mathrm{m} \times 48,5 \mathrm{~cm}$ comprimento total (40 $\mathrm{cm}$ até o detector). Eletrólito $30 \mathrm{mmol} \mathrm{L}^{-1} \mathrm{SDS}$ contendo $10 \mathrm{mmol} \mathrm{L}^{-1}$ de tetraborato de sódio, $10 \%$ acetonitrila e $10 \%$ de etanol, pH 9,2; tensão: $20 \mathrm{kV}$; injeção: $3 \mathrm{~s} \mathrm{x} 50$ mbar; temperatura: $22^{\circ} \mathrm{C}$.

Os resultados não foram satisfatórios, então optou-se por testar a eficiência da coluna na concentração dos hormônios em estudo, assim foi feita a passagem da solução de padrões pela coluna. Recuperou-se o eluído em metanol a 5\%, que por recomendação do fabricante é desprezado, para verificarmos se nessa primeira eluição não teriam saído os esteróides, e também o eluído com o metanol a 100\% também foi injetado. Os resultados são apresentados na figura 36. 

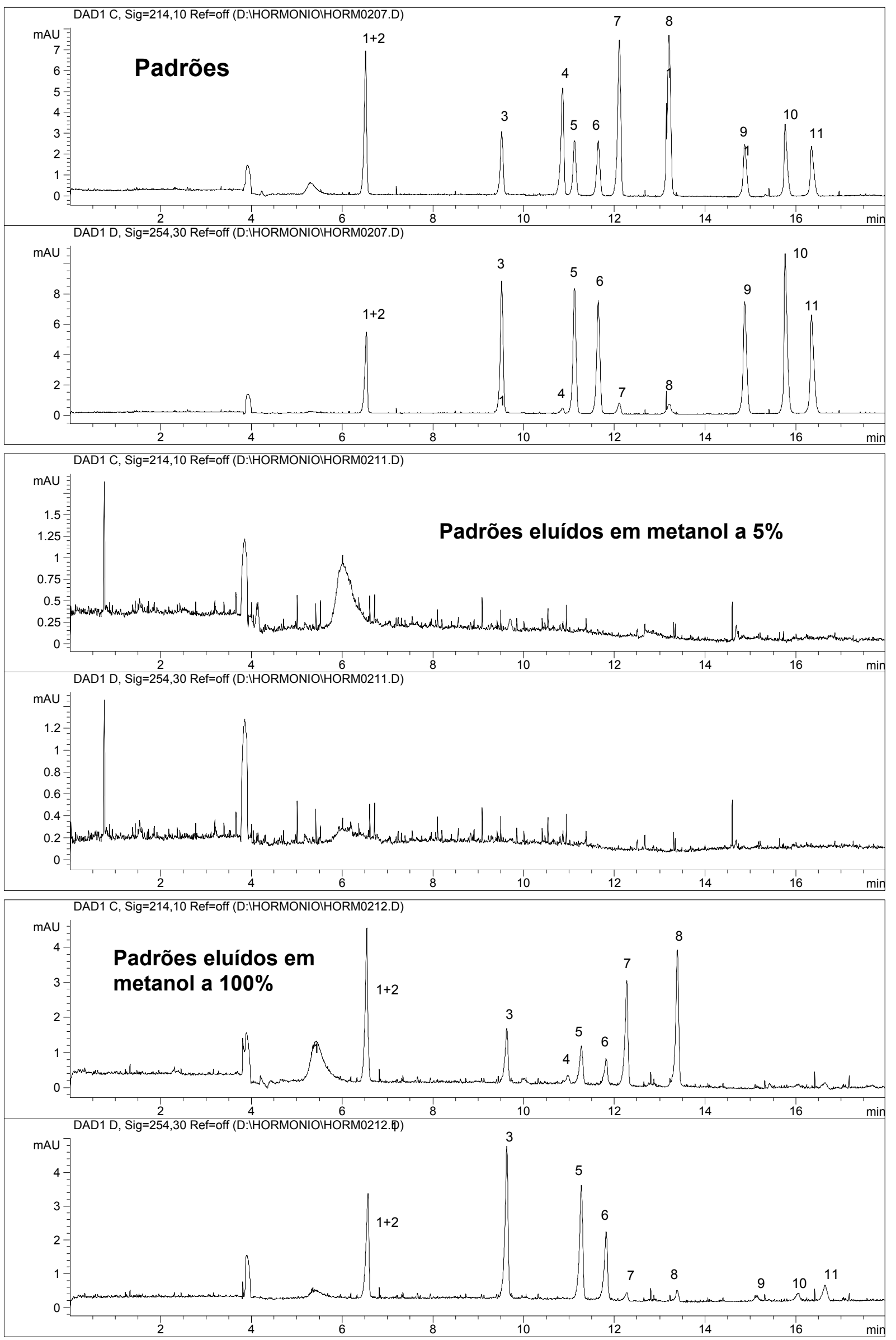
Figura 36 - Resultado do teste de eficência da extração em fase sólida SX. Capilar de $75 \mu \mathrm{m} x$ $48,5 \mathrm{~cm}$ comprimento total $\left(40 \mathrm{~cm}\right.$ até o detector). Eletrólito $30 \mathrm{mmol} \mathrm{L}^{-1} \mathrm{SDS}$ contendo $10 \mathrm{mmol}$ $\mathrm{L}^{-1}$ de tetraborato de sódio, $10 \%$ acetonitrila e $10 \%$ de etanol, $\mathrm{pH} 9,2$; tensão: $20 \mathrm{kV}$; injeção: $3 \mathrm{~s} \mathrm{x}$ 50 mbar; temperatura: $22^{\circ} \mathrm{C}$.

Observa-se por estes resultados que a fase Strata-X não foi eficiente na concentração destes esteróides, provavelmente devido a uma interação muito forte entre estes e a fase sólida, não desfeita pela passagem do metanol.

\subsubsection{Protocolo 07: Extração em Fase Sólida (SPE - C18)}

Antes de testar a C18 com as amostras optou-se por repetir o mesmo experimento que foi feito para a Strata-X, passando a solução de padrões pela coluna e recuperando o eluído em metanol a 5\% e também o eluído com o metanol a 100\%. Os resultados são apresentados na figura 37. 

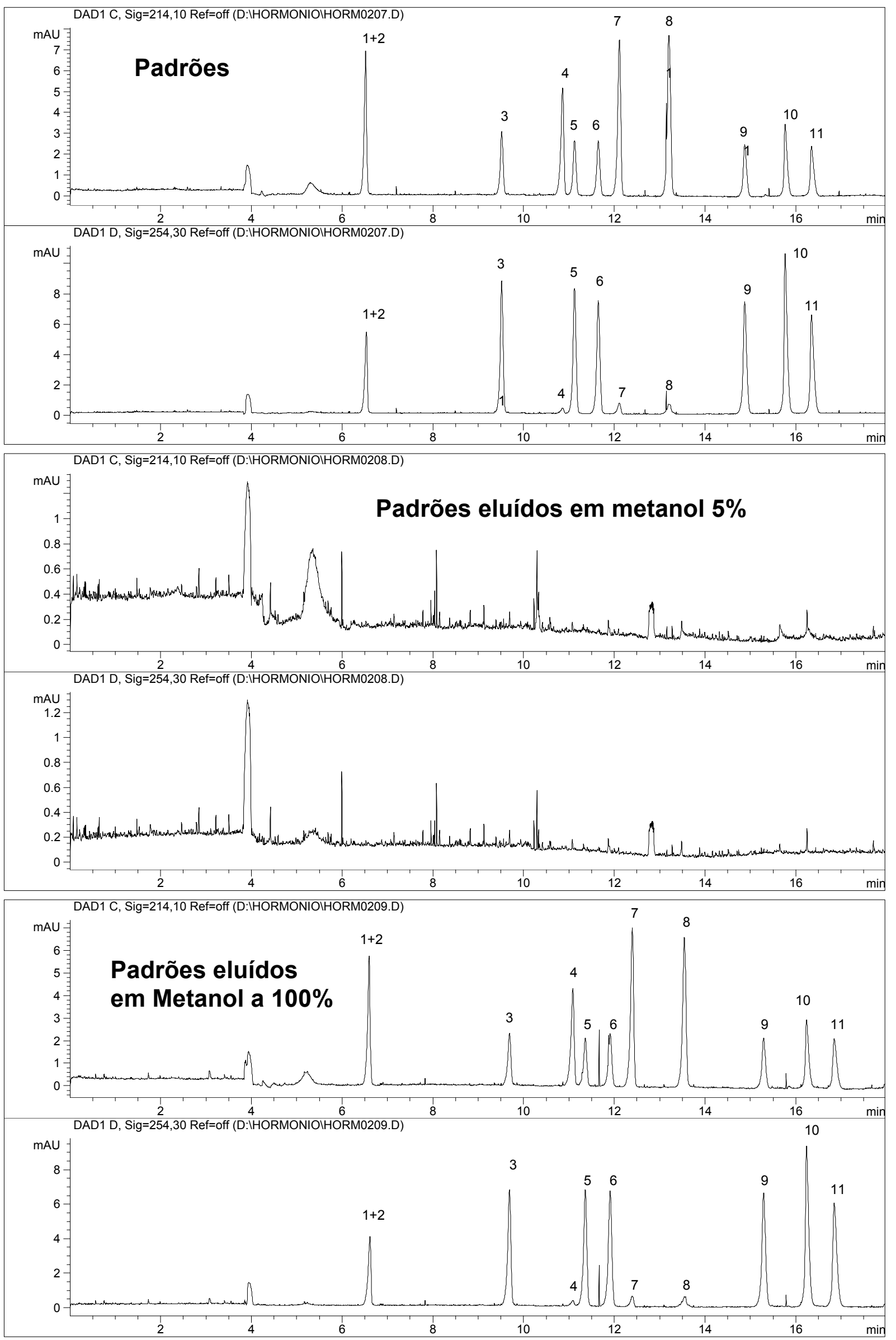
Figura 37 - Resultado do teste de eficência da extração em fase sólida C18. Capilar de $75 \mu \mathrm{m}$ $\mathrm{x} 48,5 \mathrm{~cm}$ comprimento total $\left(40 \mathrm{~cm}\right.$ até o detector). Eletrólito $30 \mathrm{mmol} \mathrm{L} \mathrm{L}^{-1} \mathrm{SDS}$ contendo $10 \mathrm{mmol}$ $\mathrm{L}^{-1}$ de tetraborato de sódio, $10 \%$ acetonitrila e $10 \%$ de etanol, $\mathrm{pH}$ 9,2; tensão: $20 \mathrm{kV}$; injeção: $3 \mathrm{~s} \mathrm{x}$ 50 mbar; temperatura: $22^{\circ} \mathrm{C}$.

Os eletroferogramas evidenciam a eficiência da coluna C-18, o eluído com metanol a 5\% não apresenta sequer traços dos hormônios e o eluído com metanol a 100\% se aproxima muito do eletroferograma dos padrões.

À partir destes resultados montou-se a experimentação com as amostras branca e dopada, seguindo o protocolo de extração em acetonitrila e ressuspensão em $500 \mu \mathrm{L}$ de Metanol e $1.500 \mu \mathrm{L}$ de água deionizada. O resultado é apresentado na figura 38. 

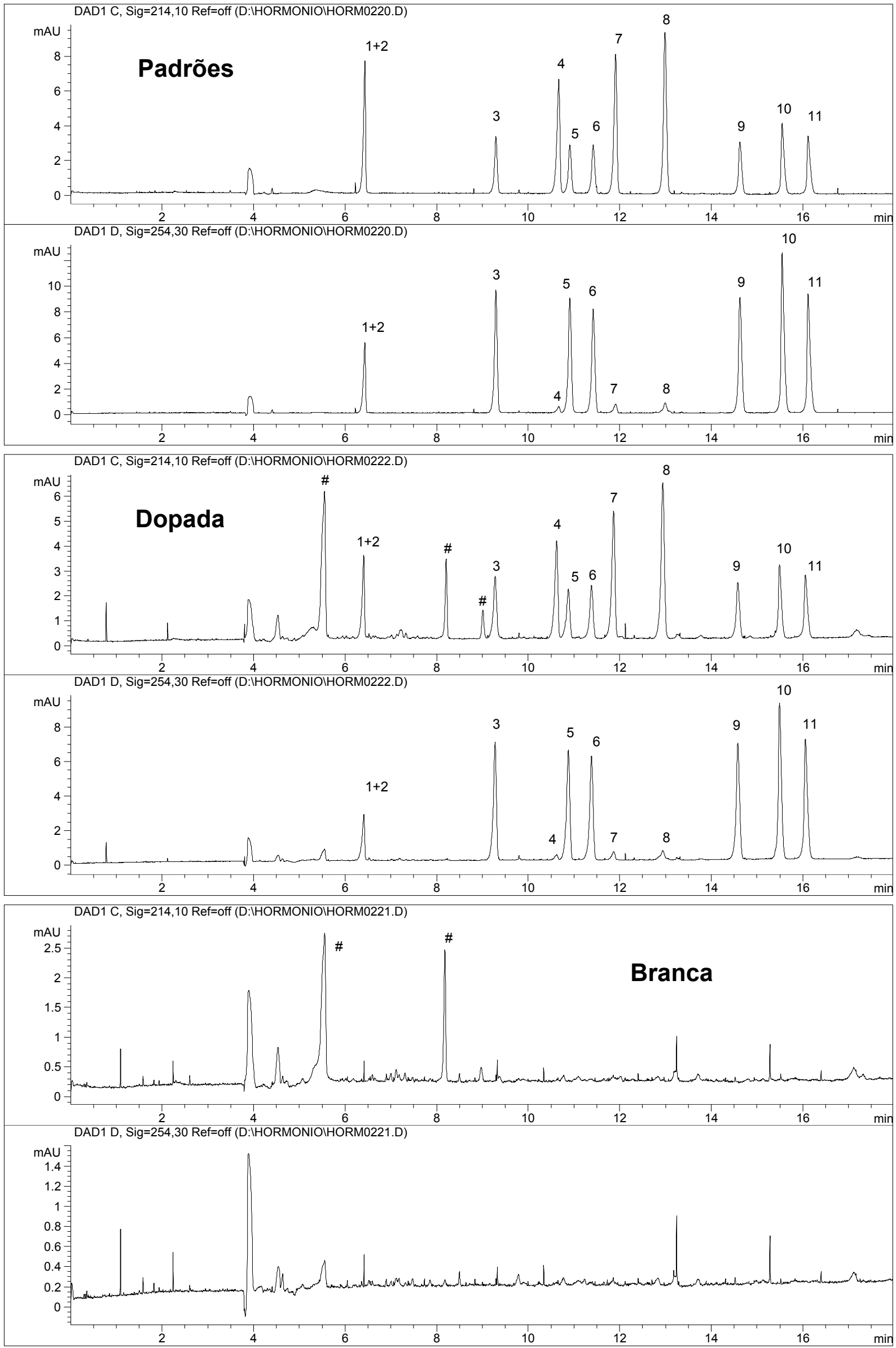
Figura 38 - Resultado da extração em fase sólida C-18, extração em acetonitrila e ressuspensão em $500 \mu \mathrm{L}$ de metanol e $1.500 \mu \mathrm{L}$ de água deionizada. Capilar de 75 $\mu \mathrm{m} \times 48,5 \mathrm{~cm}$ comprimento total (40 $\mathrm{cm}$ até o detector). Eletrólito $30 \mathrm{mmol} \mathrm{L}{ }^{-1} \mathrm{SDS}$ contendo 10 mmol L $\mathrm{L}^{-1}$ de tetraborato de sódio, $10 \%$ acetonitrila e $10 \%$ de etanol, $\mathrm{pH} 9,2$; tensão: $20 \mathrm{kV}$; injeção: $3 \mathrm{~s} \mathrm{x} 50$ mbar; temperatura: $22^{\circ} \mathrm{C}$.

Observa-se claramente nos eletroferogramas que houve uma melhora considerável na eficiência do método, mas optou-se por mais uma experimentação ressolubilizando um extrato seco da mesma amostra utilizada anteriormente num volume menor de solvente: $125 \mu \mathrm{L}$ de Metanol e $375 \mu \mathrm{L}$ de água deionizada e obtivemos o eletroferograma apresentado na figura 39.

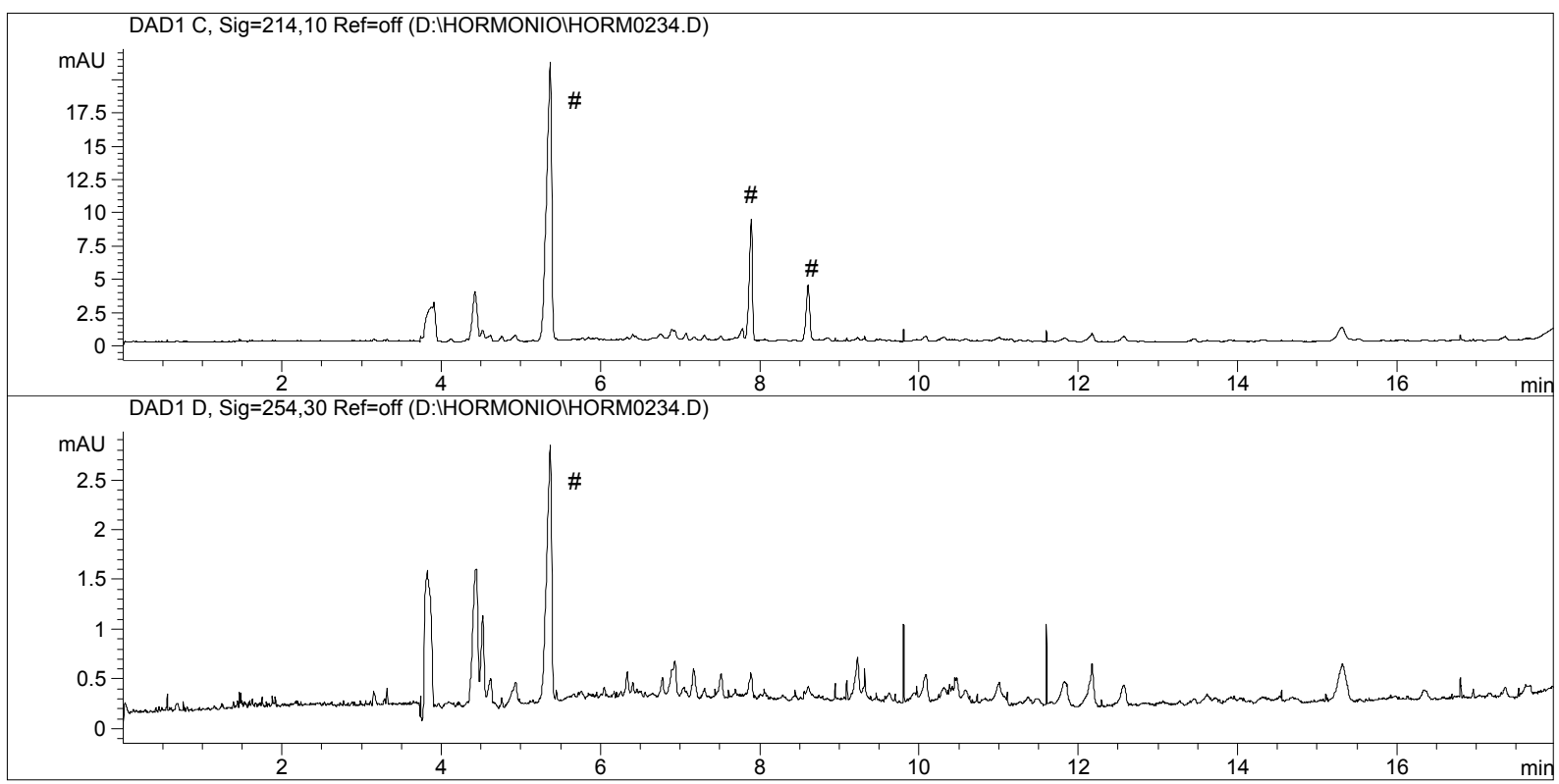

Figura 39 - Resultado da extração em fase sólida C-18, extração em acetonitrila e ressuspensão em $125 \mu \mathrm{L}$ de metanol e $375 \mu \mathrm{L}$ de água deionizada. Capilar de 75 $\mu \mathrm{m} \times 48,5 \mathrm{~cm}$ comprimento total $\left(40 \mathrm{~cm}\right.$ até o detector). Eletrólito $30 \mathrm{mmol} \mathrm{L}{ }^{-1} \mathrm{SDS}$ contendo 10 mmol L $\mathrm{L}^{-1}$ de tetraborato de sódio, $10 \%$ acetonitrila e $10 \%$ de etanol, $\mathrm{pH} 9,2$; tensão: $20 \mathrm{kV}$; injeção: $3 \mathrm{~s} \mathrm{x} 50$ mbar; temperatura: $22^{\circ} \mathrm{C}$.

Com base nestes resultados foi desenvolvido o último protocolo apresentado na seção de material e métodos, o protocolo 7. Devido à melhora na resolução do eletroferograma por diminuição da concentração de solvente na fase de dissolução do extrato seco optamos por testar se o aumento na quantidade de amostra (de $0,2 \mathrm{~g}$ para $2,0 \mathrm{~g}$ ) influenciaria o resultado final da separação. Os resultados são apresentados na figura 40. 

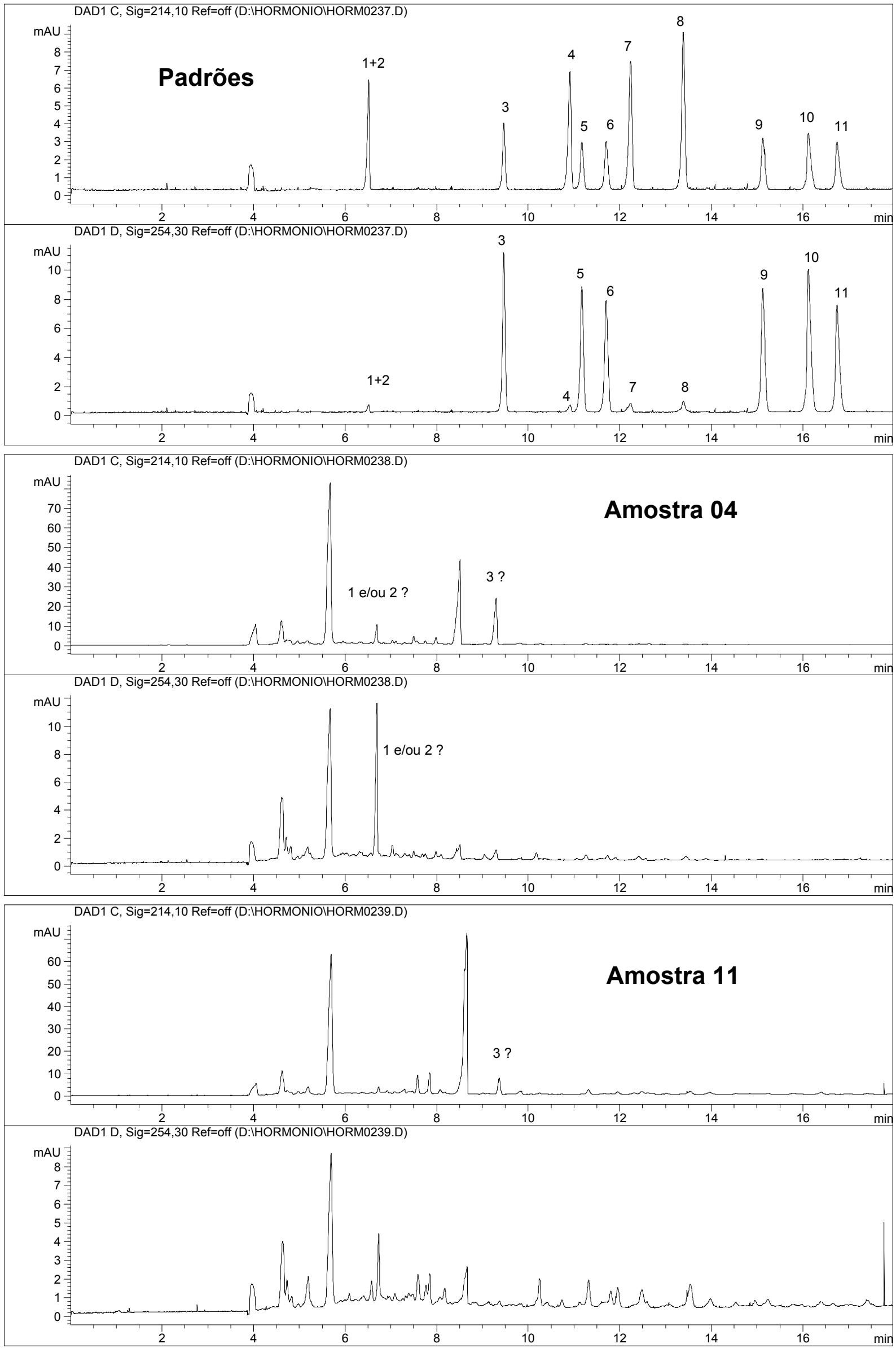
Figura 40 - Resultado da extração em fase sólida C-18, extração em acetonitrilaà partir de $2,0 \mathrm{~g}$ de fezes liofilizadas e ressuspensão em $125 \mu \mathrm{L}$ de metanol e $375 \mu \mathrm{L}$ de água deionizada. Capilar de $75 \mu \mathrm{m} \times 48,5 \mathrm{~cm}$ comprimento total ( $40 \mathrm{~cm}$ até o detector). Eletrólito 30 mmol L ${ }^{-1}$ SDS contendo $10 \mathrm{mmol} \mathrm{L}^{-1}$ de tetraborato de sódio, $10 \%$ acetonitrila e $10 \%$ de etanol, pH 9,2; tensão: $20 \mathrm{kV}$; injeção: $3 \mathrm{~s} \mathrm{x} 50$ mbar; temperatura: $22^{\circ} \mathrm{C}$.

$\mathrm{O}$ aumento na quantidade de amostra e a ressuspensão em um volume menor de solvente contribuíram sobremaneira na eficiência do método. As amostras analisadas com este protocolo tinham um intervalo de um mês entre as coletas e o resultado apresentado nos eletroferogramas demonstram claramente variação nas concentrações dos hormônios em relação ao tempo. Não se pode afirmar com exatidão quais são os hormônios expressos nas análises, para tal mais padrões de esteróides fazem-se necessários ou análise por espectrometria de massas. No entanto, a variação entre as amostras 04 e 11 quando comparadas aos resultados obtidos por Viau (2003) através de radioimunoensaio (Figura 41) confirmam a história clínica do animal do qual as amostras foram coletadas, um animal vindo de vida-livre, com idade estimada na época das coletas em torno de 10 anos e que não respondeu ao protocolo de indução de ovulação muito provavelmente por estar entrando em declínio na vida reprodutiva.

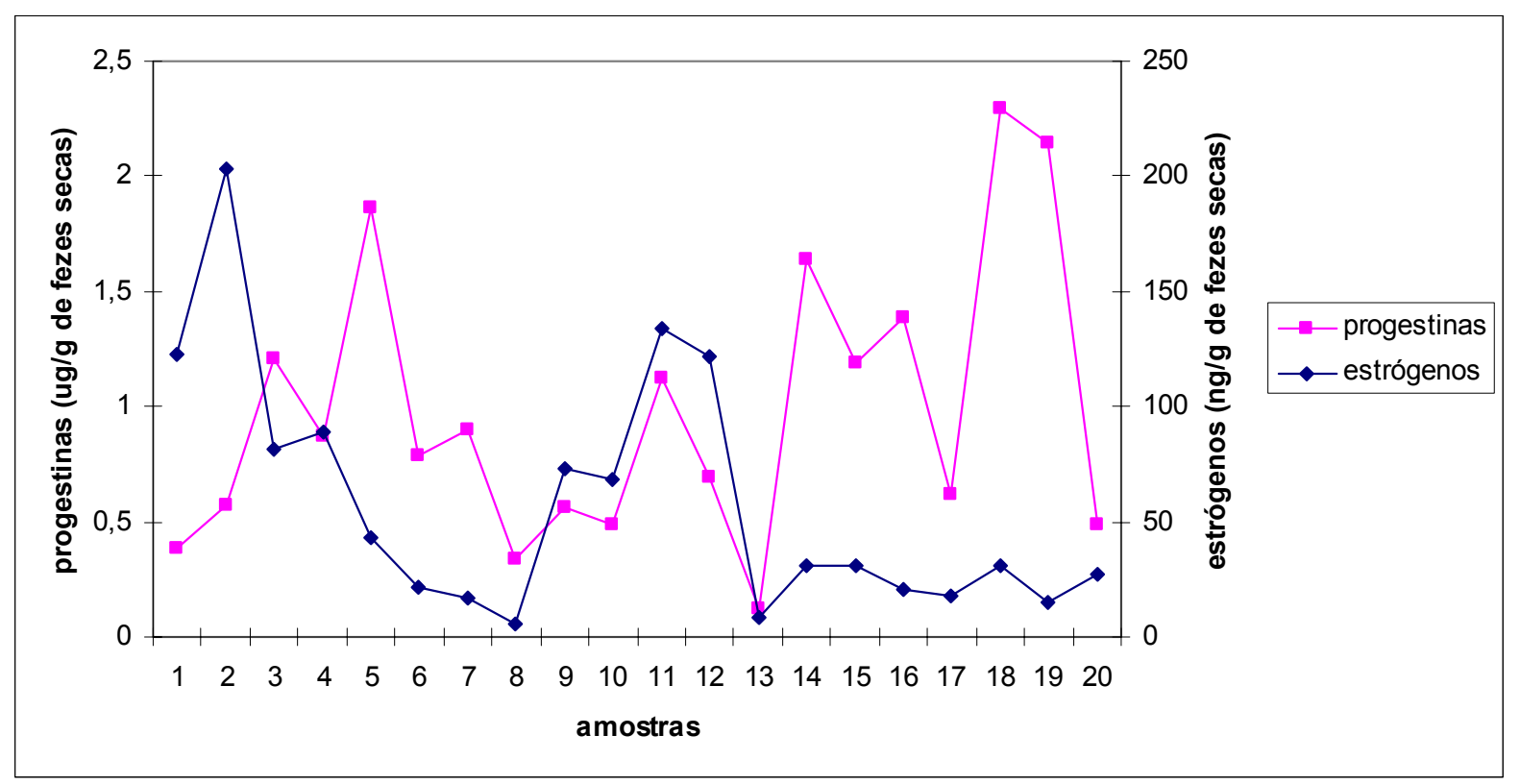

Figura 41 - Representação gráfica das concentrações de estrógenos e progestinas fecais obtidas por radioimunoensaio. 


\subsection{VALIDAÇÃO DO MÉTODO}

O método foi validado para estriol, estrona, testosterona, estradiol e progesterona.

\subsubsection{Precisão}

A repetibilidade do método proposto em relação ao tempo de migração e área dos picos foi determinada quanto ao desvio padrão relativo (RSD) para dez consecutivas injeções da mistura padrão contendo $20 \mu \mathrm{g} \mathrm{mL}^{-1}$ de cada hormônio e $5 \mu \mathrm{g} \mathrm{mL}^{-1}$ dos padrões internos. A tabela 7 apresenta os resultados obtidos. Os desvios padrão relativos foram inferiores a 0,55 \% para o tempo de migração e 1,79\% para a área relativa dos picos.

Tabela 7 - Performance do método analítico em relação à precisão.

\begin{tabular}{|l|l|l|l|}
\hline Hormônio & $\begin{array}{l}\text { Tempo de migração } \\
\text { (min) }\end{array}$ & $\begin{array}{l}\text { Tempo de } \\
\text { migração } \\
\text { RSD (\%) }\end{array}$ & $\begin{array}{l}\text { Área relativa } \\
\text { do pico } \\
\text { RSD (\%) }\end{array}$ \\
\hline Estriol & 6,82 & 0,51 & 1,70 \\
Estrona & 11,7 & 0,17 & 1,77 \\
Testosterona & 11,9 & 0,42 & 1,79 \\
Estradiol & 13,2 & 0,39 & 1,79 \\
Progesterona & 17,4 & 0,30 & 0,94 \\
\hline
\end{tabular}

$\mathrm{RSD}=$ desvio padrão relativo $(\mathrm{n}=10)$

Para avaliar a precisão do método desenvolvido, foram empregadas amostras de fezes dopadas com as respectivas soluções padrão dos hormônios estudados. A precisão intraensaios foi determinada em três níveis de concentração (baixa, média e alta), três repetições realizadas no mesmo dia. Os resultados obtidos para os experimentos de precisão estão sumarizados na tabela 8 . 
Tabela 8 - Precisão intraensaios

\begin{tabular}{|c|c|c|}
\hline Hormônio & $\begin{array}{l}\text { Concentração } \\
\mu \mathrm{g} \mathrm{mL}^{-1}\end{array}$ & $\begin{array}{l}\text { Intra-ensaios } \\
\text { RSD (\%) }\end{array}$ \\
\hline \multirow[t]{3}{*}{ Estriol } & 5,00 & 2,22 \\
\hline & 10,0 & 1,09 \\
\hline & 20,0 & 1,78 \\
\hline \multirow[t]{3}{*}{ Estrona } & 5,00 & 2,66 \\
\hline & 10,0 & 2,10 \\
\hline & 20,0 & 1,94 \\
\hline \multirow[t]{3}{*}{ Testosterona } & 5,00 & 1,38 \\
\hline & 10,0 & 1,98 \\
\hline & 20,0 & 1,56 \\
\hline \multirow[t]{3}{*}{ Estradiol } & 5,00 & 0,84 \\
\hline & 10,0 & 0,95 \\
\hline & 20,0 & 1,38 \\
\hline \multirow[t]{3}{*}{ Progesterona } & 5,00 & 0,83 \\
\hline & 10,0 & 0,88 \\
\hline & 20,0 & 1,29 \\
\hline
\end{tabular}

$\mathrm{RSD}=$ desvio padrão relativo $(\mathrm{n}=3)$

\subsubsection{Linearidade e Sensibilidade}

Para a construção das curvas de calibração foram utilizadas soluções padrão dos hormônios. As curvas analíticas e os limites de detecção estão apresentados na tabela 9. Os resultados mostraram boa linearidade $(r>0,998)$ na faixa de concentração estudada. Os limites de detecção e quantificação foram calculados com base na razão sinal/ruído 3:1 e 10:1, respectivamente.

Tabela 9 - Parâmetros estatísticos das curvas de calibração·

\begin{tabular}{|l|l|l|l|l|}
\hline Hormônio & Curva analítica & $\mathbf{R}$ & $\begin{array}{l}\text { Limite de } \\
\text { Detecção }_{\mathbf{b}} \\
\left(\mu \mathbf{g} \mathbf{~ m L}^{-\mathbf{1}}\right)\end{array}$ & $\begin{array}{l}\text { Limite } \\
\mathbf{Q u a n t i f i c a c ̧ a ̃ o c ~}^{\mathbf{c}} \\
\left(\mu \mathbf{g} \mathbf{~ m L}^{-\mathbf{1}}\right)\end{array}$ \\
\hline Estriol & $\mathrm{Y}=0,849 \mathrm{X}-0,484$ & 0,9999 & 0,46 & 1,53 \\
Estrona & $\mathrm{Y}=1,34 \mathrm{X}-0,386$ & 0,9988 & 0,30 & 1,0 \\
Testosterona & $\mathrm{Y}=1,78 \mathrm{X}+1,48$ & 0,9990 & 0,21 & 0,70 \\
Estradiol & $\mathrm{Y}=1,44 \mathrm{X}+0,634$ & 0,9998 & 0,21 & 0,70 \\
Progesterona & $\mathrm{Y}=2,03 \mathrm{X}+2,99$ & 0,9993 & 0,21 & 0,70 \\
\hline
\end{tabular}

${ }^{a}$ faixa de concentração $2,5-20 \mu \mathrm{g} \mathrm{m} \mathrm{L}^{-1}$; baseado na área relativa dos picos. ${ }^{\mathrm{b}} \mathrm{S} / \mathrm{N}=3{ }^{\mathrm{c}} \mathrm{S} / \mathrm{N}=10$ 


\subsubsection{Exatidão}

A exatidão do método foi calculada como porcentagem de recuperação de uma quantidade conhecida de analito adicionada à amostra. Na tabela 10 pode ser observado que os valores da recuperação média foram de 81,2 a 96,9\%.

Tabela 10 - Ensaios de recuperação.

\begin{tabular}{|c|c|c|c|}
\hline Hormônio & $\begin{array}{l}\text { Adicionado } \\
\mu \mathrm{g} \mathrm{mL}\end{array}$ & $\begin{array}{l}\text { Encontrado } \\
\mu \mathrm{g} \mathrm{mL}^{-1}\end{array}$ & \begin{tabular}{|l} 
Recuperação \\
$(\%)$
\end{tabular} \\
\hline Estriol & $\begin{array}{l}5,00 \\
10,0 \\
20,0\end{array}$ & $\begin{array}{r}4,06 \\
8,55 \\
17,3\end{array}$ & $\begin{array}{l}81,2 \\
85,5 \\
86,3\end{array}$ \\
\hline Estrona & $\begin{array}{l}5,00 \\
10,0 \\
20,0\end{array}$ & $\begin{array}{l}4,81 \\
9,64 \\
19,4\end{array}$ & $\begin{array}{l}96,1 \\
96,4 \\
96,9\end{array}$ \\
\hline Testosterona & $\begin{array}{l}5,00 \\
10,0 \\
20,0\end{array}$ & $\begin{array}{l}4,32 \\
8,81 \\
17,7\end{array}$ & $\begin{array}{l}86,3 \\
88,1 \\
88,5\end{array}$ \\
\hline Estradiol & $\begin{array}{l}5,00 \\
10,0 \\
20,0\end{array}$ & $\begin{array}{l}4,66 \\
9,55 \\
19,3\end{array}$ & $\begin{array}{l}93,1 \\
95,5 \\
96,4\end{array}$ \\
\hline Progesterona & $\begin{array}{l}5,00 \\
10,0 \\
20,0\end{array}$ & $\begin{array}{l}4,22 \\
8,56 \\
17,0\end{array}$ & $\begin{array}{l}84,3 \\
85,6 \\
85,1\end{array}$ \\
\hline
\end{tabular}

À partir deste mesmo protocolo de extração foi feita uma análise em HPLC, no qual obtivemos o cromatograma apresentado na figura 42. 

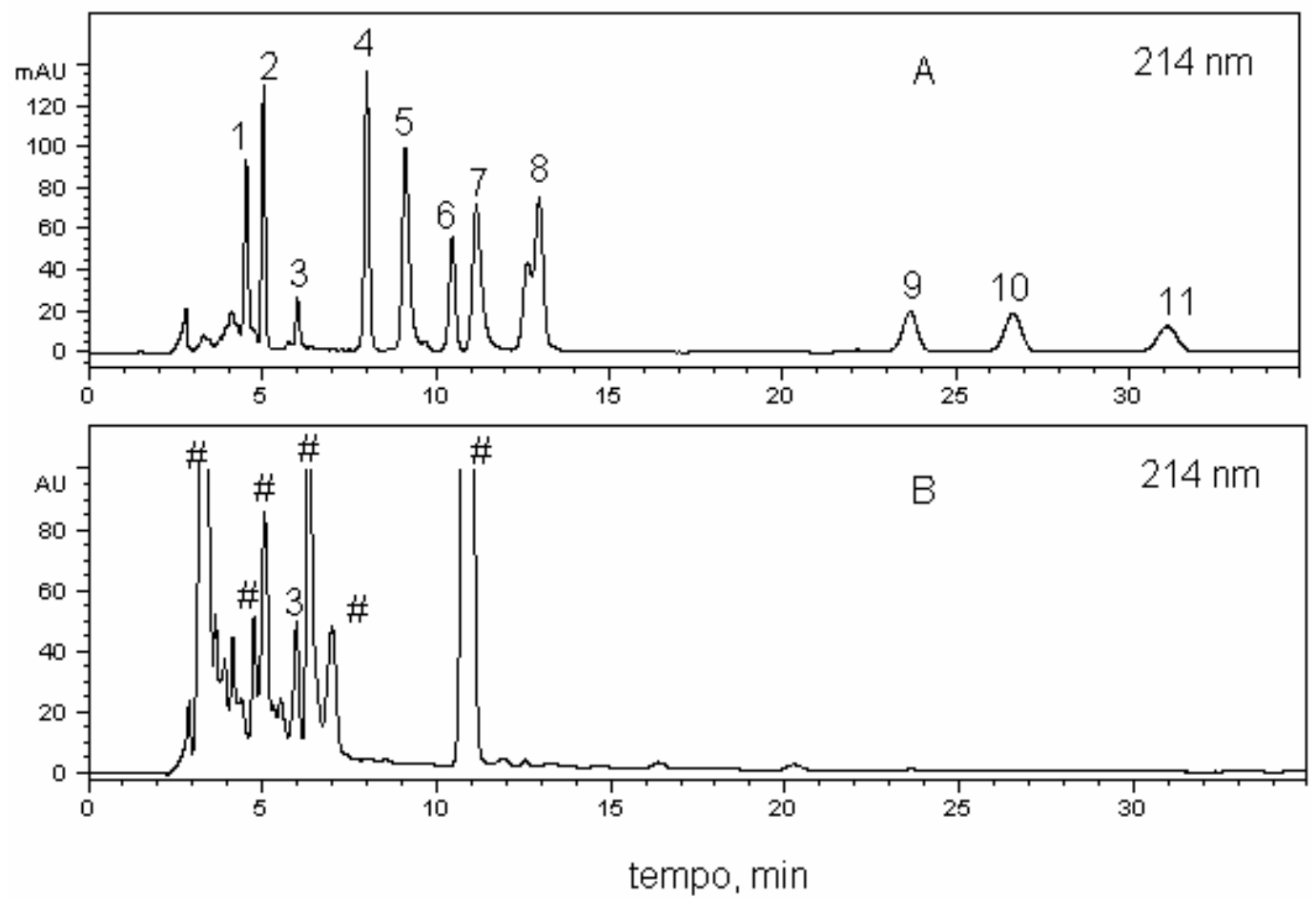

Figura 42 - Cromatograma dos hormônios analisados por HPLC-DAD, como descrito na seção experimental. A. padrão, B. amostra. Identificação dos picos: 1. estriol, 2. cortisol 3. estrona, 4. $11-\alpha-\mathrm{HP}, 5$. estradiol, 6. testosterona, 7. etinilestradiol, 8. $17-\alpha-$ HP , 9. 21 - $\alpha$ - HP, 10. progesterona, 11. medroxiprogesterona e \# não identificado.

Observa-se claramente um comportamento bastante similar aos experimentos desenvolvidos utilizando a MECK. O cromatograma indica a possível presença de estrona na amostra, o que só poderia ser confirmado por espectrometria de massas acoplada a eletroforese capilar ou cromatografia líquida.

A cromatografia líquida de alta performance é uma técnica bem estabelecida nos meios científicos, no âmbito de estudos por métodos não-invasivos é utilizada como técnica de apoio às técnicas imunométricas, permitindo a separação dos principais compostos para direcionar a escolha dos anticorpos para posterior quantificação por radioimunoensaio (RIA), enzimaimunoensaio (EIA) ou imunoadsorção enzimática (ELISA), mas, provavelmente por motivos econômicos e de operação, esta técnica não se estabeleceu como técnica de rotina, pelo menos no que se diz respeito à realidade da grande maioria das instituições de pesquisa com animais selvagens. 
CONCLUSÕES 


\section{CONCLUSÕES}

A análise por cromatografia a gás com detecção por ionização em chama mostrou-se inadequada devido ao moroso processo de tratamento do material a ser utilizado para a derivatização e a sensibilidade da reação de derivatização a umidade.

O protocolo de extração em acetonitrila foi satisfatório como pré-tratamento da amostra e aliado à extração em fase sólida em C-18 apresentou bons resultados no que diz respeito à sensibilidade, precisão, recuperação e tempo de análise.

Com base nos resultados obtidos, a metodologia de análise por eletrocromatografia micelar proposta pode ser considerada uma ótima alternativa para a análise de hormônios esteróides em amostras fecais, comprovando a eficiência da eletroforese capilar como técnica analítica no estudo dos metabólitos de esteróides sexuais em fezes, podendo ser utilizada em análises de rotina nos laboratórios de endocrinologia, sobretudo naqueles que se dedicam às metodologias não-invasivas de avaliação da função reprodutiva em animais selvagens.

As análises por eletroforese capilar refletiram o padrão de excreção de metabólitos de esteróides mensurados por radioimunoensaio.

Mais estudos são necessários, principalmente com relação à composição da amostra, análises por espectrometria de massas seriam muito interessantes para solucionar tais questões. 
REFERÊNCIAS 


\section{REFERÊNCIAS}

ADANIA, C. H.; SILVA, J. C. R.; HASHIMOTO, C. Y.; SANTOS, E. F. Studbook dos grandes felinos brasileiros: registro genealógico da onça-pintada (Panthera onca) e suçuarana (Puma concolor) em cativeiro. Jundiaí - SP: Livraria Conceito. 2005. 80 p.

ADLERCREUTZ, H.; MARTIN, F.; PULKKINEN, M.; DENCKER, H.; RIMÉR, U.; SJOBERG, N. O.; TIKKANEN, M. J. Intestinal metabolism of strogens. Journal of Clinical Endocrinology Metabolism, v. 43, n. 3, p. 497-505, 1976.

ALTRIA, K.D. Application of microemulsion electrokinetic chromatography to the analysis of a wide range of pharmaceuticals and excipients. Journal of Chromatography A, v. 844, p. 371-386, 1999.

APPELBLAD, P.; IRGUM, K. Separation and detection of neuroactive steroids from biological matrices. Journal of Chromatography A, v.955, p. 151-182, 2002.

AQUINO NETO, F. R.; NUNES, D. S. S. Cromatografia: princípios básicos e técnicas afins / Francisco Radler de Aquino Neto e Denise da Silva e Souza Nunes. Rio de Janeiro: Interciencia. 2003, 187 p.

ARANDA, M.; SÁNCHEZ-CORDERO, V. Prey spectra of jaguar (Panthera onca) and puma (Puma concolor) in tropical forests of Mexico. Studies of Neotropical Fauna and Environment, v. 31, p. 65-67, 1996.

ARRA, M.A. Distribution of Leo onca (L) in Argentina (Carnivora, Felidae). Neotrópica, v. 20, n. 63 , p. $156-158,1974$

BAKER, D. R. Capillary Electrophoresis. New York: Wiley-Intersciense, 1995, p. 54-73.

BALLARD, W. B.; TOBEY, R. W. Decreased calf production of moose immobilized with anectine administered from helicopter. Wildlife Society Bulletin, v. 9, p. 207-209, 1981.

BAMBERG, E.; CHOI, H. S.; MÖSTL, E.; WURN, W.; LORIN, D.; ARBEITER, K. Enzymatic determination of unconjugated oestrogens in faeces for pregnancy diagnosis in mares. Equine Veterinary Journal, v.16, p. 537-539, 1984. 
BAMBERG, E.; SCHWARZEMBERGER, F. Fecal steroid assay for monitoring estrous cycle and pregnancy. In: IV ${ }^{\text {th }}$ CONGR. INT. SOC. ANIM. CLIN. BIOCHEM., Davis, CA, 1990, p. 95-99.

BAMBERG, E.; MÖSTL, E.; PATZL, M.; KING, G. Pregnancy diagnosis by enzime immunoassay of estrogens in feces from nondomestic species. Journal of Zoo an Wildlife Medicine, v.22, n.1, p.73-77, 1991.

BERGER, J.; TESTA, J. W.; ROFFE, T.; MONFORT, S. L. Conservation endocrinology: a noninvasive tool to understand relationships between carnivore colonization and ecological carrying capacity. Conservation in Practice, v. 13, p. 980-989, 1999.

BOWSER, M. T.; KRANACK, A. R.; CHEN, D. Y. Analyte-additive interactions in capillary electrophoresis: a critical review. Trends in Analytical Chemistry, v. 17, n. 7, p. 424-433, 1998.

BROWN, J. L.; WASSER, S. K.; HOWARD, J.G.; WELLS, S.; LANG, K.; COLLINS, L.; RAPHAEL, B.; SHWARTZ, R.; EVANS, M.; HOYT, R.; VOLK, T.; WILDT, D. E.; GRAHAM, L.H. Development and utility of fecal progesterone analysis to assess reproductive status in felids. In: Proceedings of American Association of Zoo Veterinarians, 1993. 273-276 p.

BROWN, J. L.; WASSER, S. K.; WILDT, D. E.; GRAHAM, L. H. Comparative aspects of steroid hormone metabolism and ovarian activity in felids, measured noninvasively in feces. Biology of Reproduction, v. 51, p. 776-86, 1994.

BROWN, J. L; WILDT, D. E; GRAHAM, L. H; BYERS, A P.; COLLINS, L.; BARRET, S.; HOWARD, J.G. Natural versus chorionic gonadotropin-induced ovarian responses in the clouded leopard (Neofelis nebulosa) assessed by fecal steroid analysis. Biology of Reproduction, v. 53, p. 93-102, 1995.

BROWN, J. L.; TERIO, K. A.; GRAHAM, L. H. Fecal androgen metabolite analysis for non invasive monitoring of testicular steroidogenic activity in felids. Zoo Biology, v. 15, p. 42434, 1996.

BROWN, J. L; WILDT, D. E. Assessing reproductive status in wild felids by noninvasive faecal steroid monitoring. International Zoo Yearbook, v. 35, p. 173-91, 1997.

BROWN, J. L.; SCHMITT, D. L.; BELLEM. A.; GRAHAM, L. H.; LEHNHARDT, J. Hormone secretion in the Asian elephant (Elephas maximus): characterization of ovulatory 
and anovulatory luteinizing hormone surges. Biology of Reproduction, v.61, p. 1294-1299, 1999.

BROWN, J. L. Reproductive endocrine monitoring of elephants: an essential tool for assisting captive management. Zoo Biology, v.19, p. 347-367, 2000.

BROWN, J. L.; GRAHAM, L.H.; WIELEBNOWSKI, N.; SWANSON, W. F.; WILDT, D. E.; HOWARD, J. G. Understanding the basic reproductive biology of wild felids by monitoring of feacal steroids. Journal of Reproduction \& Fertility Supplement, v. 57, p. $71-82,2001$ a.

BROWN, J. L.; BELLEM, A. C.; FOURAKER, M.; WILDT, D. E.; ROTH, T. L. Comparative analysis of gonadal and adrenal activity in the black and white rhinoceros in North America by non-invasive endocrine monitoring. Zoo Biology, v. 20, p. 463-486, 2001 b.

BUSSO, J. M.; PONZIO, M. F.; DABBENE, V.; CUNEO, M. F.; RUIZ, R. D. Assessment of urine and fecal testosterone metabolite excretion in Chinchilla lanigera males. Animal Reproduction Science, v. 86, p. 339-351, 2005.

CARMAN, R.L. Southern limit of the distribution of the jaguar (Leo onca) in the 18th-19th centuries. Revista del Museo Argentino de Ciencias Naturales "Bernardino Rivadavia" (Zoologia), v. 13, n. 1-60, p. 293-296, 1984.

CHAKRABORTY, R.; CHAKRABORTY, S. Identification of dorsal guard hairs of Indian species of genus Panthera Oken (Carnivora: Felidae). Mammalia, v. 60, n. 3, p. 473-480, 1996.

CITES - CONVENTION ON INTERNATIONAL TRADE IN ENDANGERED SPECIES OF WILD FAUNA AND FLORA. Tenth Conference of the Parties. 1997. Harare, Zimbabwe June. P. 9-20.

CLARKE, I.J.; DOUGHTON, B.W. Effect of various anaesthetics on resting plasma concentrations of luteinizing hormone, follicle-stimulating hormone and prolactin in ovariectomized ewes. Journal of Endocrinology, v. 98, p. 79-89, 1983.

COCKREM, J. F. Conservation and behavioural neuroendocrinology. Hormones and Behaviour, v. 48, p. 492-501, 2005. 
CREEL, S. R.; CREEL, N. M.; WILDT, D. E.; MONFORT, S. L. Behavioral and endocrine mechanism of reproductive suppression in Serengeti dwarf mongooses. Animal Behaviour, v. 43, p. 231-245, 1992.

CREEL, S. R.; CREEL, N. M.; MILLS, M. G.; MONFORT, S. L. Rank and reproduction in cooperatively breeding African wild dogs: behavioral and endocrine correlates. Behavioral Ecology, v. 8, p. 298-306, 1997.

CZEKALA, N. M.; CALLISON, L. Pregnancy diagnosis in the black rhinoceros (Diceros bicornis) by salivary hormone analysis. Zoo Biology, v. 15, p. 37-44, 1996.

CZEKALA, N.M.; DURRANT, B.S.; CALLISON, L.; WILLIAMS, M..; MILLARD, S. Fecal steroid hormone analysis as an indicator of reproductive function in the cheetah. Zoo Biology, v. 13, p. 119-128, 1994.

DEHNHARD, M.; SCHREER, A.; KRONE, Q.; JEWGENOW, K.; KRAUSE, M.; GROSSMANN, R. Measurement of plasma corticosterone and fecal glucocorticoid metabolites in the chicken (Gallus domesticus), the great cormorant (Phalacrocorax carbo), and the goshawk (Accipiter gentilis). General and Comparative Endocrinology, v. 131, p. 345-352, 2003.

DITTRICH, L. Die verebung des melanismus beim jaguar (Panthera onca). Heredity of melanism in jaguars. Zoologistic Garten, v.49, p.9-23, 1979.

DLONIAK, S. M.; FRENCH, J. A.; PLACE, N. J.; WELDELE, M. I.; GLICKMAN, S..; HOLEKAMP. K. E. Non-invasive monitoring of fecal androgens in spotted hyenas (Crocuta crocutta). General and Comparative Endocrinology, v. 135, p. 51-61, 2004.

DRAISCI, R.; PALLESHI, L.; FERRETTI, E.; MARCHIAFAVA, C.; LUCENTINI, L.; CAMMARATA, P. Quantification of 17beta-oestradiol residues in bovine serum by liquid chromatography-tandem mass spectrometry with atmospheric-pressure chemical ionization. Analyst, v. 123, p. 2605-2609, 1998.

EATON, R. L. Why some felids copulate so much: a model for the evolution of copulation frequency. Carnivore, v.1, n.42-51. 1978.

EMMONS, L. H. Neotropical rainforest mammals: a field guide. Chicago: The University of Chicago Press. 1990. 218 p. 
FACURE, K.G.; GIARETTA, A.A. Food habits of carnivores in a coastal Atlantic Forest of southeastern Brazil. Mammalia, v. 60, n. 3, p. 499-502, 1996.

FELDMAN, E. C.; NELSON, R. W. Feline Reproduction. In: (Ed.). Canine and Feline Endocrinology and Reproduction. Philadelphia: W. B. Saunders Co, 1996. p.785

FOWLIS, I. A. Gas chromatography : analytical chemistry by open learning. Chichester, New York: Published on Behalf of ACOL (University of Greenwich) by Wiley, 1995. 258 p.

FRIEDEN, E.; LIPNER, H. Endocrinologia Bioquímica dos Vertebrados. São Paulo: Editora da Universidade de São Paulo. 1975. 131 p.

FULLER, G. B.; HOBSON, W.; REVES, F.L.; WINTER, J.S.D.; FAIMAN, C. Influence of restraint and ketamine anaesthesia on adrenal steroids and gonadotropins in rhesus monkeys. Proceedings of the Society for Experimental Biology and Medicine, 1984. 487-490 p.

GARNIERA, J. N.; GREEN, D. I.; PICKARD, A. R.; SHAW, H. J.; HOLT, W. V. Noninvasive diagnosis of pregnancy in wild black rhinoceros (Diceros bicornis minor) by fecal steroid analysis. Reproduction, Fertility and Development, v. 10, p. 451-468, 1998.

GARROTT, R. A.; MONFORT, S.L.; WHITE, P.J.; MASHBURN, K.L.; COOK, J.G. Onesample pregnancy diagnosis in elk using fecal steroid metabolites. Journal of Wildlife Disease, v. 34, n. 1, p. 126-131, 1998.

GONYEA, W.J. Adaptive differences in the body proportions of large felids. Acta Anatomica. v. 96, p. 81-96, 1976.

GOYMANN, W.; MÖSTL, E.; GWINNER, E. Non-invasive methodos to measure androgen metabolites in excements of european stonechats, Saxicola torquata rubicola. General and Comparative Endocrinology, v. 129, p. 80-87, 2002.

GRAHAM, L.H.; RAESIDE, J. I.; GOODROWE, K.L.; LIPTRAP, R.M. Measurements of faecal oestradiol and progesterone in non-pregnant and pregnant domestic and exotic cats. Journal of Reproduction \& Fertility Supplement, v. 47, p. 119-120, 1993.

GRAHAM, L. H.; GOODROWE, K.L.; RAESIDE, J. I.; LIPTRAP, R.M. Non-invasive monitoring of ovarian function in several felid species by measurement of fecal estradiol 17beta and progestins. Zoo Biology, v. 14, n. 3, p.223-237, 1995. 
GRAHAM, L. H.; BROWN, J. L. Cortisol metabolism in the domestic cat and implications for non-invasive monitoring of adrenocortical function in endangered felids. Zoo Biology, v. 15, p. 71-82, 1996.

GRAHAM, L. H.; BROWN, J. L. Non-invasive assessment of gonadal and adrenocortical function in felid species via faecal steroid analysis. In: International Symposium on Physiologic an Ethology of Wild and Zoo Animals, 1, 1997, Berlim, Germany. Anais... p.7882.

GROSS, T. S. Development and use of faecal steroid analysis in several carnivore species. In: INTERNATIONAL SYMPOSIUM ON FAECAL STEROID MONITORING IN ZOO ANIMALS. 1992, 1, ROYAL ROTTERDAM ZOOLOGICAL AND BOTANICAL GARDENS. Anais... p. 55-61.

GÜBITZ, G.; SCHMID, M. G., Recent progress in chiral separation principles in capillary electrophoresis. Electrophoresis, v. 21, p. 4112-4135, 2000.

GUIÃO-LEITE, F. L. Análise morfológica do testículo e do processo espermatogênico da onça-parda (Puma concolor, Wozencraft, 1993) Adulta. 2002. 64p.(Mestrado). Faculdade de Medicina Veterinária, Universidade Federal de Viçosa, Viçosa-MG.

GUIMARÃES, M.A.B.V. A aplicação de técnicas em reprodução assistida em animais silvestres mantidos em cativeiro. Revista Brasileira de Reprodução Animal, v. 25, n. 2, 2001.

HEISTERMANN, M.; TARI, S.; HODGES, J.K., Measurements of faecal steroids for monitoring ovarian function in New World primates, Callitrichidae. Journal of Reproduction \& Fertility, v. 99, p. 243-251, 1993.

HEISTERMANN, M.; AGIL, M.; BUTHE, A.; HODGES, J.K. Metabolism and excretion of oestradiol-17b and progesterone in the sumatran rhinoceros (Dicerorhinus sumatrensis). Animal Reproduction Science, v. 53, p. 157-172, 1998.

HILTON-TAYLOR, C. (compiler) 2000. 2000 IUCN Red List of Threatened Species. IUCN, Gland, Switzerland and Cambridge, UK. xviii + 61pp. Downloaded on 27 August 2002. http://www.redlist.org/search/details.php?species $=15953$

HINDLE, J.E.; HODGES, J.K. Metabolism of oestradiol-17 $\beta$ and progesterone in the white rhinoceros (Ceratotherium simum simum). Journal of Reproduction \& Fertility, v. 90, p. 571-580, 1990. 
HIRSCHENHAUSER, K.; MOSTL, E.; KOTRSCHAL, K. Seasonal patterns of sex steroids determined from feces in different social categories of greylag geese (Anser anser). General and Comparative Endocrinology, v. 114, p. 67-79, 1999.

HODGES, J. K.; CZEKALA, N. M.; LASLEY, B. L. Estrogen and luteinizing hormone secretion in diverse primate species from simplified urinary analysis. Journal of Medical Primatology, v. 8, p. 349-364, 1979.

HOPPEN, H.O.; DIAZ DE AGUIRRE, L.; HAGENBECK, D.; BOER, M.; SCHWARZENBERGER, F. Progesterone metabolitesin elephant faeces. In: PROCEEDINGS INTERNATIONAL SYMPOSIUM ON FAECAL STEROID MONITORING IN ZOO ANIMALS, 1992, 1., ROYAL ROTTERDAM ZOOLOGICAL AND BOTANICAL GARDENS. Anais... p. 51-54.

HOWARD, J. G.; BARONE, M. A.; DONOGHUE, A. M.; WILDT, D. E. The effect of preovulatory anaesthesia on ovulation in laparoscopically inseminated domestic cats. Journal of Reproduction \& Fertility, v. 96, p. 175-186, 1992.

HUBER, S.; PALME, R.; ARNOLD, W. Effects of season, sex, and sample collection on concentrations of fecal cortisol metabolites in red deer (Cervus elaphus). General and Comparative Endocrinology, v. 130, p. 48-54, 2003.

IUCN. 1982. IUCN directory of neotropical protected areas. Tycooly, Dublin.

JI, A. J.; NUNEZ, M. F.; MACHACEK, D.; FERGUSON, J. E.; IOSSI, M. F.; KAO, P. C.; LANDERS, J. P. Separation of urinary estrogens by micellar electrokinetic chromatography. Journal of Chromatography B, v. 669, p. 15-26, 1995.

JOHNSON, L. M.; GAY, V. L. Luteinizing hormone in the cat. I. Tonic secretion. Endocrinology, v. 109, p. 240-246, 1981.

JOHNSON, W. E.; O'BRIEN, S. J. Phylogenetic reconstruction of the Felidae using 165 rRNA and NADH-5 mitochondrial genes. Journal of Molecular Evolution, v. 44, p. 98-116, 1997.

JONES, W. R.; JANDIK, P. Controlled changes of selectivity in the separation of ions by capillary electrophoresis Journal of Chromatography, v. 546, p. 445-458, 1991. 
KERSEY, D. C.; BROWN, J. L.; CZEKALA, N. M.; MONFORT, S. L. Fecal steroide monitoring to study the reproductive biology of the endagered giant panda (Ailuropoda melanoleuca). Biology of Reproduction, v.68, p. 125, 2003, Supplement 01.

KHALED, M. Micelles as separation media in high-performance liquid chromatography and high-oerformance capillary electrophoresis: overview and perspective. Journal of Chromatography A, v 780, p. 03-40, 1997.

KIRKPATRICK, J.F.; BAKER, C.B.; TURNER Jr, J.W.; KENNEY, R.M.; GANJAM, V.K. Plasma corticosteroids as an index of stress in captive feral horses. Journal of Wildlife Management v. 43, p. 801-804, 1979.

KIRKPATRIC, J.F.; SHIDELER, S.E.; LASLEY, B.L.; TURNER, J.W.; CZEKALA, N.M. Field application of faecal steroid monitoring to free-ranging wildlife. In: PROCEEDINGS INTERNATIONAL SYMPOSIUM ON FAECAL STEROID MONITORING IN ZOO ANIMALS, 1992, 1., ROYAL ROTTERDAM ZOOLOGICAL AND BOTANICAL GARDENS. Anais... p. 25-33.

LANÇAS, F. M. Extração em Fase Sólida (SPE). São Carlos-SP: RiMa. 2004. 93 p.

LARSEN, D.G.; GAUTHIER, D.A. Effects of capturing pregnant moose and calves on calf survivorship. Journal of Wildlife Management v. 53, p. 564-567, 1989.

LASLEY, B.L.; KIRKPATRIC, J.F. Monitoring ovarian function in captive and free-ranging wildlife by means of urinary and fecal steroids. Journal of Zoo Wildlife Medicine v. 22, p. 23-31, 1991.

LASLEY, B.L.; LOSKUTOFF, N.M.; ANDERSON, G.B. The limitation of conventional breeding programs and the need and promise of assisted reproduction in nondomestic species. Theriogenology, v. 41, p. 119-132, 1994.

LEITE, M. R. P.; BOULHOSA, R. L. P.; GALVÃO, F.; CULLEN JR, L. Conservación del jaguar en las áreas protegidas del bosque atlántico de la costa de Brasil. In:. MEDELLÍN, R. A, EQUIHUA, C., CHETKIWICZ, C. L. B., CRAWSHAW JR, P. G., RABINOWITZ, A., REDFORD, K. H., ROBINSON, J. G., SANDERSON, E. W., TABER, A. (Ed.). Mexico: Fondo de Cultura Económica, Universidad Nacional Autónoma de Mexico, Wildlife Conservation Society, 2002, p. 648.

LIMA, E. C. Determinação de opióides em cabelo via eletroforese capilar (CE). 2003. 167 p. Tese (Doutorado). Instituto de Química, Universidade de São Paulo, São Paulo. 
LINDSAY, S. High performance liquid chromatography. West Sussex, Inglaterra: John Wiley \& Sons. 1992. 337 p.

MELLEN, J. D. Factors influencing reproductive success in small captive exotic felids (Felis spp.): A multiple regression analysis. Zoo Biology, v. 10, p. 98-110, 1991.

MONFORT, S. L.; WEMMER, C.; KEPLER, T. H.; BUSH, M.; BROWN, J. L.; WILDT, D. E. Monitoring ovarian function and pregnancy in the Eld's deer (Cervus eldi) by evaluating urinary steroid metabolite excretion. Journal of Reproduction \& Fertility, v.88, p.271-281. 1990.

MONFORT, S. L. Non-invasive endocrine measures of reproduction and stress in wild populations. In: W. V. HOLT, PICKARD, A. R., RODGER, J. C., WILDT, D. E. (Ed.). Reproductive Science and Integrated Conservation. Cambridge: Cambridge University Press, 2003, p.147-165.

NISHI, H.; TERABE, S. Micellar eletrokinetic chromatography. Perspectives in drug analysis. Journal of Chromatography A, v. 735, p. 03-27, 1996.

NORMAN, A. W.; LITWACK, G. Hormones. San Diego - CA - USA: Academic Press, 1997. $558 \mathrm{p}$.

NOWELL, K.; JACKSON, P. Wild cats, status survey and conservation action plan. Gland, Switzerland: IUCN/Cat Specialist Group, 1996.

OLIVEIRA, T. G. Cats: ecological and conservation. São Luis, MA: Edusma, 1994. 244 p.

OLIVEIRA, T. G.; CASSARO, K. Guia de identificação dos felinos brasileiros. São Paulo: Sociedade de Zoológicos do Brasil, 1999.

OLMOS, F. Notes of the food habits of brazilian "caatinga" carnivores. Mammalia, v. 57, n. 1, p.126-130. 1993.

PARIS, M. C. J.; WHITE, A.; REISS, A.; WEST, M.; SCHWARZENBERGER, F. Fecal progesterone metabolites and behavioural observations for the non-invasive assessment of oestrous cycles in the common wombat (Vombatus ursinus) and the hairy-nosed wombat (Lasiorhinus latifrons). Animal Reproduction Science, v. 72, p. 245-257. 2002. 
PEREIRA, E. A.; MICKE, G. A.; TAVARES, M. F. M. Determination of antiretroviral agents in human serum by capillary electrophoresis. Journal of Chromatography B, v. 1091, p. 161-176. 2005.

PICKARD, A. R. Reproductive and welfare monitoring for the management of ex situ populations. In: P. W. V. Holt, A. R., Rodger, J. C., Wildt, D. E. (Ed.). Reproductive Science and Integrated Conservation. Cambridge: Cambridge University Press, 2003. p. 132-146.

PUKAZHENTHI, B. S.; WILDT, D. E. Which reproductive technologies are most relevant to studying, managing and conserving wildlife? Reproduction, Fertility and Development, v. 16, p. 33-46. 2004.

RABINOWITZ, A. R.; NOTTINGHAM, B. G. Ecology and behavior of the jaguar (Panthera onca) in Belize, Central America. Journal of Zoology, v. 210, p. 149-159. 1986.

REDFORD, K. H.; EISENBERG, J.F. Mammals of the Neotropics. Chicago: Chicago Press, v.Vol. 2: The Southern Cone. 1992.

RISLER, L.; WASSER, S.K.; SACKETT, G.P. Measurement of excreted steroids in Macaca nemestrina. American Journal of Primatology, v. 12, p. 91-100, 1987.

ROSSI, JR. J. L. Estudo comparativo entre os achados clínicos de lesões orais em onçapintada (Panthera onca) e suçuarana (Puma concolor) mantidas em cativeiro no Estado de São Paulo e indivíduos de vida livre no Pantanal sul mato-grossense. 2002. 97 p. (Dissertação (Mestrado). Faculdade de Medicina Veterinária e Zootecnia, Universidade de São Paulo, São Paulo.

SAWAYA, W.N.; LONE, K. P.; HUSAIN, A.; DASHTI, B.; AL-ZENK, S. Screening for oestrogenic steroids in sheep and chicken by the application of enzyme-linked immunosorbent assay and a comparison with analysis by gas chromatography-mass spectrometry. Food Chemistry, v. 63, p. 563-569, 1998.

SCHIMITT, P. H.; GARRISON A.W.; FREITAG, D.; KETTRUP, A. Journal of Chromatography A, v. 792, p. $419-429,1997$.

SCHWARZENBERGER, F.; FRANCKE, R.; GÖLTENBOTH, R. Concentrations of faecal immunoreactive progestogen metabolites during the oestrous cycle and pregnancy in the black rhinoceros (Diceros bicornis michaeli) Journal of Reproduction \& Fertility, v. 98, p. 285291, 1993. 
SCHWARZENBERGER, F.; WALZER, C.; TOMASOVA, K.; VAHALA, J.; MEISTER, J.; GOODROWE, K. L.; ZIMA, J.; LYNCH, M. Fecal progesterone metabolite analysis for noninvasive monitoring of reproductive function in the white rhinoceros (Ceratotherium simum). Animal Reproduction Science, v. 53, p. 173-190, 1998.

SEAL, U.S.; SCHIMITT, S.M.; PETERSON, R.O. Carfentanil and xylazine for immobilization of moose (Alces alces) on Isle Royale. Journal of Zoo Wildlife Disease, v. 21, p. 48-51, 1985.

Seymour, K. L. Panthera onca. Mammalian Species, v. 340, p. 1-9, 1989.

SHIDELER, S.E.; ORTUÑO, A.M.; MORÁN, F.M.; MOORMAN, E.A.;LASLEY, B.L. Simple extraction and enzyme immunoassay for estrogen and progesterone metabolites in the feces of Macaca fascicularis during non-contraceptive and conceptive ovarian cycles. Biology of Reproduction, v. 48, p. 1290-1298, 1993.

SHILLE, V. M.; WING, A. E.; LASLEY, B.L.; BANKS, J. A. Excretion of radiolabeled estradiol in the cat (Felis catus, L): A preliminary report. Zoo Biology, v. 3, p. 201-209. 1984.

SHILLE, V.M.; HAGGERTY, M.A.; SHACKLETON, C.; LASLEY, B.L. Metabolites of estradiol in serum, bile, intestine and feces of the domestic cat (Felis catus). Theriogenology, v. 34, p. 779-794, 1990.

SHILLE, V.M.; KOLLIAS, G.V.; THATCHER, M.J.; WATERMAN, S. Determination of reproductive status in the serval and bobcat using a validated, direct radioimmunoassay of fecal estradiol. Biology of Reproduction. v. 44, p. 121, 1991. Supplement.

SOULÉ, M.; GILPIN, M.; CONWAY, W.; FOOSE, T. The millennium ark: Howm long a voyage, how many staterooms, and how many passengers? Zoo Biology, v. 5, p. 101-113, 1986.

SPANNER, A.; STONE, G. M.; SCHULTZ, D. Excretion profiles of some reproductive steroids in the faeces of captive napalese red panda (Aiulurus fulgens fulgens). Reproduction, Fertility and Development, v. 9, p. 565-570. 1997.

STALEY, A. M.; BLANCO, J. M.; DUFFY, A. M.; WILDT, D. E.; MONFORT, S. L. Noninvasive fecal steroid monitoring provides insight into gonadal and adrenal function in the golden eagle (Aquila chysaetos) and peregrine falcon (Falco peregrinus). Biology of Reproduction, v.68, p.126. 2003. Supplement 01. 
SU, P.; ZHANG, X. X.; CHANG, W. B. Direct immunoassay of estrone by capillary electrophoresis with laser-induced fluorescence detection. Electrophoresis, v. 24, p. $3197-$ 3201, 2003.

TAGLIARO. F.; BORTOLOTTI, F. Review of: clinical and forensic applications of capillary electrophoresis, first edition. Journal of Forensic Sciences, v. 47, p. 713, 2002.

TAVARES, M. F. M. Eletroforese capilar: conceitos básicos. Química Nova, v. 19, n. 2, p. 173-181. 1996.

TAVARES, M. F. M. Mecanismos de separação em eletroforese capilar. Química Nova, v. 20, n. 5, p. 493-511. 1997.

TERABE, S.; OTSUKA, K.; ICHIKAWA, K.; TSUCHIYA, A.; ANDO, T. Electrokinetic separarions with micellar solutions and open-tubular capillaries. Analytical Chemistry, v. 56, p. 111-113, 1984.

VALBUENA, G.A.; RAO, L. V.; PERTESEN, J. R.; OKORODUDU, A. O.; BISSELL, M. G.; MOHAMMAD, A. A. Anionic-zwitterionic mixed micelles in the micellar electrokinetic separation of clinically relevant steroids on a fused-silica capillary. Journal of Chromatography A, v. 781, p. 467-474, 1997.

VALKENBURG, P.R.; BOERTJE, R.O.; DAVIS, J.L. Effects of darting and netting of caribou in Alaska. Journal of Wildlife Management, v. 47, p. 1233-1237, 1983.

VIAU, P. Estudo da função ovariana em fêmeas de onça-pintada (Panthera onca Linnaeus, 1758) mantidas em cativeiro, por meio da extração e quantificação de esteróides fecais. 2003. 83 p. Dissertação (Mestrado). Faculdade de Medicina Veterinária e Zootecnia, Universidade de São Paulo, São Paulo.

VINDEVOGEL, J.; SANDRA, P. Introduction to micellar electrokinetic chromatography. Heidelberg: A. Hüthig. 1992. 231 p.

WASSER, S.K.; RISLER, L.; STEINER, R.A. Excreted steroids in primate feces over the menstrual cycle and pregnancy. Biology of Reproduction, v. 39, p. 862-872, 1988.

WASSER, S.K.; MONFORT, S.L.; WILDT, D.E. Rapid estraction of faecal steroids for measuring reproductive ciclicity and early pregnancy in free-ranging yellow baboons (Papio cynocephalus cynocephalus). Journal of Reproduction \& Fertility, v. 92, p. 415-423, 1991. 
WASSER, S. K.; HUNT, K. E.; BROWN, J. L.; COOPER, K.; CROCKETT, C. M.; BECHERT. U.; MILLSPAUGH, J. J.; LARSON, S.; MONFORT, S.L. A generalized fecal glucocorticoid assay for use in a diverse array of nondomestic mammalian and avian species. General and Comparative Endocrinology, v. 120, p. 160-275. 2000.

WEINBERGER, R. Practical Capillary Electrophoresis, San Diego, USA: Academic Press, INC., 1993, p 312.

WESTON, A.; BROWN, P. R. HPLC and CE : principles and practice. San Diego: Academic Press. 1997. 280 p.

WILDLIFE CONSERVATION SOCIETY (W.C.S.). All about jaguars: ecology. New York, 2002. Disponível em: http://wcs.org/490/jag-index/jag-allabout/jag-aboutecology/. Acesso em 6 de junho de 2002.

WIELEBNOWSKI, N. C.; ZIEGLER, K.; WILDT, D. E.; LUKAS, J.; BROWN, J. L. Impact of social management on reproductive, adrenal and behavioral activity in the cheetah (Acinonyx jubatus). Animal Conservation, v. 5, p. 291-301. 2002 a.

WIELEBNOWSKI, N. C.; FLETCHALL, N.; CARLSTEAD, K.; BUSSO, J. M.; BROWN, J. L. Non-invasive assesment of adrenal activity associated with husbandry and behavioral factors in the North American clouded leopard population. Zoo Biology, v. 21, p. 77-98. 2002 b.

WILDT, D. E. P., C. C.; CHAKRABORTY, P. K.; SEAGER, S. W. J. Oestrous and ovarian activity in a female jaguar (Panthera onca). Journal of Reproduction \& Fertility, v.56, p. 555-558. 1979.

ZIEGLER, T. E.; SHOLL, S. A.; SCHEFFLER, G.; HAGGERTY, M. A.; LASLEY, B. L. Excretion of estrone, etradiol, and progesterone in the urine and feces of the female cotton-top tamarin (Saguinus oedipus oedipus). American Journal of Primatology, v. 17, p. 185-195. 1989.

ZIEGLER, T. E.; WITTWER, D. J. Fecal steroid research in the field and laboratory: improved methods for storage, transport, processing and analysis. American Journal of Primatology, v. 67, p. 159-174. 2005. 